\title{
MICROPLÁSTICOS: OCORRÊNCIA AMBIENTAL E DESAFIOS ANALÍTICOS
}

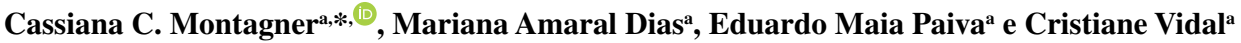 \\ aDepartamento de Química Analítica, Instituto de Química, Universidade Estadual de Campinas, 13083-970 Campinas - SP, Brasil
}

Recebido em 27/02/2021; aceito em 08/06/2021; publicado na web em 29/06/2021

\begin{abstract}
MICROPLASTICS: ENVIRONMENTAL OCCURRENCE AND ANALYTICAL CHALLENGES. Plastic pollution is a major societal, economic, and environmental issue. Upon release into the environment, plastics are altered by biological and physicochemical processes that influence their fate and transport within ecosystems. Large plastic debris can fragment into smaller pieces and are called microplastics (MPs) when occurring at sizes between $1 \mu \mathrm{m}$ and $5 \mathrm{~mm}$, fragmented or produced in this range. These small pieces of plastics are ubiquitous anthropogenic contaminants found throughout the world; however, the environmental consequences and effects on biota are not clearly understood. Scientific literature on the environmental implications of MP pollution is expanding rapidly and critical review of this literature is necessary to identify areas of evolving consensus and remaining gaps in knowledge. Herein a comprehensive literature review was performed to assess (i) the sources and distribution of MPs in different environmental compartments, (ii) the analytical methods that have been applied worldwide, and the key analytical challenges that remain in assessing MPs in the environment, and, finally, (iii) to integrate the findings of Brazilian MP research, which showed that since 2004 (80 papers up to 2020) has documented the presence of MPs in aquatic matrices and sediments with focus on marine ecosystems, mainly identified by visual inspection.
\end{abstract}

Keywords: plastic pollution; environmental contaminants; microplastic sampling; microplastic characterization; polymer identification.

\section{INTRODUÇÃO}

A poluição plástica é atualmente um problema de grande relevância sob o ponto de vista ambiental e socioeconômico, consequência principalmente da má gestão dos resíduos sólidos, dentre outros fatores. Uma ramificação da questão é dada pela poluição causada por plásticos cujos tamanhos estejam nas escalas micrométrica e milimétrica. O primeiro relato envolvendo a presença dessas partículas plásticas no ambiente foi publicado em 1972, quando esse material foi encontrado retido em redes de plâncton, em águas costeiras na região da Nova Inglaterra, nos Estados Unidos. ${ }^{1}$ No mesmo ano, partículas de polietileno e poliestireno também foram identificadas no litoral do Rio Grande do Sul, no Brasil. ${ }^{2}$ No entanto, a comunidade científica ainda não explorava a problemática e poucos trabalhos foram publicados ao longo da década de 70. Com o aumento da preocupação sobre as consequências ecológicas da presença de tais partículas em diferentes ecossistemas, os estudos envolvendo os resíduos plásticos foram incorporando novos conceitos e o termo microplástico (MP) foi introduzido em 2004. ${ }^{3-5}$

Várias definições são encontradas para o termo MP, de acordo com a faixa de tamanho das partículas, ${ }^{6,7}$ sendo a mais utilizada a que se refere a esses materiais como partículas de polímeros orgânicos sintéticos com tamanho inferior a $5 \mathrm{~mm}$. Essa definição foi proposta em 2009 pela National Oceanic and Atmospheric Administration (NOAA) e, desde então, a maioria das publicações tem a adotado como referência, inclusive este trabalho. ${ }^{3,8}$ Após um pouco mais de uma década, em 2020, foi publicada a norma intitulada "Plastics Environmental Aspects - State of Knowledge and Methodologies" (ISO/TR 21960:2020), em que o termo MP é definido como qualquer partícula plástica sólida insolúvel em água com dimensões entre $1 \mu \mathrm{m}$ e $1000 \mu \mathrm{m} .{ }^{9}$ A norma também define o termo "large microplastic" (microplástico grande, em tradução livre), para a faixa de tamanho de 1 a $5 \mathrm{~mm}$.

\footnotetext{
*e-mail: ccmonta@unicamp.br
}

Os MP são onipresentes no ambiente e são classificados atualmente como contaminantes emergentes. ${ }^{10,11}$ Seus potenciais riscos aos seres vivos, bem como os níveis da contaminação em diferentes compartimentos ambientais, precisam ser mais bem elucidados. Por isso, essa nova classe tem sido foco de pesquisas no mundo todo.

O objetivo deste trabalho de revisão é destacar aspectos importantes da temática da poluição por MP, do ponto de vista da química ambiental, abordando sobre a presença deles no ambiente e discutindo sobre os métodos e os desafios analíticos para a determinação de MP em matrizes ambientais. Além disso, o trabalho também tem por meta apresentar o cenário das pesquisas no Brasil. A primeira parte desta revisão contextualiza o problema em nível mundial e apresenta uma discussão sobre as fontes e algumas consequências dos MP no ambiente. A segunda parte discute as etapas de controle de qualidade, amostragem, preparo de amostras e caracterização, que têm sido empregadas mundialmente para a determinação de MP nos compartimentos ambientais solo/ sedimento, água e ar. Finalmente, a terceira parte apresenta, com base nos trabalhos publicados em literatura indexada, o cenário de ocorrência de MP no Brasil, destacando os métodos analíticos que foram empregados nas pesquisas.

Deste modo, esta revisão é apresentada de forma a levar aos químicos ambientais e a outros pesquisadores das demais áreas de conhecimento deste tema transdisciplinar, as ferramentas que darão subsídios para políticas públicas e elaboração de projetos nessa área, que ainda é carente de pesquisa no Brasil.

\section{A PRODUÇÃO E O DESTINO DOS PLÁSTICOS}

Os plásticos são materiais poliméricos sintéticos leves, impermeáveis e duráveis, que podem ser formulados para serem rígidos ou flexíveis, transparentes ou coloridos, e apresentam baixo custo. Por tantas vantagens, são amplamente empregados em todos os setores da sociedade moderna. No entanto, problemas relacionados 
ao gerenciamento inadequado dos resíduos sólidos fazem com que estes materiais sejam considerados contaminantes onipresentes no ambiente..$^{12,13}$

A produção mundial de plásticos, que se iniciou em 1950, cresceu consideravelmente nos últimos 60 anos, com estimativas de que 8,3 bilhões de toneladas de plásticos virgens tenham sido produzidos para as mais diferentes aplicações. Os números atuais mostram que 6,3 bilhões de toneladas de resíduos plásticos foram gerados entre o início da produção, na década de 50, e 2015. Dessa quantidade, $9 \%$ foram reciclados, $12 \%$ incinerados e $79 \%$ foram dispostos em aterros ou no ambiente, demonstrando as deficiências no saneamento e no controle dos resíduos sólidos. Até 2050, estão previstos que cerca de 12 bilhões de toneladas de resíduos plásticos sejam lançados no ambiente, caso a produção atual de plásticos permaneça nesse ritmo acelerado e sem melhoria da gestão de resíduos. ${ }^{14,15}$

Estudos apontam que, dentre os plásticos mais encontrados no ambiente, estão os polímeros termoplásticos polipropileno (PP), polietileno (PE) (podendo ser PEBD - polietileno de baixa densidade ou PEAD - polietileno de alta densidade), poliestireno (PS), policloreto de vinila (PVC), politereftalato de etileno (PET), poliamida (PA) e o polímero termorrígido poliuretano (PU). ${ }^{16}$

No Brasil, os dados da Associação Brasileira da Indústria do Plástico (Abiplast), que monitora os números desse setor, apontam crescimentos anuais na indústria de transformados plásticos. ${ }^{17}$ Ao mesmo tempo, o país ocupa a quarta posição em geração de resíduo plástico (posicionado após os Estados Unidos, a China e a Índia), com aproximadamente 11 milhões de toneladas desses resíduos sendo gerados por ano, o que equivale a cerca de $11 \%$ do total mundial. Além disso, apesar de haver programas de incentivo ao processo de reciclagem, o qual pode afetar positivamente a cadeia socioeconômica do país, somente $1,28 \%$ tem essa destinação no Brasil. ${ }^{18} \mathrm{Um}$ aspecto especialmente importante que pode ser atribuído ao baixo índice de reciclagem é o fato de que muitos desses materiais têm sido usados na produção de plásticos chamados de "uso único", por exemplo os descartáveis, os quais, em sua maioria, são de difícil reciclagem e representam uma parcela significativa da poluição plástica global.

Os impactos do ponto de vista ecológico e ambiental, aliados aos prejuízos estéticos e econômicos causados pela disposição inadequada desses resíduos, tornaram a poluição plástica alvo de ações e pesquisas nas mais diferentes áreas em âmbito mundial. Se o plástico é o material mais utilizado, é esperado que ele represente uma fração considerável dentre os resíduos sólidos. Além disso, é sabido que o destino final majoritário dos plásticos é o oceano e que cerca de $80 \%$ desses resíduos provém dos sistemas terrestres. ${ }^{19,20}$ Como consequência, há, atualmente, pelo menos cinco grandes ilhas de plásticos nos oceanos. Carregadas pelas correntes marítimas, toneladas de resíduos plásticos flutuantes se acumulam nos vórtices oceânicos, causando prejuízos inestimáveis ao ecossistema marinho, incluindo a morte de milhares de animais de acordo com o Panorama da Biodiversidade Global da Organização das Nações Unidas. ${ }^{21}$

\section{MICROPLÁSTICOS NO AMBIENTE}

\section{Microplásticos primários e secundários}

Os MP podem ser classificados como primários ou secundários de acordo com a sua fonte, ou seja, a origem do MP.,22-24 Os MP de fonte primária são aqueles produzidos propositalmente para serem usados na escala de até $5 \mathrm{~mm}$ e, consequentemente, são lançados no ambiente nesse tamanho. Esses podem se apresentar em escala microscópica (microesferas), como os utilizados na formulação de cosméticos (dentre eles, os que contém glíter tem recebido especial destaque) e produtos de higiene pessoal (PHP) como esfoliantes, sabonetes e cremes dentais. Além disso, são, também, utilizados na indústria farmacêutica, na indústria de plásticos, como matéria prima (pellets), e na indústria química em geral, como abrasivos industriais. ${ }^{25-27}$

Os MP secundários, por sua vez, são aqueles que resultam da fragmentação dos resíduos plásticos maiores (ex: embalagens) expostos às intempéries no ambiente e outros agentes estressores, degradando-se em fragmentos cada vez menores, até atingir o tamanho dos MP. ${ }^{28,29}$ A degradação de um polímero está relacionada ao rompimento de ligações químicas covalentes, seja na cadeia principal ou em cadeia lateral. Esse rompimento é consequente da geração de espécies reativas (na maioria dos casos, radicais livres) que são também os responsáveis pela propagação do processo de degradação. ${ }^{30} \mathrm{~A}$ iniciação do processo pode ser causada por fotodegradação e/ou degradação física, química e biológica. ${ }^{31}$ Todas essas formas de iniciação implicam no fornecimento de energia para o rompimento das ligações químicas. Dessa forma, é possível entender porque alguns polímeros se degradam mais facilmente do que outros. Nos polímeros ramificados, por exemplo, a presença da ramificação implica na existência de átomos de carbono terciário na cadeia polimérica principal. A energia da ligação química $\mathrm{C}-\mathrm{H}$ é menor em átomos de carbono terciário do que nos secundários, de forma que o processo de degradação pode ser iniciado mais facilmente em polímeros de cadeias ramificadas quando comparados aos polímeros lineares, os quais possuem majoritariamente átomos de carbono secundário. ${ }^{32}$ Os processos de degradação resultam em perda da massa molar do polímero, aumento da molhabilidade e da cristalização, bem como a formação de fissuras, gerando os fragmentos de MP. ${ }^{33} \mathrm{~A}$ degradação física das partículas leva à geração de diferentes formas de MP, por exemplo, fibras, fragmentos e filmes. Os pellets, por sua vez, permanecem em sua forma física original após a degradação, mas podem ter algumas de suas propriedades alteradas. ${ }^{34,35}$

\section{Microplásticos como vetores de transporte de outros contaminantes}

Além da fragmentação, a degradação dos polímeros também favorece a liberação dos aditivos químicos, tais como, estabilizantes, corantes, plastificantes, retardantes de chama, entre outros, os quais são empregados na formulação do polímero para atingir as características necessárias ao uso pretendido no produto final. Durante a degradação, esses compostos podem ser lixiviados para o ambiente através da difusão até a superfície do MP. ${ }^{4,36}$ Além disso, principalmente em ambientes aquáticos, a via contrária, ou seja, a sorção de outros contaminantes no MP, tem sido objeto de estudos que visam elucidar a ação dos MP como vetores de transporte de outros contaminantes químicos orgânicos utilizados ou não no processamento do polímero. Tais contaminantes, como ftalatos, bisfenol A e éteres difenílicos polibromados, por exemplo, são conhecidos por interferirem no sistema endócrino. Além desses, compostos inorgânicos, como metais também podem se associar $\operatorname{aos} \mathrm{MP}^{37}$

Contaminantes de origem antrópica, como bifenilas policloradas (PCB, do inglês Polychlorinated Biphenyls), pesticidas, hidrocarbonetos policíclicos aromáticos e dioxinas foram identificados sorvidos em MP ao redor do mundo. ${ }^{37} \mathrm{O}$ projeto chamado International Pellet Watch, criado em 2006 é uma iniciativa de monitorar, em nível mundial, a quantidade de contaminantes orgânicos associados aos pellets. ${ }^{38}$ Do Brasil, 21 amostras foram analisadas e concentrações de PCB foram detectadas entre $43 \mathrm{ng} \mathrm{g}^{-1}$ e $3892 \mathrm{ng} \mathrm{g}^{-1}$ de pellet. ${ }^{38}$

Uma vez no ambiente, a sorção de contaminantes pode potencializar os riscos relacionados à ingestão acidental de MP pela biota, deixando de ser apenas um efeito físico (obstrução do trato 
digestivo, sufocamento e estresse), mas também provocando outros efeitos fisiológicos (alterações hormonais, distúrbios na produção de enzimas, reprodução e crescimento) que estariam correlacionados aos elevados níveis de degradação dos corpos de água aos quais os organismos estão expostos..$^{39-48}$

Os MP se comportam ainda como potenciais vetores de transporte de microrganismos, incluindo patógenos, através da formação de um biofilme na superfície do MP. ${ }^{49-51}$ Espécies invasoras também são transportadas por MP e seus efeitos à biodiversidade do ecossistema ainda são desconhecidos, bem como os prejuízos relacionados à migração de espécies exóticas para outros habitats. ${ }^{37,42}$

\section{Distribuição e fontes dos microplásticos no ambiente}

Uma expedição ao local mais profundo dos oceanos, a Fossa das Marianas, revelou a presença de lixo plástico na coluna d'água. Foram encontrados MP em organismos dessa e de outras cinco fossas profundas do oceano. ${ }^{52}$ Outros estudos recentes relevaram a presença de MP na neve da montanha de maior altitude do planeta, o Monte Everest, ${ }^{53}$ bem como no ar de cidades populosas na China. ${ }^{54}$ Esses exemplos ilustram que os MP são contaminantes que podem ser encontrados em todas as matrizes ambientais e nos seres vivos, tanto em grandes centros urbanos, quanto em regiões remotas no nosso planeta, dada a dinâmica com que são lançados e transportados no ambiente..$^{55-58}$

Diversas práticas e atividades usam e lançam resíduos plásticos no ambiente, de maneira proposital ou não. Os resíduos plásticos relacionados a essas atividades são as principais fontes de MP para o ambiente. A Figura 1a apresenta exemplos das principais atividades com potencial de emissão de plásticos (que serão geradores de MP) e MP (primários e/ou secundários) ao ambiente, bem como a distribuição deles nos diferentes compartimentos ambientais. A Figura 1b ilustra a distribuição dos MP ao longo da coluna d'água.
O descarte inadequado de resíduos sólidos é uma prática que culmina para a poluição plástica em ambientes terrestres e aquáticos, com a possível formação de MP nesses compartimentos. Em ambiente terrestre, os resíduos plásticos presentes em lixões e aterros (Figura 1a, exemplo 1) são responsáveis pela formação de MP secundários, os quais são determinados em amostras de lixiviado de aterros sanitários urbanos. ${ }^{59}$ Além disso, os resíduos plásticos descartados inadequadamente no ambiente terrestre (Figura 1a, exemplo 2) podem atingir os corpos de água e também contribuem para a formação de MP em ambientes aquáticos. Outras fontes de emissão de MP em ambientes terrestres são o processo de desgaste de pneus (Figura 1a, exemplo 3), os quais são constituídos de borracha de estireno butadieno e inúmeros aditivos e o desgaste de pinturas em rodovias, através da abrasão dos veículos e ação do intemperismo. ${ }^{24}$

Algumas atividades cotidianas, como o uso de cosméticos ou lavagem de roupa, também contribuem para o lançamento de MP em ambientes aquáticos. As microesferas contidas em cosméticos e PHP (Figura 1a, exemplo 4) podem atingir concentrações de mais de 50 mil partículas por grama de produto. ${ }^{60} \mathrm{Em}$ um estudo realizado na Eslovênia, foi estimada uma média diária de lançamento de microesferas no sistema de esgoto de $15 \mathrm{mg}$ por pessoa. Utilizando um processo de tratamento de esgoto com sistema biológico, em escala de laboratório, foi concluído que cerca de 52\% das microesferas são retidas no lodo ativado. Assim, para a região avaliada, é previsto um aporte diário de mais de 1 bilhão de microesferas no rio receptor do esgoto tratado. ${ }^{61}$

Inúmeras fibras de tecidos naturais ou sintéticos são liberadas no efluente do processo de lavagem de roupas (Figura 1a, exemplo 5). As fibras sintéticas são constituídas em sua maioria de poliéster, acrílico e/ou PA. Uma única peça de roupa pode produzir mais de 1900 fibras por lavagem e suas concentrações podem superar $300 \mathrm{mg} \mathrm{kg}^{-1}$ de tecido lavado, porém, esses valores variam de acordo com as características de lavagem. ${ }^{62-64}$ Essas fibras são despejadas

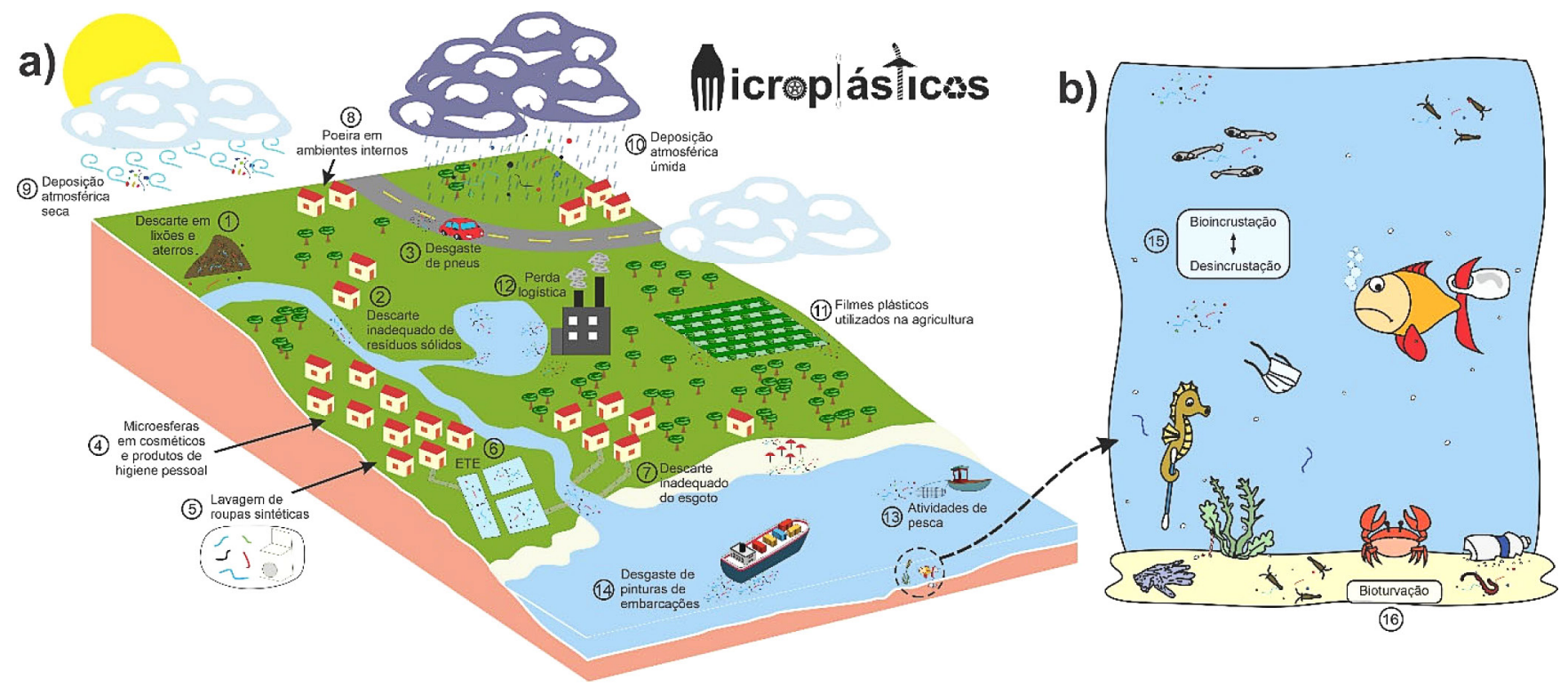

Figura 1. (a) Principais exemplos de práticas e atividades que são fontes de emissão de microplásticos (MP) primários e/ou secundários e sua distribuição em diferentes compartimentos ambientais, como: (1) descarte de resíduos plásticos em lixões e aterros; (2) descarte inadequado de resíduos sólidos no ambiente; (3) desgaste de pneus de borracha; (4) utilização de produtos de higiene pessoal e cosméticos compostos por microesferas poliméricas; (5) lavagem de roupas sintéticas com desprendimento de fibras poliméricas; (6) aporte de microfibras e microesferas no esgoto e entrada na Estação de Tratamento de Esgoto (ETE); (7) lançamento do esgoto diretamente no ambiente, sem nenhum tratamento; (8) transporte de MP pelo ar na poeira de ambientes internos; (9) transporte de MP pelo ar em ambientes externos via deposição seca e (10) úmida; (11) uso de filmes plásticos na agricultura; (12) perda logística nas atividades industriais com a utilização de pellets; (13) uso de materiais plásticos em atividades pesqueiras e (14) desgaste de pinturas de embarcações. (b) Principais exemplos de fenômenos que ocorrem em ambientes aquáticos e afetam a distribuição de MP na coluna d'água, como: (15) formação de um biofilme na superfície das partículas de MP - bioincrustação; (15) desprendimento da camada de biofilme no MP - desincrustação e (16) desprendimento de MP aderidos ao sedimento - bioturvação 
no sistema de esgoto doméstico e encaminhadas para as Estações de Tratamento de Esgoto (ETE) (Figura 1a, exemplo 6). No entanto, em países em que grande parte da população não possui rede coletora e/ou tratamento de esgoto, o aporte de MP é agravado no ambiente, pois o esgoto é lançado diretamente nos corpos aquáticos (Figura 1a, exemplo 7). Por exemplo, no Brasil, a taxa de coleta e afastamento de esgoto é cerca de $60 \%$ e aproximadamente $50 \%$ de todo o esgoto bruto gerado no país é lançado diretamente nos rios, sem nenhum tratamento. ${ }^{65}$

A comunidade científica ainda discute a classificação das fibras têxteis, consideradas uma das principais fontes de contaminação de MP no ambiente. Alguns autores classificam as fibras como sendo de origem primária, uma vez que são lançadas no ambiente já nesse tamanho pelo descarte da lavagem. Entretanto, as fibras são produzidas para serem longas e o rompimento físico delas é considerado por outros autores como um mecanismo de degradação, sendo nesse caso classificadas como MP secundários. ${ }^{62} \mathrm{O}$ Guia do GESAMP (do inglês Joint Group of Experts on the Scientific Aspects of Marine Environmental Protection) classifica as fibras têxteis como MP secundários. ${ }^{66}$

Estudos relataram quantidades significativas de fibras na poeira de ambientes internos (Figura 1a, exemplo 8). ${ }^{54,67,68}$ As concentrações de fibras coletadas em amostras de poeira dentro de apartamentos foram cerca de 40 vezes maiores do que em ambientes externos. Devido à dificuldade em caracterizar quimicamente essas fibras, os autores concluíram que somente $33 \%$ das amostras correspondiam a polímeros sintéticos (PP e PA, em sua maioria). O restante das fibras encontradas na poeira foi classificado como de origem natural, como algodão, acetato de celulose e lã. ${ }^{69}$

Em ambientes externos, os MP no ar podem ser transportados a outros compartimentos ambientais via deposição seca (Figura 1a, exemplo 9) e úmida (Figura 1a, exemplo 10). Em 2015 foi publicado o primeiro estudo sobre a possível presença de MP na atmosfera, que reportou uma média de 118 partículas $\mathrm{m}^{-2} \mathrm{~d}^{-1}$ na cidade de Paris. Dentre as partículas observadas, mais de $90 \%$ foram classificadas como fibras. ${ }^{70} \mathrm{~A}$ necessidade de confirmação da composição das partículas e a correlação com as características locais e dados atmosféricos como condições do vento, impulsionou outros trabalhos nessa matriz ambiental em áreas urbanas e rurais. Recentemente, pesquisadores encontraram MP em água de chuva coletada em áreas de proteção ambiental em concentrações médias de 132 partículas $\mathrm{m}^{-2} \mathrm{~d}^{-1}$, e estimaram que mais de mil toneladas de partículas plásticas são depositadas pela atmosfera anualmente no oeste dos Estados Unidos..$^{71}$

Outros pesquisadores encontraram ainda partículas de MP em regiões montanhosas localizadas entre a Espanha e a França. Essa região é considerada intocada, devido ao difícil acesso e à distância de grandes cidades e centros industriais. A predominância da composição das partículas encontradas foi de PS e PE, polímeros muito utilizados em materiais de uso único e embalagens. ${ }^{72}$ A presença de MP em áreas remotas retrata, portanto, a facilidade com que essas partículas podem ser transportadas por longas distâncias pela ação do vento. ${ }^{72-74}$

Outros exemplos de fontes terrestres de emissão de MP estão relacionados à atividade agrícola. Os MP também são provenientes da degradação de filmes plásticos (Figura 1a, exemplo 11), normalmente de PE, utilizados na agricultura para aplicação da técnica mulching, a qual é destinada à proteção da plantação. ${ }^{75}$ Concentrações de MP entre 80,3 a 1075,6 partículas $\mathrm{kg}^{-1}$ de solo foram identificadas em áreas agrícolas, evidenciando que os filmes plásticos podem contribuir significativamente na contaminação do solo. ${ }^{76} \mathrm{Na}$ agricultura, a aplicação do lodo de esgoto como fertilizante orgânico também pode ser uma via de contaminação do solo por MP, pois o lodo é a fração onde os MP ficam majoritariamente retidos após o tratamento de esgoto. ${ }^{77,78}$ Dependendo do sistema de tratamento utilizado na ETE, a remoção de MP no afluente pode chegar até mais que $99 \% .{ }^{22}$ Estudos realizados em ETE na Dinamarca estimam concentrações superiores a 18 mil partículas de $\mathrm{MP} \mathrm{L}^{-1} \mathrm{~d}^{-1}$ no afluente de uma estação com tratamento secundário. ${ }^{79}$ No entanto, no Brasil, a aplicação do lodo na agricultura está protegida por legislações rigorosas como a Resolução CONAMA N³75/2006, o que torna uma prática pouco comum no país. ${ }^{80}$

Atividades industriais e logísticas relacionadas à produção de plásticos também são fontes de MP primários. Os pellets são perdidos durante seu transporte até seu uso como matéria prima na manufatura de produtos diversos (Figura 1a, exemplo 12), entrando acidentalmente no ambiente. Zonas portuárias são conhecidas por apresentarem altas concentrações de pellets e outros MP, pois estão expostas a grandes quantidades de descarte de resíduos provenientes de diversas fontes, por exemplo embarcações comerciais e turísticas.

Atividades pesqueiras também geram resíduos plásticos, como as redes e linhas de nylon (PA) e PE, que podem eliminar fragmentos plásticos no ambiente (Figura 1a, exemplo 13). As embarcações podem também contaminar o ambiente aquático com MP através do desgaste de suas pinturas (Figura 1a, exemplo 14), as quais são constituídas de tintas poliméricas como PU e epóxido para evitar a corrosão e a incrustação. ${ }^{24}$

Em ambientes aquáticos, a densidade e a forma dos MP são, via de regra, os fatores determinantes quanto à sua distribuição ao longo da coluna d'água (Figura 1b). Tabelas com os valores de densidade dos principais polímeros são facilmente encontradas na literatura, porém, essas informações referem-se aos materiais puros. ${ }^{23,81-83} \mathrm{~A}$ incorporação de ar e aditivos promove um aumento ou diminuição na densidade do material polimérico processado, tornando-o mais susceptível ou não à decantação. Algumas exceções à regra são encontradas, visto que na prática nem sempre a densidade de um polímero justifica sua presença em determinada profundidade. Isso ocorre porque os polímeros são materiais altamente persistentes e os processos de degradação a que estão expostos no ambiente alteram as suas propriedades físico-químicas se comparados ao polímero virgem. ${ }^{31}$

A bioincrustação (Figura 1b, exemplo 15), causada pela formação de biofilme e colonização de microrganismos, também é capaz de promover um aumento na densidade da partícula, tornando-a facilmente encontrada em camadas mais profundas da coluna d'água e até no sedimento. $\mathrm{O}$ fenômeno inverso, chamado de desincrustação (Figura 1b, exemplo 15), ocorre através do desprendimento do biofilme pela ação de microrganismos e possibilita que os MP retornem à interface água-ar. ${ }^{31}$

$\mathrm{O}$ aparecimento de ranhuras na superfície, alterações na cristalinidade causadas pela degradação e a presença de bolsas de ar no interior do polímero são capazes de levar a uma diminuição em sua densidade, tornando-os mais propensos à flutuação. Além disso, o movimento da água oriundo das correntes promove a agitação dos MP, o que ocasiona sua presença em toda a coluna d'água, desde a superfície até o sedimento. . $^{23,31}$

Nos oceanos, há ainda um processo de sedimentação de partículas com materiais provenientes da decomposição de células, chamado de neve marinha. Além de prover alimento para o fundo do mar, a neve marinha é também uma via de transporte de MP. Partículas com tamanho $\geq 200 \mu \mathrm{m}$ como argila e detritos orgânicos, bem como fitoplâncton presentes na coluna d'água, aderem-se aos MP e podem, assim, deslocá-los a diferentes profundidades até atingir o sedimento. ${ }^{84,85}$ Uma vez no sedimento, alguns organismos são capazes de promover a bioturvação (Figura 1b, exemplo 16), que possibilita o desprendimento de MP através da abertura de caminhos nas camadas superficiais, sendo assim carregados pela corrente marítima. Essa 
dinâmica de distribuição permite que os MP ocupem diferentes profundidades em momentos distintos ao longo do seu tempo de vida no ambiente. ${ }^{34,47}$

\section{Exposição da biota e dos seres humanos aos microplásticos}

De maneira geral, os MP são facilmente ingeridos quando presentes no ambiente, diretamente por organismos ou indiretamente através do consumo de espécies de nível trófico inferior. A ingestão de MP é observada em organismos desde o primeiro nível trófico, como fitoplâncton e zooplâncton, até espécies maiores, como tartarugas e pássaros. ${ }^{86}$ Alguns fatores influenciam a biodisponibilidade de MP no ambiente, por exemplo, tamanho, densidade e coloração. Os MP menos densos são ingeridos pelas espécies que habitam superfícies dos corpos de água e os mais densos afetam as espécies presentes na coluna d'água e sedimento. Por serem resistentes aos processos de metabolização, os MP podem se bioacumular em diferentes organismos e, de acordo com a distribuição ao longo dos níveis tróficos, também podem ser biomagnificados. ${ }^{87}$

Partículas de lixo marinho foram encontradas no intestino de tartarugas no litoral do Rio Grande do Sul, dentre as quais mais de $70 \%$ eram MP. Resultados semelhantes foram observados em pássaros marinhos na mesma região, onde mais de $95 \%$ das partículas encontradas foram identificadas como MP. ${ }^{88} \mathrm{~A}$ presença de MP e resíduos plásticos também foi reportada em diferentes organismos, como plâncton, ${ }^{89}$ peixes, ${ }^{90-101}$ tartarugas, ${ }^{88,102}$ aves marinhas,,${ }^{88,103-105}$ mexilhões, ${ }^{106}$ anêmonas, ${ }^{107}$ peixe-boi, ${ }^{108}$ pinguins,,${ }^{109}$ tubarão baleia, ${ }^{110}$ cachalote, ${ }^{111}$ caranguejo, ${ }^{112}$ além de outros organismos que habitam a areia das praias. ${ }^{113}$

Recentemente, pesquisadores também encontraram MP de diferentes composições em fezes de pinguins na Antártica, evidenciando a ingestão desses materiais inclusive em áreas pouco habitadas do nosso planeta. ${ }^{114}$ Algumas consequências da ingestão de MP pelos organismos são a perda da habilidade de capturar e digerir alimentos, perda de apetite devido ao bloqueio do canal alimentar e dificuldade de locomoção. ${ }^{37}$ Além da ingestão, em alguns organismos, como caranguejos, os MP são encontrados nas brânquias devido aos mecanismos de respiração. ${ }^{86}$ Após ingeridos, os MP também podem entrar no sistema circulatório causando danos em tecidos e células. ${ }^{87}$ Estudos in vitro mostraram que o contato de partículas de PP com células mononucleares do sangue periférico pode causar problemas à saúde, induzindo a produção de citotoxinas de células imunes. ${ }^{115}$

$\mathrm{Na}$ maioria dos casos, os MP são encontrados no trato gastrointestinal de peixes, portanto, raramente entram na dieta humana, pois são frações não comumente consumidas. ${ }^{116}$ Porém, em peixes processados, como as sardinhas, essas partículas podem ser ingeridas pelos seres humanos com maior facilidade. Um estudo relatou a presença de partículas de MP em sardinhas enlatadas provenientes de diferentes regiões do mundo, como Canadá, Alemanha, Irã, Japão, Letônia, Malásia, Marrocos, Polônia, Portugal, Rússia, Escócia, Tailândia e Vietnã. ${ }^{117}$ Outros estudos detectaram a presença de MP em água envasada comercializada na Itália e em vários países, ${ }^{118}$ inclusive no Brasil. ${ }^{119}$ Os MP também têm sido encontrados em diversos alimentos presentes na dieta humana, como mel, sal, cerveja, vinho, refrigerante, leite, entre outros. ${ }^{120}$ Com isso, os seres humanos estão constantemente expostos aos MP pela dieta alimentar, sendo estimada uma média de ingestão semanal de 0,1 a $5 \mathrm{~g}$ de MP por pessoa. ${ }^{121} \mathrm{E}$, finalmente, outra via de exposição humana aos MP se dá através da inalação de partículas no ar durante a respiração. Estima-se que um homem adulto inale 170 partículas diariamente, ${ }^{122}$ no entanto, os efeitos na saúde do sistema respiratório relacionados a essa exposição ainda são desconhecidos. ${ }^{123}$

\section{MICROPLÁSTICOS E A QUÍMICA AMBIENTAL: DESAFIOS ANALÍTICOS}

Os estudos envolvendo a elucidação dos níveis de contaminação e, consequentemente, o impacto causado pela presença dos MP no ambiente devem considerar inúmeros fatores, dentre eles, alguns estão intrinsicamente ligados à química ambiental, como: i) a extensão da contaminação e a variação sazonal das concentrações; ii) a identificação e a caracterização dos MP incluindo os estágios de degradação dos mesmos; iii) a capacidade de sorção de outros contaminantes incluindo compostos orgânicos, inorgânicos e patógenos e iv) a capacidade de transporte deste material, bem como a identificação de fontes pontuais e difusas de contaminação.

Dentre os desafios na elucidação da distribuição dos MP nos diferentes compartimentos ambientais está a harmonização de métodos analíticos, por conta da complexidade de cada compartimento e do tamanho alvo do MP. Apesar de existir alguns direcionamentos para determinadas matrizes, como o guia do GESAMP $^{66}$ e da NOAA, ${ }^{124}$ ainda não existem métodos oficiais para a determinação de MP em cada compartimento ambiental. Além disso, são encontradas na literatura diversas unidades de concentração para expressar a quantidade de MP em determinado ambiente, o que pode causar confusão na tentativa de comparar resultados. ${ }^{23}$ Um panorama das várias possibilidades de um método analítico para a investigação de MP no ambiente que tem sido estudada internacionalmente é resumido na Figura 2. Esse panorama será discutido e detalhado a seguir.

\section{Controle de qualidade na determinação de microplásticos em amostras ambientais}

Independentemente das muitas possibilidades do método analítico, uma etapa deve estar presente em todo o processo: evitar a contaminação cruzada.

Com o passar dos anos, grandes avanços analíticos têm sido observados nos trabalhos envolvendo a análise de MP. Um deles está relacionado ao controle cada vez mais rigoroso da qualidade dos resultados. Sabe-se que partículas de MP provenientes de outras fontes são responsáveis pela contaminação durante cada etapa da análise de MP. Portanto, o cuidado para evitar a contaminação das amostras inicia-se logo na etapa de amostragem. As duas principais fontes de contaminação de MP são: o local onde as amostras são manuseadas e o analista. Alguns materiais plásticos utilizados na coleta, como as redes e os copos de amostragem, podem contribuir para a contaminação das amostras. A caracterização química desses materiais é uma opção para realizar a identificação do polímero e possivelmente descartá-lo das amostras. Além disso, evita-se, sempre que possível, o uso de materiais plásticos durante a análise de MP, recomendando-se fortemente o uso de utensílios de vidro e de metal. No entanto, o cuidado com a limpeza desses utensílios também é fundamental para garantir a qualidade dos resultados. ${ }^{125,126}$ Alguns procedimentos de limpeza podem ser encontrados no trabalho de Dehaut e colaboradores. ${ }^{125}$

Fibras poliméricas sintéticas são as principais responsáveis pela contaminação das amostras e, consequentemente, pela obtenção de resultados superestimados. Essas fibras podem se desprender das roupas do analista e também se aderirem na superfície das luvas. Para amenizar esse problema, a utilização de tecidos de algodão (material polimérico natural) é uma alternativa simples, que pode ser facilmente adotada na rotina do laboratório. Além disso, o cuidado com as luvas também merece atenção. Indica-se que tais luvas sejam guardadas em recipientes fechados e lavadas com água e/ou etanol previamente filtrados. ${ }^{125-127}$ 


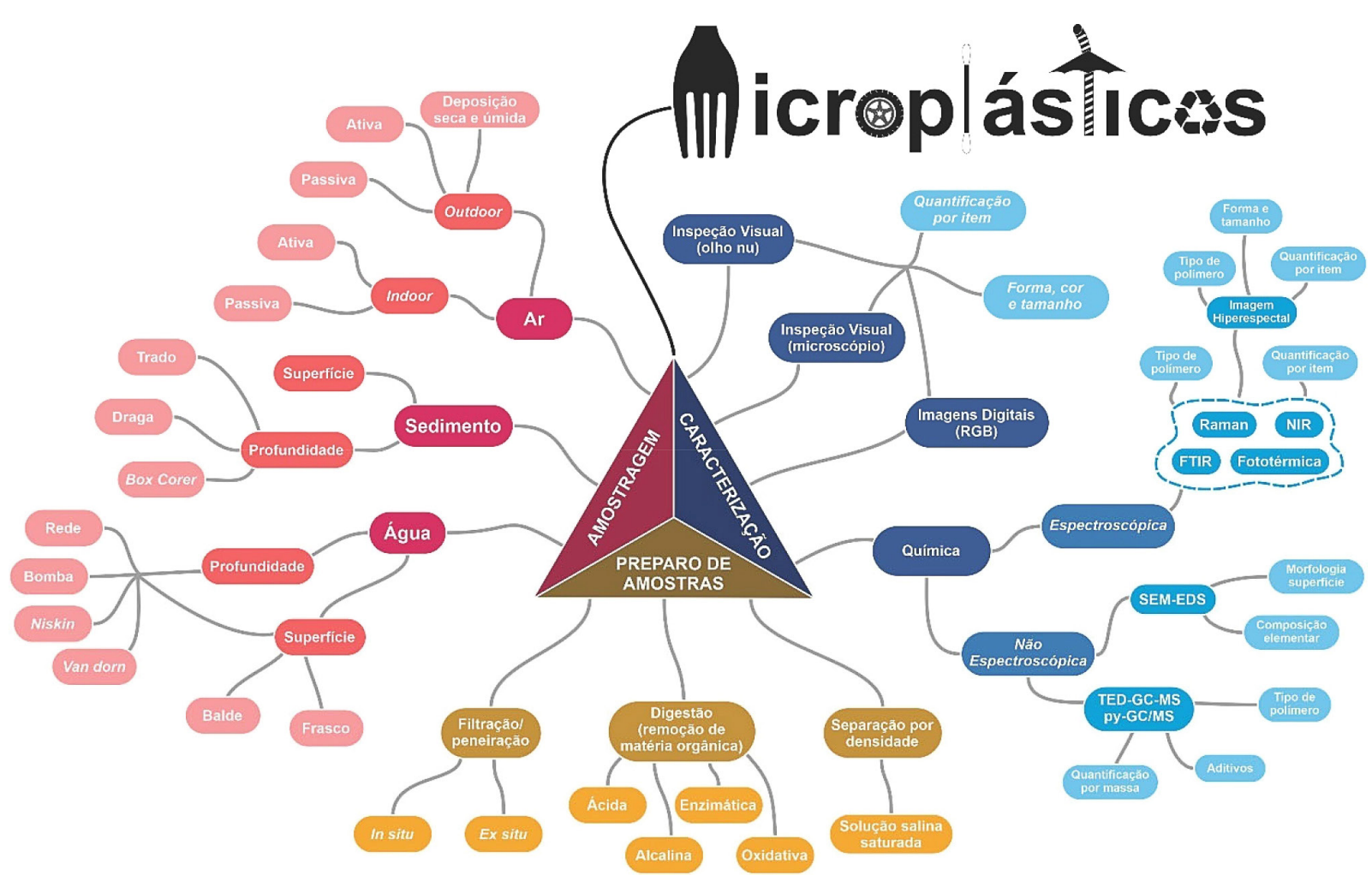

Figura 2. Panorama das possibilidades de um método analítico para a determinação de microplásticos no ambiente, considerando amostragem do compartimento ambiental de interesse, preparo de amostras e caracterização

Tendo em vista essas diversas fontes de MP, a adoção de medidas que possam reduzir a contaminação das amostras é uma prática bastante comum e cada vez mais necessária. Para isso, no laboratório, tem-se recomendado a utilização de ambientes limpos e com baixa circulação de pessoas durante a manipulação das amostras de MP. Algumas opções, como a utilização de capelas de fluxo laminar ou capelas com exaustão, têm se mostrado bastante eficientes para reduzir a contaminação. Além disso, a inserção de brancos/controles no estudo de quantificação de MP permite identificar possíveis fontes de contaminação cruzada. A prática mais comum é a inclusão de brancos de procedimento, os quais seguem o mesmo procedimento das amostras. A frequência em que tais brancos são preparados fica a critério do analista, visto que não existe procedimento padrão para a análise de MP em matrizes ambientais. Além disso, controles atmosféricos também podem ser inseridos durante a análise, a fim de quantificar a deposição de microfibras e podem tramitar em paralelo aos brancos de procedimento. ${ }^{125-127}$

A eliminação das fontes de contaminação cruzada de MP durante a análise de amostras ambientais ainda é considerada um grande desafio para os analistas, pois a identificação dessas fontes é uma tarefa laboriosa. Assim, a quantificação da contaminação cruzada através do uso de brancos/controles é uma alternativa que pode ser adotada. No entanto, alterações nos brancos/controles podem ocorrer, por exemplo, devido à variação da concentração de fibras no ar dentro do laboratório durante todo o procedimento, e também em cada dia de análise. Portanto, a adoção de protocolos padronizados no laboratório permite que os resultados obtidos sejam comparáveis, reprodutíveis e confiáveis.

\section{Amostragem}

O primeiro desafio envolvendo a amostragem é a estratégia utilizada, pois MP são contaminantes insolúveis, de diferentes composições e propriedades físico-químicas, estando dispersos de forma não homogênea na amostra.
Em 2012 foi criada uma classificação para a amostragem de MP em ambientes marinhos, baseada em três abordagens diferentes, e essa classificação tem sido utilizada para as demais matrizes ambientais. As amostras de MP que são coletadas por extração direta no ambiente e reconhecidas a olho nu (partículas com diâmetro entre 1 a $5 \mathrm{~mm}$ ) fazem parte da abordagem de amostragem seletiva, como a amostragem de pellets diretamente na areia em áreas litorâneas. A amostragem no bulk é aquela onde todo o volume de amostra é utilizado, sem a necessidade de redução durante o processo de coleta, como a amostragem de sedimentos marinhos. A amostragem realizada a partir da redução da amostra global, preservando somente a porção de interesse, é chamada de amostragem de volume reduzido, como a coleta de MP em águas superficiais através de redes de plâncton. ${ }^{128}$

Uma vez que cada matriz ambiental tem suas particularidades quanto à amostragem e o preparo de amostras, a discussão desse tópico será dividida entre as três principais matrizes estudadas na química ambiental: água, solo/sedimento e ar. Nesta revisão não serão abordadas as técnicas de amostragem e preparo de amostras biológicas, para tal, a leitura de outros trabalhos mais específicos é recomendada..$^{34,81,129}$

\section{Matriz: água}

A escolha da técnica de amostragem de MP em matrizes aquáticas é dependente da profundidade de estudo e da logística de acesso ao ponto amostral, pois existe uma ampla variedade de equipamentos destinados à coleta nesse compartimento ambiental. As redes de coleta são, sem dúvida, a técnica mais comum para a obtenção de amostras de MP nessa matriz. São utilizadas para a amostragem em superfície e em profundidades rasas de até $1 \mathrm{~m}$, tanto em ambiente marinho, ${ }^{56,57,130}$ quanto em água doce ${ }^{70,131,132}$ e salobra, como os estuários. ${ }^{130,133,134}$ Porém, há a necessidade do uso de embarcações ou pontes para ter acesso ao local de amostragem, além de profundidade e vazão mínima para que a rede possa ser armada. 
Para a quantificação de MP é preciso conhecer o volume exato de água amostrado, o qual é adquirido por meio de informações geradas por medidores de vazão acoplados nas redes e de sua área de abertura. ${ }^{135,136}$ Porém, a imprecisão de volume é algo recorrente, podendo ser gerada pela ação do movimento da água, por exemplo, ondas e correntezas, em que a submersão da rede pode não ser constante durante toda a amostragem, impedindo a entrada de água na rede. ${ }^{135} \mathrm{~A}$ abertura das redes pode ser circular ou retangular, com dimensões variáveis, as quais são essenciais para o posterior cálculo da área de abertura. Diversos modelos de rede são encontrados na literatura (redes de plâncton, nêuston e bongô) e, em geral, são fabricadas em nylon (PA) e acopladas a um recipiente para armazenamento da amostra (copo de amostragem) produzido em PVC, com uma malha de mesmo tamanho da rede. Além disso, as redes podem conter um sistema de estabilização em águas turbulentas, como ocorre nas redes manta e catamarãa ${ }^{137} \mathrm{O}$ trabalho de Silva e colaboradores descreve com mais detalhes os diferentes modelos de rede. ${ }^{137}$

Redes com malhas na faixa de 300 a $350 \mu$ m são as mais utilizadas para a amostragem de MP. ${ }^{81}$ Com isso, é esperado que partículas com tamanhos inferiores ao da malha não sejam encontradas, pois são perdidas ao passarem em seu interior, levando à subestimação da concentração de MP. ${ }^{138}$ Assim, a utilização de redes com malhas de tamanhos inferiores, possibilita uma amostragem mais representativa, obtendo partículas de MP em uma faixa de tamanho mais ampla. Em um estudo de comparação, onde foram utilizadas redes com três tamanhos de malha $(100,300$ e $500 \mu \mathrm{m})$, foi observado que na rede de $100 \mu \mathrm{m}$ a quantidade de MP foi 10 vezes maior do que na rede de $500 \mu \mathrm{m}$ e 2,5 vezes maior do que na rede de $300 \mu \mathrm{m} .{ }^{139}$ No entanto, com a diminuição do tamanho da malha, as redes tornam-se mais propensas a sofrer entupimento com material orgânico, podendo resultar em perda da sua eficiência e em diminuição do volume de água coletado. ${ }^{82,139}$

A coleta de MP em ambiente aquático também pode ser realizada com a utilização de bombas de amostragem, as quais possibilitam a separação in situ das partículas através do uso de peneiras com diferentes aberturas ou de copos de amostragem. A coleta com bombas de amostragem torna-se viável devido à capacidade de separação de partículas com diferentes tamanhos e à operação em diferentes profundidades, ilustrando, assim, que essas técnicas podem ser consideradas complementares e a escolha deve priorizar as logísticas da amostragem como acesso ao local de coleta, vazão, profundidade, condições climáticas, entre outras. ${ }^{140,141}$ Além disso, essa coleta pode ser aplicada tanto em águas superficiais quanto ao longo da coluna d'água, em ambientes marinhos ${ }^{135,138,141,142}$ e de água doce ${ }^{143}$ incluindo lagos ${ }^{140}$ e ETE ${ }^{144}$ As bombas permitem maior precisão de volume quando comparadas às redes, porém a quantidade de água amostrada geralmente é menor, considerando uma coleta com o mesmo tempo de duração. ${ }^{135,141}$ Isso porque a rede abrange uma área de amostragem maior devido ao seu tamanho e, ao mesmo tempo, garante a amostragem na superfície, o que é um grande desafio para a amostragem realizada com bombas que necessitam estar minimamente mergulhadas nos corpos aquáticos para evitar danos ao sistema. Além disso, as bombas necessitam de uma fonte de energia próxima ao local para mantê-las em funcionamento durante toda a coleta e esse recurso nem sempre é viável. Dos pontos já discutidos, outro fator que deve ser levado em consideração durante a amostragem de MP, seja ela realizada com redes ou com bombas, é o volume de amostra, o qual também está ligado ao tempo de coleta. Para amostragens mais representativas em águas superficiais, recomenda-se a coleta de um volume de água maior que $500 \mathrm{~L}$, no entanto, esse volume é dependente da vazão do corpo hídrico e do material utilizado na coleta. ${ }^{145}$
Amostragem discreta utilizando baldes de metal ${ }^{146} \mathrm{e}$ de plástico,${ }^{147}$ frascos de vidro ${ }^{131,148,149}$ e de aço inoxidável ${ }^{150}$ são opções de baixo custo para a coleta de MP em ambientes aquáticos e bastante atrativos quando o acesso ao local de amostragem é restrito, a vazão ou a profundidade do corpo hídrico são baixas. Os coletores são inseridos manualmente em águas superficiais, o que torna a coleta bastante laboriosa ao considerar que, na maioria das vezes, a introdução do coletor no corpo hídrico deve ser realizada várias vezes a fim de obter um volume de amostra representativo. $\mathrm{O}$ volume amostrado pode ser medido com precisão empregando balanças portáteis. O uso de copos de amostragem ou peneiras com diferentes granulometrias facilita o tratamento da amostra, que é posteriormente manuseada no laboratório. ${ }^{148-150} \mathrm{Em}$ comparação com as redes nêuston ${ }^{148} \mathrm{e}$ com as redes de plâncton, bongô e manta, ${ }^{149} \mathrm{a}$ amostragem discreta obteve concentrações de MP de 3 a 4 vezes maiores. Essas altas concentrações podem ser explicadas devido à capacidade de obtenção de MP menores (entre $100 \mu \mathrm{m}$ e 1,5 mm). Com isso, essa técnica de amostragem, embora laboriosa, pode ser considerada uma opção eficiente para a captura de partículas que passariam através da malha das redes. ${ }^{148}$ Outros modelos de frascos coletores, porém menos utilizados, também são encontrados para a amostragem discreta, por exemplo garrafas de Van Dorn ${ }^{151}$ e frascos Niskin. ${ }^{152,153}$

\section{Matriz: solo/sedimento}

A preocupação com a presença de MP em ambientes terrestres vem ganhando espaço na pesquisa. No entanto, assim como em ambientes aquáticos, até o momento, a amostragem de MP em solo e sedimento não possui protocolo padrão e a falta de consenso sobre as técnicas de amostragem geram uma variedade de unidades de concentração nessa matriz ambiental. Em geral, a quantificação de MP é expressa em itens por unidade de massa seca ou úmida $(\mathrm{g}, \mathrm{kg})$, de volume $\left(\mathrm{mL}, \mathrm{L}, \mathrm{m}^{3}\right)$ ou de área $\left(\mathrm{m}^{2}\right)$. $^{23,46,154} \mathrm{As}$ amostras das camadas superficiais podem ser retiradas manualmente com a utilização de utensílios de metal como espátulas, pás, colheres e pinças. Para a amostragem de MP em profundidade, normalmente são utilizados equipamentos específicos destinados a esse tipo de matriz ambiental como trados, dragas e corer (gravity corer, box corer). ${ }^{154,155} \mathrm{Em}$ um estudo comparativo de amostragem em sedimentos marinhos na profundidade de $42 \mathrm{~m}$, não foi observada diferença significativa na abundância de MP entre as coletas com draga Van Veen, box corer e gravity corer. ${ }^{155} \mathrm{Um}$ histórico de sedimentação pode ser adquirido através de testemunhos, em que um tubo de PVC é utilizado para a obtenção de várias camadas de amostra. Com isso, é possível estimar a taxa de deposição de MP em sedimentos, por exemplo. Na areia de praia, a coleta de MP ou resíduos plásticos de tamanho superior ao de MP geralmente é realizada por meio de transectos com larguras e distâncias previamente definidas. ${ }^{156}$ Essa e outras abordagens também podem ser utilizadas para amostragem em solo. ${ }^{154}$ Embora não exista um padrão de profundidade, bem como de massa de amostra, geralmente coletam-se massas entre $500 \mathrm{~g}$ a $10 \mathrm{~kg}$ de sedimento e entre $50 \mathrm{~g}$ a $4 \mathrm{~kg}$ de solo. ${ }^{34,81,154}$

\section{Matriz: ar}

Uma das formas de coletar amostras de MP na atmosfera é por amostragem passiva. Nesse método, as amostras são depositadas naturalmente e podem ser obtidas por via seca ou via úmida (através da água da chuva). Alguns trabalhos que utilizam esse método são encontrados na literatura e a concentração de MP pode ser expressa em partículas $\mathrm{m}^{-2} \mathrm{~d}^{-1}{ }^{70,72,157-161}$ Outra forma de obter amostras de MP da atmosfera é com a utilização de amostradores ativos. Nesse caso, o ar é forçado a passar por um suporte sólido, como filtros, utilizando bombas de amostragem com vazões conhecidas possibilitando que a concentração de MP seja expressa em partículas por unidade de 
volume. ${ }^{69,162-165}$ Filtros de diferentes composições e porosidades são utilizados nessa amostragem e sua escolha é baseada na técnica de caracterização química que será utilizada. ${ }^{166}$

\section{Preparo de amostras}

Em geral, o preparo de amostras de MP coletados em ambientes aquáticos é composto por duas etapas: (i) separação das partículas e (ii) remoção da matéria orgânica. A separação das partículas coletadas é um processo fundamental, pois detritos orgânicos e inorgânicos (por exemplo, minerais e impurezas não dissolvidas) são facilmente confundidos com MP, quando apenas uma inspeção visual é realizada. A separação pode ser realizada por filtração, peneiração ou por diferença de densidade. A filtração ou peneiração da água coletada pode ser realizada in situ ou ex situ. Para isso, comumente são utilizadas peneiras granulométricas ou membranas de filtração. A abertura ou porosidade desses materiais varia de acordo com o tamanho das partículas a serem estudadas.

Para isolar os MP da matriz de estudo, soluções salinas com altas densidades, como $\mathrm{NaCl}\left(\mathrm{d}=1,2 \mathrm{~g} \mathrm{~cm}^{-3}\right), \mathrm{NaI}\left(\mathrm{d}=1,6-1,8 \mathrm{~g} \mathrm{~cm}^{-3}\right)$, $\mathrm{ZnCl}_{2}\left(\mathrm{~d}=1,5-1,8 \mathrm{~g} \mathrm{~cm}^{-3}\right)$ ou $\mathrm{ZnBr}_{2}\left(\mathrm{~d}=1,7 \mathrm{~g} \mathrm{~cm}^{-3}\right)$ podem ser adicionadas à amostra. Assim, de acordo com a diferença de densidade das partículas, duas frações são obtidas no sistema, uma com baixa e outra com alta densidade. A separação pode ser realizada em funis de separação com ação da gravidade ou em sistema de centrifugação. Trata-se de uma técnica simples na qual é possível separar os MP de outros componentes da matriz e, também, separar os MP com diferentes composições poliméricas, facilitando a primeira triagem da amostra. No entanto, alguns erros podem ser cometidos devido à degradação do polímero e incrustação de matéria orgânica. ${ }^{34,81,82}$ Além das soluções citadas anteriormente, para amostragens em ambiente marinho, a própria água do $\operatorname{mar}\left(\mathrm{d}=1,03 \mathrm{~g} \mathrm{~cm}^{-3}\right)$ pode ser utilizada nessa etapa ${ }^{82}$ Cada solução apresenta uma particularidade e a escolha do reagente deve se basear em seu custo-benefício e facilidade de obtenção e manuseio. Com a utilização da solução de $\mathrm{NaCl}$ é possível separar os polímeros com densidade até $1,2 \mathrm{~g} \mathrm{~cm}^{-3}$ (PP, PU, PE, PA e PS), enquanto os polímeros com densidade superior, como PET e PVC, permanecerão no precipitado. Por outro lado, com a solução de $\mathrm{NaI}$ ou $\mathrm{ZnBr}_{2}$, uma gama maior de polímeros pode ser separada, conforme observado na Figura 3. Utilizando a água do mar para separação, somente os polímeros PP e PE ficarão na superfície devido às suas densidades serem inferiores a $1,0 \mathrm{~g} \mathrm{~cm}^{-3}$.

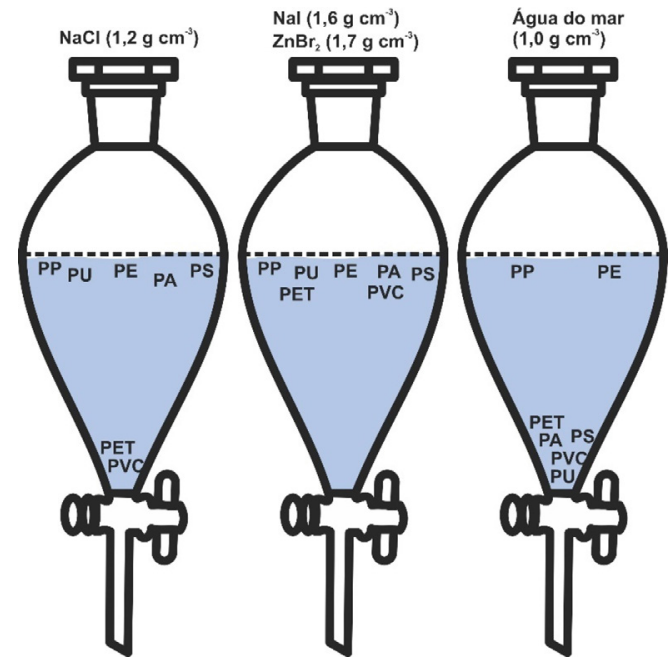

Figura 3. Separação por densidade contendo microplásticos de diferentes composições poliméricas utilizando as principais soluções salinas saturadas ( $\mathrm{NaCl}, \mathrm{NaI}, \mathrm{ZnBr}_{2}$ ) e água do mar
Devido à presença de matéria orgânica na superfície do MP, possíveis interferências na etapa de caracterização química podem ser observadas. Portanto, é necessária a utilização de métodos para eliminação da matéria orgânica que não danifiquem as propriedades químicas e estruturais dos polímeros. Os métodos mais comuns encontrados na literatura são aqueles baseados em digestão com soluções ácidas ou alcalinas, digestão enzimática e digestão branda utilizando oxidantes como $\mathrm{H}_{2} \mathrm{O}_{2}$ ou $\mathrm{NaClO}^{82}$ A digestão ácida e alcalina pode promover degradação e descoloração de alguns polímeros, prejudicando sua caracterização química. ${ }^{81,82} \mathrm{~A}$ oxidação com $\mathrm{H}_{2} \mathrm{O}_{2}$ é o método mais encontrado na literatura, pois promove a digestão da matéria orgânica de uma forma mais branda. No entanto, pode afetar a integridade de alguns polímeros e, o tempo de exposição dos $\mathrm{MP}$ ao $\mathrm{H}_{2} \mathrm{O}_{2}$ é um fator que deve ser controlado. ${ }^{145,167}$ A NOAA estabeleceu um protocolo para tratamento de amostras de água e sedimento marinho, que consiste na utilização do reagente de Fenton para oxidação da matéria orgânica e posterior separação por densidade com solução de $\mathrm{NaCl}{ }^{124}$

A falta de harmonização de procedimentos de coleta e preparo de amostras de MP em ambientes aquáticos possibilita a enorme variedade de métodos encontrados na literatura, ficando a critério do pesquisador a escolha do qual será aplicado, em função de seu objetivo. O protocolo apresentado pela NOAA é um dos mais completos para ser adotado quando se deseja estudar MP nesses ambientes, pois conta com etapas de separação de partículas e remoção de matéria orgânica. No entanto, a maior parte dos estudos envolvendo essa temática não apresenta nenhuma etapa de preparo de amostra ${ }^{82}$ Isso também está relacionado à falta de caracterização química das partículas, em que somente a identificação visual (a olho nu ou por microscopia) é realizada. Portanto, a escolha do método de preparo é também dependente da técnica utilizada para caracterizar as partículas, visto que possíveis interferências podem ocorrer prejudicando a análise.

O preparo de amostras em matrizes ambientais sólidas (sedimento e solo) em geral, pode seguir as mesmas etapas das amostras aquosas, como citado anteriormente. ${ }^{154,168,169}$ A NOAA estabeleceu um protocolo que utiliza uma solução de metatungstato de lítio ( $\mathrm{d}=1,6 \mathrm{~g} \mathrm{~cm}^{-3}$ ) na separação por densidade para MP coletados na areia e no sedimento marinho. Além disso, para a digestão da matéria orgânica em ambas as amostras, o uso do reagente de Fenton é recomendado. ${ }^{124}$ No entanto, as mesmas soluções salinas citadas no preparo de amostras aquosas para a separação por densidade, também podem ser utilizadas para amostras coletadas em ambientes terrestres. $^{170-174}$

Quando as amostras de areia e sedimento são submetidas somente à inspeção visual, a remoção da matéria orgânica não é uma etapa de preparo muito utilizada. No entanto, com a utilização de técnicas para a caracterização química das partículas, esse processo é fundamental, pois amostras de solo e sedimento são consideradas complexas e heterogêneas. Para tal, diferentes estudos descrevem a utilização de agentes oxidantes, digestão ácida, alcalina e enzimática para a remoção da matéria orgânica. ${ }^{154,168,169,175}$

Finalmente, alguns procedimentos de preparo de amostra de MP coletados no ar atmosférico e na poeira estão descritos na literatura. No entanto, muitos estudos utilizam somente uma simples filtração das amostras que se encontram em meio líquido, para a retenção das partículas em um suporte sólido (filtros de fibra de vidro, quartzo, celulose, PTFE, entre outros) e a amostra é submetida diretamente para inspeção visual e/ou caracterização química. ${ }^{70,157,158,162,164} \mathrm{~A}$ utilização de técnicas de separação por diferença de densidade também pode ser utilizada, bem como de oxidação de matéria orgânica. ${ }^{54,67,69,159}$ No entanto, assim como para amostras coletadas em ambiente aquático e terrestre, a necessidade dessas etapas de preparo 
deve ser avaliada considerando, principalmente, a técnica que será utilizada para a caracterização química.

\section{Caracterização química e quantificação de microplásticos}

Os MP são caracterizados majoritariamente por tamanho, forma (fibras, fragmentos, filmes, esferas ou pellets), cor, tipo (composição polimérica) e origem (primário ou secundário), tanto por técnicas que averiguam se o material é um plástico, quanto pelas que identificam o polímero majoritário. A inspeção visual com ou sem microscópio óptico foi e ainda é muito usada em triagem de suspeitos MP, podendo ser uma identificação subjetiva se não houver uma confirmação química com outra técnica instrumental. A vantagem é seu baixo custo e acessibilidade, inclusive em campo, com a ciência de que uma maior taxa de falsos positivos e negativos podem ocorrer sem a etapa de confirmação. Por outro lado, são coletadas centenas ou milhares de partículas nas amostragens, tornando o tempo de análise um fator importante para a decisão de realizar a confirmação química de todas as partículas.

Para uma visão geral sobre a caracterização morfológica por inspeção visual e outras categorizações físicas, que não são o foco desta revisão, sugere-se a leitura de Lusher e colaboradores, ${ }^{176}$ bem como do Guia proposto pelo GESAMP. ${ }^{66}$ Nesta revisão, serão abordadas as principais técnicas para caracterização química da identidade do polímero, sendo que outras informações como tamanho, massa e forma também podem ser levantadas nessas análises em função da instrumentação utilizada.

Embora as técnicas de caracterização química de materiais plásticos sejam bastante consolidadas, a temática de ocorrência de MP no ambiente trouxe o desafio de caracterizar polímeros pósformulados com aditivos e processados, em tamanho reduzido, resultante de materiais envelhecidos por ação ambiental e dispersos em uma matriz complexa de onde serão extraídos. Assim, o MP encontrado no ambiente pode ter sofrido os mais diversos efeitos físico-químicos e microbiológicos, trazendo complexidade à interpretação dos resultados das análises, mesmo para técnicas já amplamente empregadas na caracterização de materiais.

Para a caracterização química de MP já foram reportados o uso do teste clássico de ponto de fusão (hot-stage melting ou "hot-needle"), ${ }^{176}$ das técnicas instrumentais como espectroscopia vibracional (infravermelho - IR, do inglês infrared, e Raman), técnicas termoanalíticas (pirólise - py, análises térmicas como termogravimetria ou análise termogravimétrica - TGA) hifenadas à cromatografia gasosa e/ou espectrometria de massas (pirólise acoplada à cromatografia gasosa - GC do inglês gas chromatography e espectrometria de massas - MS do inglês mass spectrometry, pyGC-MS). Essas técnicas instrumentais são as mais frequentemente encontradas na literatura e serão detalhadas nas próximas seções. No entanto, outras técnicas como cromatografia de exclusão de tamanho - SEC (do inglês Size Exclusion Chromatography); microscopias (microscopia eletrônica de varredura - SEM, do inglês Scanning Electron Microscopy, acoplada à espectroscopia de raios X por dispersão em energia, do inglês Energy-Dispersive X-Ray Spectroscopy - EDS, EDX, EDXS) também já foram reportadas na análise de MP. ${ }^{7}$

A escolha da técnica de caracterização para a análise ambiental deverá ser fundamentada em função da pergunta que se deseja responder no estudo, buscando aquela capaz de fornecer a informação relevante para a resposta, após considerado o seu contexto. Assim, uma técnica pode ser suficiente ou pode ser necessário o uso de técnicas complementares. Por exemplo, caso o objetivo seja a identificação do polímero majoritário do MP, as técnicas termoanalíticas acopladas (como py-GC-MS) e as técnicas espectroscópicas vibracionais são, a priori, capazes de fornecer essa informação. Entretanto, as técnicas termoanalíticas são destrutivas e as espectroscópicas, em sua maioria, não.

Além disso, uma mesma técnica analítica pode ter diferentes arranjos instrumentais que permitirão ou não acessar a informação desejada. Logo, a consideração de outros fatores (tamanho alvo do MP investigado e matriz em estudo) é muito importante para guiar a escolha do instrumento e, consequentemente, o preparo de amostras que antecede a análise instrumental.

A seguir serão discutidas as técnicas mais utilizadas, bem como as estratégias para a identificação e/ou caracterização e os avanços analíticos utilizados para análise de MP, em amostras padrão (como prova de conceito) e em amostras ambientais.

\section{Técnicas espectroscópicas}

\section{Espectroscopia no infravermelho}

Essa tem sido a técnica analítica instrumental mais utilizada para confirmação da identidade de MP. Por meio da interação do polímero com a radiação eletromagnética na região do IR (comprimentos de onda entre $780 \mathrm{~nm}$ e $50 \mu \mathrm{m}$ ), obtém-se o espectro de absorção do polímero através de medidas de transmitância ou reflectância, que é característico para cada tipo de material. Assim, a confirmação da identidade do polímero é fundamentada pela atribuição das bandas.

O tamanho mínimo de MP que a espectroscopia no IR pode acessar será dependente da instrumentação utilizada, podendo variar de dezenas a centenas de micrometros. Assim, reforça-se que o tamanho do MP em estudo é um fator chave para selecionar instrumentos adequados dentro da mesma técnica, impactando diretamente no custo de aquisição e manutenção das pesquisas.

Para exemplificar as diferentes aplicações e instrumentações, considera-se a técnica de espectroscopia no IR médio (MIR, do inglês mid-infrared, de 400 a $4000 \mathrm{~cm}^{-1}$ ). Por exemplo, pellets ou MP na forma de fragmentos medindo $3 \times 3 \times 1 \mathrm{~mm}$ são facilmente isolados da matriz ambiental e podem ser identificados por meio da análise no instrumento espectrômetro MIR com transformada de Fourier (FTIR, do inglês Fourier Transform Infrared) convencional, usando uma unidade ou acessório para aquisição de dados por reflectância total atenuada (espectroscopia ATR-FTIR, do inglês Attenuated Total Reflection-Fourier Transform Infrared). Nela, cada partícula de MP é prensada individualmente sobre um cristal $(\mathrm{ZnSe}, \mathrm{ZnS}$, diamante ou $\mathrm{Si})$ para análise. Como exemplo, MP maiores que $630 \mu \mathrm{m}$ coletados de sedimento de rio foram analisados por essa instrumentação, ${ }^{177}$ assim como MP coletados do trato intestinal de baleias. ${ }^{178}$ Observa-se que nesse caso a instrumentação não tem um microscópio acoplado. Assim, a técnica é de fácil exequibilidade para partículas maiores que $500 \mu \mathrm{m}$, sendo limitada pelo tamanho. A limitação se dá tanto pelo manuseio, quanto pela qualidade do espectro. Sem um tamanho ou formato adequado para total contato da partícula com o cristal, a intensidade das bandas pode ser afetada. Isso ocorre especialmente naquelas de comprimentos de onda mais curtos na região de 2800 a $4000 \mathrm{~cm}^{-1}$, devido à menor penetração da radiação na amostra e, portanto, interferindo em bandas resultantes dos modos vibracionais de $\mathrm{C}-\mathrm{H}, \mathrm{O}-\mathrm{H}$ e N-H, importantes para a identificação de polímeros. ${ }^{23}$

Assim, um ATR-FTIR convencional deixa de ser adequado para a investigação de MP menores, por exemplo, quando o objetivo da análise é investigar uma fibra de $50 \mu \mathrm{m}$ de diâmetro depositada em um substrato após filtração de água de rio ou amostragem atmosférica. Para analisar o MP nesse tamanho, sobre a matriz, é necessário o uso do espectrômetro MIR acoplado a um microscópio (em geral referido como $\mu$-FTIR), adquirindo espectros no modo de transmitância, reflectância ou ATR ( $\mu$-ATR-FTIR). Lindeque e colaboradores utilizaram as duas instrumentações, sendo um ATR-FTIR convencional 
para partículas maiores que $100 \mu \mathrm{m}$ e um $\mu$-FTIR para as partículas menores. ${ }^{139}$ Utilizando $\mu$-FTIR, há trabalhos sobre a ocorrência de MP no trato digestivo de peixes coletados no estuário do Rio Amazonas, ${ }^{94}$ MP coletados no mar em regiões remotas da Islândia, ${ }^{149}$ MP coletados em amostras de deposição atmosférica, ${ }^{69,161}$ entre outros. ${ }^{150}$

Quando a quantidade de MP coletados é muito grande durante a amostragem ambiental, é comum uma subamostragem das partículas para reportar a caracterização de somente uma fração (ou um subset). Embora seja uma prática que deveria ser evitada para redução de viés, fatores como tempo de processamento, custo analítico, operacional ou indisponibilidade de equipamentos tornam muitas vezes inviável a caracterização da composição de toda a amostragem. ${ }^{176}$ Em especial, no caso de MP pré-concentrados ou depositados sobre filtros (o substrato mais utilizado para análises microscópicas por $\mu$-FTIR), recomenda-se que pelo menos $25 \%$ do filtro seja analisado. ${ }^{145} \mathrm{O}$ analista pode procurar possíveis MP sobre o filtro realizando uma inspeção visual não padronizada pelo microscópio para posterior aquisição do espectro do suspeito MP, mas é um trabalho muito laborioso e pouco preciso. Nesse caso, para buscar partículas em uma maior extensão do filtro de forma padronizada sem prévia inspeção visual, diminuindo a subjetividade, pode-se utilizar as técnicas de mapeamento ou imageamento hiperespectral (HSI, do inglês hyperspectral imaging). ${ }^{179}$ Nesse caso, a aquisição de espectros segue uma ordenação espacial por meio de varredura pontual (aquisição de um espectro em um determinado ponto da amostra, seguindo sucessivamente a ordenação espacial estabelecida, usando um detector monodimensional), ou pela aquisição simultânea dos espectros em vários pontos da amostra por meio de um detector bidimensional, em arranjo no plano focal, FPA (do inglês focal plane array). A análise de uma mesma área do filtro utilizando detectores bidimensionais tipo FPA é mais rápida que a aquisição pelos detectores monodimensionais. ${ }^{180} \mathrm{O}$ processamento de dados fornece uma imagem em cores falsas em que é possível localizar os MP, obter tamanho, forma e a identidade do polímero.

Estudos recentes utilizando imageamento $\mu$-FPA-FTIR versaram sobre a ocorrência de MP em neve dos alpes ao ártico, ${ }^{181} \mathrm{MP}$ no oceano Atlântico, ${ }^{182} \mathrm{em}$ estudo de bacias de retenção de águas pluviais como fonte terrestre de MP a ambientes aquáticos ${ }^{183} \mathrm{e}$ em estudo de remoção de MP em ETE. ${ }^{184}$

O tipo de substrato requerido para apresentar a amostra ao $\mu$-FTIR depende do modo de aquisição. No modo reflectância usando um $\mu$-ATR-FTIR, em geral usam-se membranas de filtração ou superfícies metálicas, como Au e Ag. ${ }^{161}$ Entretanto, o substrato deve ser transparente à faixa espectral MIR no caso de medidas por transmitância, sendo utilizado cristal de $\mathrm{KBr}$ ou $\mathrm{CaF}_{2}$, membrana de óxido de alumínio ou de silício, ${ }^{185-187}$ sendo que as janelas espectrais acessadas variam de acordo com a membrana. ${ }^{23}$ Ao se utilizar $\mu$-FTIR no modo transmitância, é possível detectar MP de até $20 \mu \mathrm{m}$, sendo um tamanho próximo do limite de difração no IR $\left(10 \mu \mathrm{m}\right.$ em $\left.1000 \mathrm{~cm}^{-1}\right)$. Porém, pode haver saturação do sinal quando empregada medida $\mu$-FTIR por transmissão. ${ }^{188}$ Já o $\mu$-ATR-FTIR apresenta a limitação das partículas eventualmente se aderirem ao cristal, o que limitaria o menor tamanho a centenas de micrometros. ${ }^{185}$ Uma melhoria recente para a aquisição de dados por imageamento $\mu$-FPA-FTIR foi o uso de uma janela de $\mathrm{BaF}_{2}$, transparente ao IR, sobre a amostra depositada na membrana de óxido de alumínio. O objetivo do uso da janela foi para nivelar a superfície da amostra e apresentar os MP (inclusive fibras) no plano focal do microscópio, sendo que a falta de nivelamento era considerada uma dificuldade para ajuste de foco na medida, principalmente de fibras. Como resultado, a quantidade de MP detectados com a amostra coberta foi maior do que das mesmas amostras analisadas sem a janela de $\mathrm{BaF}_{2}{ }^{189}$

Importante observar que MIR é uma técnica muito sensível à presença de água, portanto, é preciso controlar a umidade da amostra antes da medida, caso contrário uma larga banda do estiramento $\mathrm{OH}$ em $3300 \mathrm{~cm}^{-1}$ pode sobrepor outras bandas, dificultando a análise. Outro aspecto importante a ser considerado na escolha da técnica é o grau de envelhecimento dos polímeros. Fragmentos degradados podem se quebrar com facilidade durante uma análise por ATR-FTIR ou $\mu$-ATR-FTIR, bem como podem apresentar biofilme ou matéria orgânica sorvida em sua superfície e aderir ao cristal, trazendo problemas à medida. Por isso, é comum realizar a digestão da amostra antes da análise por FTIR, para diminuir interferências. Por outro lado, FTIR é uma ferramenta consolidada quando o objetivo da análise é estudar a degradação dos polímeros, por exemplo, por meio dos índices de carbonila e hidroxila, grupos formados na cadeia polimérica de poliolefinas devido às oxidações que ocorrem no processo de degradação fotoquímica do plástico. ${ }^{33}$

Os trabalhos abordados até o momento nessa seção utilizaram IR médio (MIR, de $400 \mathrm{~cm}^{-1}$ a $4000 \mathrm{~cm}^{-1}$ ou $2500 \mathrm{~nm}$ a $25000 \mathrm{~nm}$ ). Outra região espectral do IR começou a ser explorada mais recentemente, ${ }^{190}$ em comprimentos de onda de 780-2500 nm: o IR próximo (NIR, do inglês near-infrared). ${ }^{191,192}$ Uma das modalidades exploradas foi pela utilização de instrumentos portáteis, com potencial de análises em campo. ${ }^{193,194}$ Outra modalidade foi a espectroscopia NIR combinada com imageamento em linha (line-scan). ${ }^{195}$ Diferente do modo de escaneamento pontual (point-scan), comum em microscópios, a instrumentação em linha permite análises mais rápidas por adquirir dados de várias amostras simultaneamente e escanear uma área amostral da ordem de centímetros em menos de um minuto, ${ }^{196}$ a depender do instrumento. Essa técnica é denominada HSI-NIR (do inglês near-infrared hyperspectral imaging), em região espectral também reportada como SWIR (do inglês shortwave infrared). A maior vantagem da técnica é a sua rapidez de aquisição dos espectros, entretanto, demanda um tratamento de dados mais complexo. Devido ao perfil espectral com bandas mais largas, efeitos de espalhamento da luz na aquisição por reflectância e uma quantidade expressiva de dados a serem tratados (uma imagem pode conter centenas de milhares de espectros), ela é uma técnica que deve ser combinada com quimiometria e tratamento de imagem. A técnica já foi reportada para a identificação de MP coletados em água, solo e em peixes, por meio de análise exploratória e modelos supervisionados de classificação, detectando MP na faixa de tamanho de $200 \mu \mathrm{m}$ a $5 \mathrm{~mm}$ nestes trabalhos. ${ }^{152,190,196-198}$

\section{$\underline{\text { Raman }}$}

A espectroscopia Raman já foi reportada para comprovar a ocorrência de MP em ambientes aquáticos (oceanos, mares, rios, lagos, estuários e seus respectivos sedimentos), ${ }^{199-214}$ terrestres, ${ }^{72}$ atmosféricos ${ }^{159,166} \mathrm{e}$ em organismos. ${ }^{86,97,215-220}$ Complementar às espectroscopias NIR e MIR, a espectroscopia Raman se destaca pela sua capacidade de alcançar resolução espacial sub-micrométrica, permitindo preencher uma lacuna deixada pela espectroscopia MIR, que é a análise de MP menores do que $20 \mu \mathrm{m} .{ }^{221}$ A espectroscopia Raman é uma técnica essencialmente microscópica que apresenta limite de difração muito menor que aquele alcançado pela $\mu$-FTIR (de até $266 \mathrm{~nm}$ utilizando laser $532 \mathrm{~nm}$, por exemplo). Não apresenta influência significativa do sinal da água e possui bandas estreitas que facilitam a caracterização química. Porém, apresenta alguns inconvenientes como: i) um sinal de fundo devido à fluorescência e ao aquecimento da amostra, provocado pelo laser, que pode degradar amostras sensíveis alterando seu estado físico-químico; ii) necessita de maior tempo de integração do sinal espectral devido ao fraco sinal Raman e, por isso, maior tempo de análise e iii) possui mais variáveis instrumentais (comprimento do laser, lente objetiva, ajuste do foco do laser na amostra, grade de difração, entre outros) que dificultam a padronização 
do método, mas também, abrange as possibilidades de análise.

Considerando os aspectos citados acima, a resolução espacial é a principal característica que trouxe a espectroscopia Raman para análise de MP em amostras ambientais e impulsionada pela demanda por análises de MP menores que $20 \mu \mathrm{m}$. Nesse tamanho, eles são mais facilmente absorvidos pelos organismos e possuem propriedades físico-químicas diferentes dos MP maiores.

O primeiro trabalho a utilizar a espectroscopia Raman com a finalidade de analisar MP na temática de análise ambiental foi publicado em 2012. ${ }^{222}$ No entanto, esse estudo empregou amostras simuladas em laboratório utilizando sedimento e plásticos comerciais que não sofreram ação ambiental. $\mathrm{O}$ trabalho descreve uma prova de conceito de um método de separação, por meio do desenvolvimento de um aparato que favorecesse a recuperação de partículas de unidades de micrometros, utilizando $\mathrm{ZnCl}_{2}$ como solução para separação por densidade. As partículas foram classificadas como "large microplastic particles" (L-MPP; entre 5 e $1 \mathrm{~mm}$ ) e "small microplastic particles" (SMPP; $<1 \mathrm{~mm}$ ). Após o processo de separação, as L-MPP foram coletadas manualmente de uma membrana de filtração de quartzo e apresentadas ao microscópio para a aquisição espectral, enquanto as S-MPP foram analisadas diretamente na membrana. A caracterização química dos MP foi realizada utilizando espectroscopia Raman com laser em $633 \mathrm{~nm}$. A inspeção visual e aquisição espectral das partículas S-MPP puderam ser feitas simultaneamente, pelo fato do espectrômetro Raman estar acoplado a um microscópio óptico confocal. Os espectros obtidos, na faixa de $50-4000 \mathrm{~cm}^{-1}$, foram comparados por meio da sobreposição dos dados de espectros obtidos de materiais de referência contidos em bases de dados comerciais, variando parâmetros instrumentais para otimizar a aquisição de dados. Foi possível identificar partículas de PE e PS de $5 \mu \mathrm{m} .{ }^{222} \mathrm{~A}$ base desse método ainda é bastante utilizada hoje em dia, a qual consiste na separação/filtração da amostra, seleção das partículas seguindo um critério visual (utilizando ou não microscopia óptica), aquisição dos espectros das partículas selecionadas e, por fim, confirmação da composição do MP comparando com o espectro de um padrão.

A comunidade científica levantou alguns problemas desse método de análise utilizando a inspeção visual como base de seleção de partículas apresentadas à espectroscopia Raman para análise de MP < $20 \mu \mathrm{m}$. O principal é o viés entre partículas elencadas como suspeitas e os MP realmente presentes. A taxa de sucesso na identificação de partículas de MP é baixa para aquelas menores que $100 \mu \mathrm{m}$ e com cores e formas similares aos detritos orgânicos e minerais da matriz, confundindo o analista, enquanto que as maiores taxas de sucesso foram obtidas para partículas maiores que $100 \mu \mathrm{m}$, com cores mais vivas (azul por exemplo) e com forma de fibra. ${ }^{223}$

O grau de degradação, presença de aditivos e variabilidades de composição influenciam na análise dos MP por espectroscopia Raman. As fragmentações das cadeias poliméricas causam alterações nas intensidades das bandas no espectro. A oxidação, a sorção de compostos e os aditivos podem acrescentar bandas ao espectro ou mascarar as bandas dos MP. Os biofilmes provocam fluorescência que pode impedir a caracterização do MP, sendo esse último um dos principais inconvenientes da análise de MP em amostras ambientais utilizando Raman. Nesse sentido, alguns autores propuseram métodos de digestão branda da matéria orgânica nas amostras de MP. A utilização de solução de $\mathrm{KOH}$ como agente de digestão faz parte de um desses métodos e com a utilização da espectroscopia Raman como método de confirmação, vantagens e desvantagens desse preparo de amostra foram observados na análise dos MP degradados. ${ }^{224}$

As inovações publicadas na literatura que descrevem métodos de análise de MP em amostras ambientais utilizando a espectroscopia Raman, em sua maior parte se resumem a novos preparos de amostra a fim de melhorar a resposta espectral ou contornar os problemas já conhecidos dessa técnica vibracional. Além disso, técnicas como aquisição de imagens hiperespectrais (HSI) por Raman, Espalhamento Coerente de Raman Anti-Stokes (CARS, do inglês Coherent AntiStokes Raman Scattering) e Espalhamento Raman Estimulado (SRS, do inglês Stimulated Raman Scattering) também têm sido exploradas para análise de MP.

HSI Raman, em que na maior parte dos casos utiliza-se a técnica point-scan, tem um custo de tempo de aquisição muito elevado, podendo facilmente passar de dias, se for utilizada uma alta resolução espacial ( $1 \mu \mathrm{m}$, por exemplo) para medir uma área com centenas de micrômetros quadrados. Outro ponto importante é o elevado volume de dados adquiridos que chega facilmente a centenas de gigabytes por imagem. Por outro lado, as HSI carregam consigo uma riqueza de informações físico-químicas que permitem responder sobre a composição química de cada partícula da amostra com alto contraste molecular dada pela espectroscopia, sobre o tamanho e a morfologia das partículas e, por fim, a contagem delas.

A HSI utilizando a espectroscopia Raman foi aplicada na análise de MP em amostras de areia de praia. Imagens com áreas de $88 \times 88 \mu \mathrm{m}$ e $55 \times 55 \mu \mathrm{m}$ foram adquiridas em amostras peneiradas com tamanho de poro de $125 \mu \mathrm{m}$. As amostras foram lavadas com etanol e água ultrapura antes das medidas. A resolução espacial foi de $1 \mu \mathrm{m}$ pixel $^{-1} \mathrm{e}$ a faixa espectral foi de 0 a $4000 \mathrm{~cm}^{-1}$. Cinco tipos de MP (PS, PET, PE, PVC e PP) foram monitorados nas amostras com e sem areia, sendo essa última também identificada pelo espectro Raman. Utilizando um tempo de integração de sinal Raman de $0,5 \mathrm{~s}$, as imagens com $88 \mu \mathrm{m}^{2}$ foram adquiridas em $64,5 \mathrm{~min}$. Os autores concluíram que a técnica distinguiu os diferentes MP em uma mesma amostra, de forma a obter sinais separados de cada partícula, mas isso requereu um cuidadoso preparo da amostra a fim de obter uma superfície plana, em virtude da alta resolução espacial que o instrumento apresenta. ${ }^{225}$

A ingestão, digestão e aderência de partículas de PS, entre 1,4 a $30 \mu \mathrm{m}$ de diâmetro, foi identificada em zooplânctons. Essa identificação foi realizada por meio de imagens químicas CARS sintonizando o laser sonda em bandas específicas do polímero (2845 $\mathrm{cm}^{-1}$ do estiramento $\mathrm{C}-\mathrm{H}$ e $3050 \mathrm{~cm}^{-1}$ do estiramento $\mathrm{C}-\mathrm{H}$ de aromáticos). ${ }^{215} \mathrm{Um}$ método para análise de MP baseado na microscopia SRS foi descrito na literatura, em que foram adquiridas imagens de uma amostra teste preparada em laboratório, de uma amostra de esmalte de unha que continha PET e de uma amostra de sedimento do estuário do rio Reno. Os plásticos foram investigados, sintonizando o laser sonda em bandas específicas de 5 polímeros (PA, PET, PS, PP e PE), encontrados frequentemente nas amostras ambientais de MP. Foi utilizada uma membrana de óxido de alumínio devido ao baixo sinal de fundo da mesma e à sua superfície plana, uma vez que a resolução espacial da técnica é alta. As imagens foram adquiridas em uma área de $1 \mathrm{~cm}^{2}$ do filtro e duraram cerca de $5 \mathrm{~h}$, com espaçamento de $3 \mu \mathrm{m}$ entre os pixels e tempo de $100 \mu \mathrm{s}_{\text {pixel }}{ }^{-1}$. Ressaltou-se que a análise dessa mesma área da membrana, com o mesmo tamanho de passo, mas utilizando o Raman convencional que requer em média um tempo de integração de $1 \mathrm{~s} \mathrm{pixel}^{-1}$, demoraria 116 dias para aquisição de dados. ${ }^{226}$ Vale a pena destacar que o volume de bytes de dados é drasticamente reduzido utilizando as técnicas CARS e SRS, pois ao invés de adquirir milhares de comprimentos de onda por pixel, somente um ou algumas unidades por pixel são monitorados por imagem. Tais técnicas possuem características muito atrativas, mas dispõem de instrumentação bastante complexa, requerendo analistas especializados.

\section{Espectroscopia fototérmica no infravermelho}

A espectroscopia fototérmica excitada por radiação IR (MIP, do inglês mid-IR Photothermal) é uma técnica bastante recente. ${ }^{227}$ Essa técnica tem várias implicações como a não influência de sinal de 
fundo e alta velocidade de aquisição, pois é limitada somente pelo tempo de relaxação térmica. Além disso, possui alta sensibilidade assim como no IR e permite aquisição de espectros IR por meio de medidas por reflectância. Uma das vantagens da técnica é a resolução espacial similar aos espectrômetros Raman, devido ao uso do mesmo tipo de laser no visível, ou seja, permite a aquisição de espectros no IR com resolução sub-micrométrica. ${ }^{198}$

Embora seja uma técnica bastante recente, um equipamento comercial que emprega essa tecnologia já está disponível. O instrumento permite medir o espectro IR pelo efeito fototérmico e o espalhamento Raman simultaneamente. ${ }^{228} \mathrm{Na}$ Figura 4 é mostrada a análise de MP obtido de ambiente marinho por meio de imagem hiperespectral, onde foram identificadas partículas de PS e polimetilmetacrilato (PMMA) dispersas em sal sobre uma lâmina de $\mathrm{CaF}_{2}$. A imagem química de dimensões 200 x $150 \mu \mathrm{m}$ levou $20 \mathrm{~min}$ para ser adquirida monitorando somente dois comprimentos de onda, sintonizados no máximo de bandas do PMMA e do PS, 1730 e $1492 \mathrm{~cm}^{-1}$, respectivamente. Em destaque na imagem óptica pode-se observar a identificação de uma partícula de PS com aproximadamente $900 \mathrm{~nm}$ de diâmetro. A espectroscopia MIP foi descrita recentemente em um estudo de revisão dentre a perspectiva global sobre MP como uma técnica capaz de analisar partículas sub-micrométricas. ${ }^{229}$

\section{Confirmação da identidade dos polímeros e bibliotecas espectroscópicas}

Como pode ser notado, a identificação do MP de origem ambiental é um desafio de alta complexidade. Um dos fatores é que as confirmações baseadas em bibliotecas espectrais de polímeros puros ignoram as alterações dos MP que sofreram ação ambiental podem apresentar. Outra dificuldade está em produzir bibliotecas que englobem a enorme variabilidade química que MP podem apresentar, especialmente quando expostos às intempéries. ${ }^{230}$

Uma das bibliotecas de espectros mais utilizadas para caracterização dos materiais plásticos é chamada KnowItAll ${ }^{\mathrm{TM}}$ database, a qual contém dados espectrais de diversas técnicas incluindo IR e Raman. ${ }^{166,223,231}$ Nessa base de dados espectrais são encontrados espectros de praticamente todos os polímeros que compõem os MP. O software calcula um índice de similaridade espectral (chamado de HQI, do inglês Hit Quality Index) e ranqueia os compostos mais prováveis para o material desconhecido. As considerações para o cálculo do HQI são demonstradas na norma ASTM E2310-04. ${ }^{232}$ No entanto, os dados dessa biblioteca são de materiais de referência, sendo que a construção de base de dados com polímeros degradados é uma demanda emergente para a análise de MP, visto que a similaridade de espectros entre um polímero de referência e o MP formulado e degradado do mesmo polímero pode ser prejudicada.

Uma biblioteca livre contendo mais de 250 espectros Raman de plásticos comerciais e de amostras de MP coletadas no ambiente foi publicada como parte de um esforço de ampliar a acessibilidade da espectroscopia Raman neste contexto. Os materiais obtidos apresentaram variadas cores e morfologias. Algumas variáveis instrumentais foram acrescentadas como fontes de variabilidade espectral como o tipo do laser, filtro de densidade, grade de difração, tamanho da fenda, tempo de aquisição, número de acumulações, entre outras, a fim de enriquecer o banco de dados. ${ }^{233}$ Bancos de dados espectrais Raman e FTIR de MP coletados no ambiente também foram adquiridos e nesse caso o principal objetivo foi o estudo das modificações físico-químicas causadas na superfície dessas partículas e, por isso, imagens obtidas por SEM também foram utilizadas na análise..$^{234}$

Outra tendência para análises espectroscópicas mais rápidas e confiáveis é a identificação do polímero empregando algoritmos para processamento dos espectros e para reconhecimento de padrões espectrais, desenvolvido por meio de métodos quimiométricos (um tipo de aprendizado de máquinas, do inglês machine learning, voltado ao tratamento de dados químicos), os quais são embutidos no software dos equipamentos ou desenvolvidos in-house. ${ }^{235-243}$ Apesar da análise de MP utilizando técnicas quimiométricas e de processamento de HSI ser bastante informativa, a complexidade e o custo não a tornam tão popular quanto a inspeção visual e espectroscopia convencional, que são mais simples e de menor custo para serem implementadas às análises de rotina. No entanto, a capacitação de especialistas que tenham domínio sobre a técnica de aquisição e de tratamento dos dados multivariados, tem se mostrado uma demanda crescente importante para a área de química ambiental na temática de MP.

\section{Técnicas termoanalíticas}

A decomposição térmica controlada de um material, sob atmosfera inerte, é denominada pirólise (py). Ao serem aquecidos, os MP passam por transformações físico-químicas, degradam-se e perdem massa nesse processo. A caracterização de MP por técnicas térmicas é fundamentada nesses fenômenos e a principal informação que elas fornecem é a identidade do polímero por meio da análise de seus produtos de degradação, podendo inclusive ser feita a detecção de aditivos ou contaminantes sorvidos nos MP. Os fragmentos de maior abundância são geralmente monômeros, dímeros ou trímeros formados pela decomposição da cadeia polimérica do MP. ${ }^{244}$ A priori, as técnicas por degradação térmica não fornecem a informação de tamanho do MP, entretanto, ele pode ser conhecido se houver um pré-tratamento de amostra que separe as frações antes da análise.
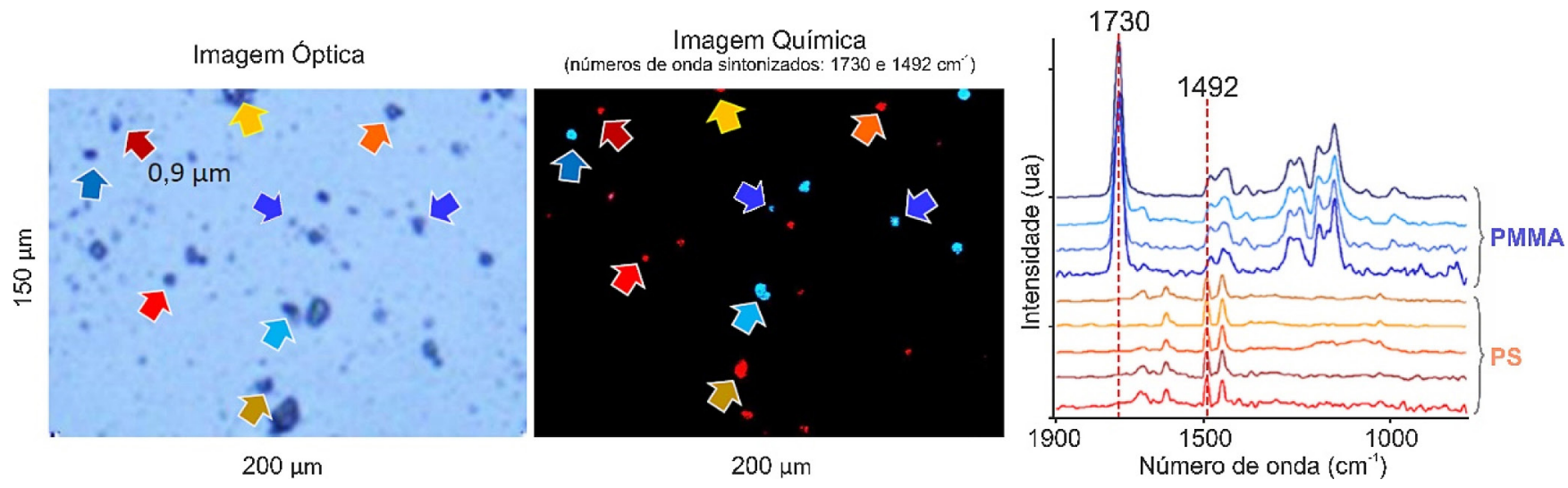

Figura 4. Imagem óptica, imagem química infravermelho (IR) e espectros das partículas indicadas pelas setas, adquiridas utilizando espectroscopia fototérmica no IR. Os dados são uma cortesia do fabricante do instrumento mIRage da empresa Photothermal Spectroscopy Corp 
A técnica de py-GC-MS consiste em um pirolisador acoplado a um GC-MS ou diretamente no espectrômetro de massas (py-MS), em que o MP é inserido no pirolisador. O uso de atmosfera inerte é importante para garantir a reprodutibilidade da pirólise, que também é influenciada pelo tipo de pirolisador utilizado e a matéria orgânica residual no MP, podendo-se utilizar um padrão interno no processo de pirólise. ${ }^{245,246}$ Quando a introdução da amostra ao pirolisador antes da análise cromatográfica é feita com o MP isolado, o tamanho do MP a ser analisado é limitado pela habilidade do analista no manuseio da amostra e é da ordem de $100 \mu \mathrm{m} .{ }^{247,248}$ Entretanto, avanços recentes no desenvolvimento de métodos por py-GC-MS reportam a análise do MP diretamente na matriz, o que pode possibilitar o estudo de MP menores. ${ }^{246}$ Solos fortificados com PE, PP e PS na concentração de 50 a $250 \mu \mathrm{g} \mathrm{g}^{-1}$ foram solubilizados com 1,2,4-triclorobenzeno (TCB) e alíquotas com até $4 \mathrm{~g}$ de solo foram analisadas por py-GC-MS, apresentando recuperações de 70-128\% para o nível de $250 \mu \mathrm{g} \mathrm{g}^{-1}$ para solos com até $2,5 \%$ de carbono orgânico. ${ }^{249}$ Em outro trabalho, a análise de MP menores que $100 \mu \mathrm{m}$ em água foi feita pela filtração da água e deposição dos MP em uma membrana de PTFE, posteriormente cortada a laser e então submetida à py-GC-MS, utilizando MS de alta resolução para maior detectabilidade dos produtos de degradação. A membrana de PTFE foi escolhida pela alta resistência térmica do material e uma prova de conceito feita em $200 \mathrm{~mL}$ de água do rio Tawe (Reino Unido), sugerindo a ocorrência de PS em tamanho da ordem submicrométrica nesse rio. ${ }^{250} \mathrm{~A}$ combinação de extração com líquido pressurizado (PLE, do inglês pressurized liquid extraction) e py-GC-MS atingiu limites de detecção dos MP mais comuns (PE, PET, PS, PP) na faixa de 7 a $30 \mu \mathrm{g} \mathrm{g}^{-1}$ para matrizes complexas como solo, sedimento e lodo de esgoto. ${ }^{251,252}$ Por fim, outro avanço foi a avaliação de instrumento py-MS portátil como potencial ferramenta para análise de MP em campo. ${ }^{253}$

Outra maneira de explorar os produtos de degradação de MP para identificá-los é pela utilização de análises térmicas. Tanto TGA quanto calorimetria exploratória diferencial (DSC, do inglês differential scanning calorimetry) fornecem informação das relações entre uma propriedade da amostra e temperatura, ao submetê-la a rampas de aquecimentos e/ou resfriamentos controlados em determinada atmosfera. Essas análises térmicas não são em geral utilizadas isoladamente no contexto de análise de MP, dado que os MP têm histórias térmicas únicas pela exposição ambiental, o que influencia suas propriedades e a curva obtida, ${ }^{254}$ além dos MP secundários terem sido processados com formulações e condições diversas. Assim, o mais comum é a utilização de TGA combinada ou acoplada a outras técnicas, obtendo as informações de variação de massa em função de temperatura por TGA e a caracterização do gás liberado durante a pirólise por MS ou GC-MS, ${ }^{248}$ sendo que os gases liberados podem ou não ser retidos em uma fase sólida para posterior dessorção térmica em uma unidade de dessorção térmica (TDU, do inglês thermal desorption unit ou TDS, thermal desorption system) e análise por MS ou GC-MS. Essa configuração combinando TGA, sorção dos voláteis na fase sólida e posterior dessorção térmica é encontrada na literatura como TED-GC-MS, sendo TED do inglês thermal extraction desorption. ${ }^{255,256}$ Essa combinação permitiu analisar uma quantidade maior de amostras, sendo uma vantagem de TED-GCMS sobre py-GC-MS. Por conta de temperaturas diferentes, limpeza da amostra e etapa de extração/dessorção após a pirólise, os perfis de decomposição obtidos por TED-GC-MS podem ser ligeiramente diferentes que os obtidos por py-GC-MS. ${ }^{244}$

Como características, tanto py-GC-MS quanto TED-GC-MS são técnicas destrutivas e fornecem resultados em base de concentração para a quantificação de MP, permitindo análise simultânea de diferentes polímeros, podendo atingir níveis de detecção e quantificação na faixa de nanogramas. Embora até o momento as técnicas térmicas tenham sido menos utilizadas que as espectroscópicas na análise de $\mathrm{MP},{ }^{82}$ elas têm ganhado importância e são consideradas promissoras para a análise de nanoplásticos. Duas revisões recentes sobre o uso de técnicas térmicas apresentam uma tendência de sua aplicação para a matriz sedimento, bem como discutem as particularidades das técnicas em função de fundamentos, preparo de amostra, interferência da matriz, representatividade da subamostragem, limites de detecção, quantificação e validação na análise de MP. ${ }^{244,246}$

\section{Estratégias multitécnicas}

A comparabilidade do desempenho das mesmas técnicas entre diferentes trabalhos fica limitada pela falta de padronização dos métodos, sendo que a comunidade científica discute sobre a harmonização de procedimentos. O princípio de cada técnica leva a resultados quantitativos expressos em unidades diferentes, baseados em massa ou baseados em número de partícula, o que compromete a comparação de resultados de ocorrência entre estudos, ou mesmo de remoção. ${ }^{184}$ Por exemplo, as técnicas termoanalíticas acopladas à cromatografia tem resultados expressos em concentração, $\mu \mathrm{g} \mathrm{L}^{-1}$ para matrizes líquidas ou $\mathrm{mg} \mathrm{kg}^{-1}$ para matrizes sólidas e fornecem informação de teores totais, independentemente do número e distribuição de tamanho de partículas inseridos no instrumento. As técnicas espectroscópicas reportam contagens, ou seja, número de MP extraídos de um determinado volume ou massa de amostra, sem a informação da massa total de MP durante a análise. Outra consideração são as particularidades de cada MP, por exemplo, um MP muito degradado poderia quebrar durante uma análise por ATR-FTIR, sugerindo que fosse analisado por Raman. Porém, se o mesmo MP fosse muito pigmentado ou escuro, teria interferência de fluorescência ou não teria sinal no Raman, sugerindo que fosse analisado por FTIR.

Assim, não há técnicas melhores ou piores, mas aquelas mais adequadas em função do objetivo do estudo, dado que tamanhos, particularidades e matrizes podem favorecer uma ou outra técnica de confirmação química. Em função das potencialidades e limitações de cada uma, existe uma tendência para se utilizar uma estratégia multitécnica na caracterização química de MP, explorando que as técnicas são, na verdade, complementares.

Uma contribuição nesse sentido foi dada por Elert e colaboradores, que padronizaram uma amostra para ser analisada qualitativamente por quatro técnicas, com o objetivo de verificar se detectavam o MP ao final. Partículas de até $125 \mu \mathrm{m}$ de PE, PP, PS e PET foram intencionalmente adicionadas em um solo a uma concentração de $1 \% \mathrm{~m} / \mathrm{m}$ de cada polímero, totalizando $4 \% \mathrm{~m} / \mathrm{m}$ no solo e, em seguida, a amostra sintética foi analisada por espectroscopia vibracional combinada com imagem ( $\mu$-FPA-FTIR em modo de transmissão e Raman), TED-GC-MS e SEC. ${ }^{187}$ Os polímeros não continham aditivos, o que a priori excluiu interferências causadas por eles, dado que, por exemplo, a fluorescência de um pigmento poderia desfavorecer o Raman, enquanto que a presença de outros aditivos poderia ser um fator desfavorável para TED-GC-MS ou $\mu$-FPA-FTIR. Observa-se que apesar da amostra ter sido padronizada em função do tipo, concentração e tamanho de MP, cada técnica demandou uma quantidade diferente de amostra, consequentemente, na quantidade de MP introduzida ao instrumento. Como resultado, exceto por SEC, as técnicas detectaram os 4 polímeros, entretanto, diferentes aspectos foram adicionalmente discutidos. As técnicas baseadas em massa, TED-GC-MS e SEC, utilizaram quantidades maiores de solo, sendo menos vulneráveis à falta de homogeneidade; ressalta-se que elas possibilitam calibração para posterior quantificação, mas não fornecem diretamente informação de tamanho e número de partículas. Por outro lado, as técnicas espectroscópicas combinadas com imagem analisaram uma quantidade menor de amostra, o que 
poderia comprometer um protocolo de quantificação pela baixa amostragem. No entanto, forneceram diretamente a identidade, número e tamanho de partículas. Assim, Elert e colaboradores sugerem que o mais importante na escolha da técnica é decidir qual a questão que se quer responder da mesma: em casos que tamanho de partícula e grau de degradação do MP importam, as espectroscópicas seriam mais indicadas, enquanto TED-GC-MS e SEC responderiam mais rapidamente com quais tipos de MP o solo estaria contaminado, sem fornecer outras informações de cada partícula individualmente.

A técnica SEM-EDS fornece detalhes da morfologia na superfície da partícula e da composição elementar (de carbono e outros elementos), mas sem identificar de fato o polímero. Para a finalidade de identificar, é necessário associar um preparo de amostras que vise separar as partículas (por densidade, por exemplo) e considera-se que as partículas são MP em função do isolamento e da remoção de matéria orgânica durante o preparo de amostras. A posterior análise por SEM visaria uma caracterização morfológica de um MP já identificado e caracterizado por uma técnica espectroscópica, fornecendo detalhes da superfície degradada em resoluções na ordem nanométrica, ou a presença de outros elementos por SEM-EDS. Em um trabalho de avaliação da exposição humana a MP, reportou-se o emprego de SEM-EDS como método de identificação e quantificação dos MP, ${ }^{118}$ entretanto, foi refutado sob o argumento de que a utilização do teor de carbono não seria suficiente para a confirmação, além de outras falhas analíticas. ${ }^{257,258}$

Outra estratégia bastante utilizada na análise de MP é o uso do corante vermelho do Nilo (do inglês Nile Red), um composto fluorescente que auxilia a inspeção visual. Esse corante é originalmente utilizado para corar o tecido lipídico de células, pois é um composto bastante hidrofóbico. Isso faz com que ele core facilmente vários tipos de materiais plásticos, assim, sua visualização na microscopia de fluorescência torna-se favorecida. ${ }^{259,260}$ Por exemplo, foi desenvolvido um método de fabricação de microfibras de materiais plásticos (PA, PET e PP com 10-28 $\mu \mathrm{m}$ de diâmetro e 40-100 $\mu \mathrm{m}$ de comprimento), para uso em estudos sobre a ingestão de MP por organismos. A motivação foi a dificuldade de encontrar microfibras comerciais para tais estudos. Nesse trabalho, o corante foi usado para imagear as microfibras dentro do trato intestinal de artêmias. ${ }^{261}$

O procedimento de corar os MP, a fim de reconhecê-los mais facilmente através da fluorescência, chamou a atenção de diversos grupos de pesquisa, que logo desenvolveram e otimizaram as condições de coloração em amostras ambientais. ${ }^{262-264}$ Diversos trabalhos passaram a adotar o corante em seus métodos de análise de MP, a fim de melhorar a taxa de sucesso na identificação dessas partículas utilizando a inspeção visual. ${ }^{262,265-270}$

Em artigo recente, Prata e colaboradores ${ }^{264}$ concluíram que dentre uma série de corantes testados, o Nile Red foi o mais adequado para o desenvolvimento do método de baixo custo proposto para contagem de partículas de MP. O método consiste na análise de imagem digital, da fluorescência do corante Nile Red, depois de corar as partículas de MP da amostra. As imagens foram adquiridas utilizando uma câmera fotográfica convencional. Vários comprimentos de onda de excitação da fluorescência foram testados bem como vários tipos de MP virgens e degradados. A validação da eficiência do método proposto foi realizada com base em espectros no IR, a qual obteve um percentual de recuperação entre $89 \%$ e $111 \%$. O método proposto tem forte apelo de aplicação devido seu baixo custo e devido ao ganho de velocidade e automação na contagem das partículas que eliminam a subjetividade da inspeção visual. Por outro lado, o método não responde sobre a composição química das partículas de MP e sobre a cor original, uma vez que a amostra necessita passar por processo de digestão. Nesse caso, o método poderia ser empregado como uma análise complementar. Importante diferenciar as técnicas de imagens digitais $^{264,271,272}$ das HSI que foram discutidas na seção de técnicas espectroscópicas. Ao final do processamento, ambas fornecem informações sobre forma e tamanho de partículas, entretanto, apenas HSI fornecem identidade química do polímero (PE, PP, entre outros), dado que a imagem é obtida em função do espectro IR ou Raman de cada pixel.

Além das técnicas já discutidas nesse trabalho, já foi reportado na literatura o uso de TGA-FTIR-GC-MS, sendo que nesse caso a análise de IR é feita no gás evoluído da TGA, ${ }^{273}$ técnicas de ionização e dessorção acopladas à MS de alta resolução para a caracterização química. ${ }^{274}$ Assim, estabelecido o objetivo da análise, árvores de decisão baseadas na pergunta que se deseja responder no estudo podem ser úteis para guiar a escolha da técnica de análise, como a proposta por Zarfl ${ }^{275}$ e Lusher e colaboradores. ${ }^{176}$

Por fim, a caracterização química e/ou quantificação de MP é a última etapa do método analítico, que já propagou os erros devido à amostragem, subamostragem e preparo de amostra, e isso deve ser considerado. A qualidade analítica do método como um todo foi avaliada por Koelmans e colaboradores, baseada na publicações envolvendo a análise de MP em água doce e água potável. ${ }^{145}$ Foram avaliados os parâmetros como tipo e volume de amostragem, tamanho de partícula alvo, armazenamento e processamento de amostras, local apropriado (ex: sala limpa) para evitar contaminação durante o processamento da amostra, controles negativos como amostra branco, controles positivos e ensaios de recuperação com amostras enriquecidas com quantidades ou concentrações conhecidas de MP e, por fim, o método de caracterização química do tipo do polímero, demonstrando os desafios no contexto global da análise de MP. ${ }^{145}$

\section{O CENÁRIO NO BRASIL}

Para finalizar esse trabalho de revisão, uma pesquisa na literatura sobre a ocorrência de MP em matrizes ambientais brasileiras foi realizada a fim de trazer o cenário de contaminação reportado até o momento sobre a presença de MP e os métodos analíticos que vêm sendo empregados (Tabela 1). A revisão foi baseada em artigos indexados nas bases de dados Scielo e Web of Science, publicados entre 2004 (primeiro trabalho nestas matrizes no Brasil) e dezembro de 2020, utilizando uma busca avançada combinando os termos "microplastic/microplástico", "marine litter/lixo marinho", "plastic debris/detritos de plástico", "plastic pellets/pellets plásticos", "plastic pollution/poluição plástica", "marine debris/detritos marinhos", "Brazil/Brasil", selecionando aqueles com foco em ocorrência.

Ao todo, foram considerados 80 trabalhos, dos quais 61 referemse aos estudos na matriz sedimento (incluindo areia de praia) e 19 na matriz água. Nenhum trabalho sobre MP na atmosfera e no solo foi encontrado no Brasil, considerando o método de busca de publicações empregado neste processo de revisão. Dos 19 trabalhos sobre a matriz água, 7 referem-se à água salobra, 9 à água salgada e 3 à água doce, conforme mostra a Figura 5a. Os ecossistemas marinhos foram de forma geral, os mais estudados quando comparados aos sistemas de água doce. Embora esses últimos sejam considerados como as maiores fontes de aporte dos resíduos plásticos para os oceanos, apenas recentemente vêm recebendo mais atenção da comunidade científica. Do total de trabalhos selecionados nesta revisão, apenas $8 \%$ avaliaram a presença de MP em ecossistemas (água/sedimento) de águas doces, enquanto $92 \%$ foram realizados nos oceanos e regiões costeiras (incluindo os sistemas de água salobra). Considerando a abrangência dos estudos ao longo de todo o território brasileiro, $44 \%$ das amostragens foram realizadas na região sudeste, seguido pela região nordeste $(35 \%)$, sul $(17 \%)$ e norte $(4 \%)$, como pode ser visualizado na Figura $5 \mathrm{~b}$. 
a)

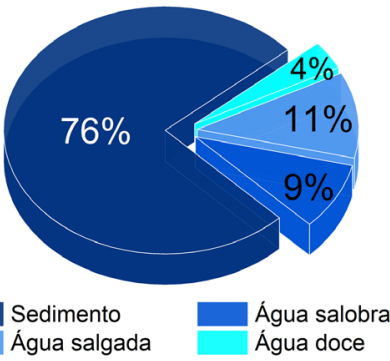

b)

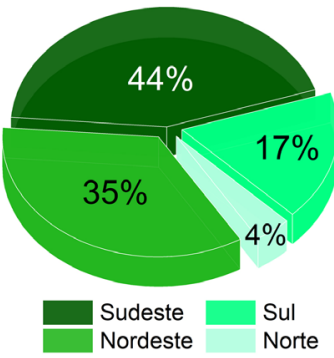

Figura 5. Do total de 80 trabalhos publicados em revistas indexadas até 2020 sobre microplásticos e resíduos plásticos nas matrizes sedimento e água no Brasil temos, (a) porcentagens de estudos por matrizes ambientais e (b) porcentagens de estudos realizados nas diferentes regiões do Brasil

A Tabela 1 descreve os trabalhos publicados com foco em ocorrência de MP e de resíduos plásticos no Brasil em matrizes ambientais (água salobra, água salgada, água doce e sedimento) e ilustra a falta de harmonização de métodos discutida anteriormente.

A areia de praia foi a matriz mais estudada em território brasileiro e isso pode ser facilmente justificado devido à facilidade de amostragem nesse compartimento, em que a coleta é feita manualmente, sem o uso de equipamentos específicos. Os pellets são um bom exemplo de materiais que podem ser coletados a olho nu, com o auxílio de pinças. Na região litorânea do Brasil, a presença de pellets tem sido evidenciada tanto em estudos que visam quantificar contaminantes associados ${ }^{311,312,315,320,321,334}$ ou somente para identificálos em meio ao resíduo marinho. ${ }^{89,174,276,299}$

Em relação à amostragem na matriz água (salobra, salgada e doce), observou-se uma ampla abrangência de faixas de tamanho de MP devido à utilização de redes com diferentes tamanhos de malha, pois esses variaram de $60 \mu \mathrm{m}$ a $42 \mathrm{~mm}$. Com isso, seria esperado que MP com tamanho inferior a $60 \mu \mathrm{m}$ não fossem encontrados nesse compartimento ambiental. No entanto, como as partículas podem se aderir ao restante do material retido nas redes durante a coleta, foram encontrados, por exemplo, MP com tamanho entre 5 e $100 \mu \mathrm{m}$ em uma abundância de cerca de 20\% no lago Guaíba no Rio Grande do Sul. ${ }^{286}$ Além disso, a maioria dos trabalhos realizados na matriz água

Tabela 1. Ocorrência de microplásticos (MP) e resíduos plásticos em matrizes ambientais de água e sedimento no Brasil

\begin{tabular}{|c|c|c|c|c|c|}
\hline Local & $\begin{array}{c}\text { Amostragem e preparo de } \\
\text { amostra }\end{array}$ & Identificação & $\begin{array}{l}\text { Caracterização } \\
\text { química }\end{array}$ & Quantificação & Referência \\
\hline \multicolumn{6}{|l|}{ Água salobra } \\
\hline Estuário do rio Goiana/PE & $\begin{array}{l}\text { Rede de plâncton de } 300 \mu \mathrm{m} ; \\
\text { secagem a } 60^{\circ} \mathrm{C}\end{array}$ & Microscopia óptica & - & $\begin{array}{c}14.724 \mathrm{MP} \\
\left(26,04 \mathrm{MP}^{\left.100 \mathrm{~m}^{-3}\right)}\right.\end{array}$ & 133 \\
\hline Estuário do rio Goiana/PE & $\begin{array}{l}\text { Rede de plâncton de } 300 \mu \mathrm{m} \text {; } \\
\text { secagem a } 60^{\circ} \mathrm{C}\end{array}$ & Microscopia óptica & - & $26,1 \mathrm{MP} 100 \mathrm{~m}^{-3}$ & 276 \\
\hline Estuário do rio Goiana/PE & Rede de $1000 \mu \mathrm{m}$ & Microscopia óptica & - & 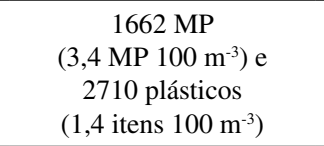 & 134 \\
\hline Estuário do rio Goiana/PE & Rede de plâncton de $300 \mu \mathrm{m}$ & Microscopia óptica & - & $26,06 \mathrm{MP} 100 \mathrm{~m}^{-3}$ & 277 \\
\hline Estuário do rio Paraíba/PB & $\begin{array}{l}\text { Rede de } 5 \mathrm{~mm} \text {; secagem a } \\
60{ }^{\circ} \mathrm{C}\end{array}$ & Inspeção visual & - & $\begin{array}{l}88,37 \% \text { dos itens coletados } \\
\text { eram plásticos }\end{array}$ & 278 \\
\hline Estuário de Paranaguá/PR & Rede de arraste de 26 e $42 \mathrm{~mm}$ & Inspeção visual & - & $\begin{array}{c}291 \text { itens } \\
(92,4 \% \text { plásticos })\end{array}$ & 279 \\
\hline Estuário Santos-São Vicente/SP & $\begin{array}{c}\text { Coleta manual de resíduos } \\
\text { flutuantes }\end{array}$ & Inspeção visual & - & $\begin{array}{c}2339 \text { itens } \\
(89,64 \% \text { plásticos })\end{array}$ & 280 \\
\hline
\end{tabular}

Água salgada

Arquipélagos São Pedro e São Paulo/PE
Rede de plâncton de $300 \mu \mathrm{m} \quad$ Microscopia óptica
99 MP e 22 itens plásticos

$(47,2 \%$ das amostras contaminadas com plásticos)

Arquipélagos São Pedro e São Paulo/PE

Ilhas de Fernando de Noronha/PE, Rede manta de $300 \mu \mathrm{m}$ Abrolhos/BA e Trindade/ES

Litoral do Atlântico entre Maranhão e Ceará

Redes de plâncton de 120 e $300 \mu \mathrm{m}$

Microscopia óptica

71 itens $\left(1\right.$ item $\left.100 \mathrm{~m}^{-3}\right)$

243 partículas plásticas (1,52 partículas por rede)

$0,14 \mathrm{MP} \mathrm{m}^{-3}$

(rede de $120 \mu \mathrm{m}) \mathrm{e}$

$0,02 \mathrm{MP} \mathrm{m}^{-3}$

Microscopia óptica (rede de $300 \mu \mathrm{m}$ )

ATR-FTIR

$16,4 \mathrm{MP} \mathrm{m}^{-3}$ de acetato de celulose e peneiração em 7 malhas

Rede de plâncton 300 m; peneiração em 2 malhas,

Baía de Guanabara/RJ (partículas $>1 \mathrm{~mm}$ )

Microscopia óptica 56 moção de matéria orgânica

Microscopia óptica

ATR-FTIR 1,4-21,3 $\mathrm{MP} \mathrm{m}^{-3}$
57

89 com $\mathrm{H}_{2} \mathrm{O}_{2}$, filtração em (partículas > $1 \mathrm{~mm}$ ) $300 \mu \mathrm{m}$ 
Tabela 1. Ocorrência de microplásticos (MP) e resíduos plásticos em matrizes ambientais de água e sedimento no Brasil (cont.)

\begin{tabular}{|c|c|c|c|c|c|}
\hline Local & $\begin{array}{l}\text { Amostragem e preparo de } \\
\text { amostra }\end{array}$ & Identificação & $\begin{array}{c}\text { Caracterização } \\
\text { química }\end{array}$ & Quantificação & Referência \\
\hline Baía de Guanabara/RJ & $\begin{array}{l}\text { Água superficial em frascos e } \\
\text { plásticos flutuantes com rede } \\
\text { de pesca }\end{array}$ & Inspeção visual & ATR-FTIR & 14 itens caracterizados & 283 \\
\hline Baía de Guanabara/RJ & $\begin{array}{c}\text { Água superficial com rede } \\
\text { de plâncton } 200 \text { e } 64 \mu \mathrm{m} \text { e } \\
\text { nêuston } 64 \mu \mathrm{m}\end{array}$ & Microscopia óptica & $\mu$-FTIR & 0,6 a $11 \mathrm{MP} \mathrm{m}^{-3}$ & 284 \\
\hline Niterói/RJ & $\begin{array}{l}\text { Água superficial com rede de } \\
\text { plâncton } 120 \mu \mathrm{m} \text {; separação } \\
\text { com solução de } \mathrm{NaCl} \text {, filtração } \\
\text { em } 0,45 \mu \mathrm{m} \text {, secagem a } \\
\text { temperatura ambiente }\end{array}$ & Microscopia óptica & ATR-FTIR & 1319 itens $\left(7,62\right.$ itens $\left.\mathrm{m}^{-3}\right)$ & 285 \\
\hline
\end{tabular}

Água doce

Água superficial com rede de plâncton $60 \mu \mathrm{m}$; peneiração em $63 \mu \mathrm{m}$, remoção de matéria orgânica com $\mathrm{H}_{2} \mathrm{O}_{2} / \mathrm{Fe}(\mathrm{II}) /$

Lago Guaíba/RS

$\mathrm{H}_{2} \mathrm{SO}_{4}$, filtração em membrana de acetato de celulose

$9519 \mathrm{MP}$

$0,45 \mu \mathrm{m}$, separação com NaI,

filtração em membrana de fibra de vidro $0,45 \mu \mathrm{m}$

Água superficial e água tratada com frascos de vidro; remoção de matéria orgânica com

$\mathrm{KOH}$, filtração em membrana de fibra de vidro $7 \mu \mathrm{m}$,

Rio Sinos/RS separação com $\mathrm{NaCl}$, filtração em membrana de fibra de vidro $7 \mu \mathrm{m}$, adição de solução de vermelho do Nilo, secagem a $40{ }^{\circ} \mathrm{C}$

\begin{tabular}{|c|c|c|c|c|c|}
\hline Lagoa Acaraí/SC & $\begin{array}{l}\text { Água superficial com rede de } \\
\text { plâncton } 300 \mu \mathrm{m} \text {; filtração em } \\
500 \mu \mathrm{m} \text {, secagem a } 70^{\circ} \mathrm{C}\end{array}$ & Microscopia óptica & - & $1,4-3,4$ itens $100 \mathrm{~m}^{-3}$ & 288 \\
\hline \multicolumn{6}{|l|}{ Sedimento } \\
\hline Rios do Amazonas & $\begin{array}{l}\text { Sedimento; draga Van Veen, } \\
\text { secagem a } 50{ }^{\circ} \mathrm{C} \text {, peneiração } \\
\text { em } 63 \mu \mathrm{m} \text {, remoção de matéria } \\
\text { orgânica com } \mathrm{H}_{2} \mathrm{O}_{2} \text {, separação } \\
\text { com } \mathrm{ZnCl}_{2} \text {, filtração em } \\
\text { membrana de celulose } 18 \mu \mathrm{m}\end{array}$ & Microscopia óptica & - & $\begin{array}{c}417-8178 \mathrm{MP} \mathrm{kg}^{-1} \\
\text { (faixa de } 0,063-5 \mathrm{~mm} \text { ) e } \\
0-5725 \mathrm{MP} \mathrm{kg}^{-1} \\
\text { (faixa de } 0,063-1 \mathrm{~mm} \text { ) }\end{array}$ & 289 \\
\hline Ilha Cotijuba/PA & $\begin{array}{c}\text { Areia de praia; diferentes } \\
\text { profundidades; peneiração } \\
\text { em } 300 \mu \mathrm{m} \text {; separação com } \\
\text { solução de } \mathrm{NaCl} \text {; filtração em } \\
\text { membrana de celulose } 2 \mu \mathrm{m}, \\
\text { secagem a } 35^{\circ} \mathrm{C}\end{array}$ & Microscopia óptica & - & $\begin{array}{l}\text { 3040-20.300 } \\
\text { partículas } \mathrm{m}^{-3}\end{array}$ & 290 \\
\hline Praia da Corvina/PA & $\begin{array}{l}\text { Areia de praia; peneiração em } \\
250-500 \mu \mathrm{m} \text { e } 500-5000 \mu \mathrm{m}\end{array}$ & Microscopia óptica & - & $\begin{array}{c}5819 \text { partículas } \\
\left(492,5 \text { partículas } \mathrm{m}^{-3}\right)\end{array}$ & 291 \\
\hline Lençóis Maranhenses/MA & Areia de praia & Inspeção visual & ATR-FTIR & 88 partículas & 292 \\
\hline Rio Potengi/RN & Sedimento & Inspeção visual & - & $\begin{array}{l}400 \text { plásticos no período } \\
\text { chuvoso e } \sim 900 \text { plásticos } \\
\text { no período seco }\end{array}$ & 293 \\
\hline Praia Mansa de Fortaleza/CE & Areia de praia & Inspeção visual & - & $\begin{array}{c}7510 \text { itens } \\
\left(0,21-1,15 \text { itens } \mathrm{m}^{-2}\right)\end{array}$ & 294 \\
\hline Estuário do rio Goiana/PE & $\begin{array}{l}\text { Sedimento; corer cilíndrico, } \\
\text { peneiração em } 1 \mathrm{~mm}\end{array}$ & Inspeção visual & - & $6,36-15,89$ itens $\mathrm{m}^{-2}$ & 295 \\
\hline Estuário do rio Goiana/PE & Areia de estuário & Inspeção visual & - & $\begin{array}{c}6944 \text { itens } \\
\text { (> 95\% plásticos) }\end{array}$ & 296 \\
\hline Praia de Boa Viagem/PE & Areia de praia & Inspeção visual & - & $\begin{array}{l}32.045 \text { itens } \\
(60 \% \text { plásticos })\end{array}$ & 297 \\
\hline
\end{tabular}


Tabela 1. Ocorrência de microplásticos (MP) e resíduos plásticos em matrizes ambientais de água e sedimento no Brasil (cont.)

\begin{tabular}{|c|c|c|c|c|c|}
\hline Local & $\begin{array}{l}\text { Amostragem e preparo de } \\
\text { amostra }\end{array}$ & Identificação & $\begin{array}{l}\text { Caracterização } \\
\text { química }\end{array}$ & Quantificação & Referência \\
\hline Praia de Boa Viagem/PE & $\begin{array}{l}\text { Areia de praia; peneiração } \\
\text { em } 1 \mathrm{~mm} \text {; separação com } \\
\text { solução de } \mathrm{NaCl} \text {; filtração em } \\
\text { membrana de celulose } 2 \mu \mathrm{m} ; \\
\text { secagem a } 40^{\circ} \mathrm{C}\end{array}$ & Microscopia óptica & - & 838 itens & 298 \\
\hline Praia de Boa Viagem/PE & $\begin{array}{l}\text { Areia de praia; secagem a } \\
100{ }^{\circ} \mathrm{C} \text { e peneiração em } \\
2 \text { malhas }\end{array}$ & Microscopia óptica & - & $\begin{array}{c}90 \text { pellets } \\
\left(0,01 \text { pellet } \mathrm{cm}^{-2}\right) \\
2661 \text { fragmentos plásticos } \\
\left(2-231 \text { fragmentos } \mathrm{cm}^{-2}\right)\end{array}$ & 299 \\
\hline Litoral de Pernambuco & Areia de praia & Inspeção visual & - & $\begin{array}{c}12.815 \text { itens } \\
(57,3 \% \text { plásticos })\end{array}$ & 300 \\
\hline
\end{tabular}

Areia de praia; peneiração

em $1 \mathrm{~mm}$, separação com

Praias de Fernando de Noronha/PE solução de $\mathrm{NaCl}$, filtração em

Microscopia óptica

504 partículas membrana de fibra de vidro $\left(11,1-455,6\right.$ partículas $\left.\mathrm{m}^{-2}\right)$

$1 \mu \mathrm{m}$, secagem a $40{ }^{\circ} \mathrm{C}$

\begin{tabular}{|c|c|c|c|c|c|}
\hline $\begin{array}{l}\text { Arquipélago de Fernando de } \\
\text { Noronha/PE }\end{array}$ & $\begin{array}{c}\text { Areia de praia; secagem a } \\
100{ }^{\circ} \mathrm{C} \text { e peneiração em } 1 \mathrm{~mm}\end{array}$ & Inspeção visual & - & $\begin{array}{c}207 \text { itens } \\
(93,5 \% \text { plásticos })\end{array}$ & 55 \\
\hline Costa dos Coqueiros/BA & Areia de praia & Inspeção visual & - & $\begin{array}{c}1974 \text { itens } \\
(69,8 \% \text { plásticos })\end{array}$ & 302 \\
\hline Praia da Costa do Dendê/BA & Areia de praia & Inspeção visual & - & 7189 itens ( $76 \%$ plásticos) & 303 \\
\hline Litoral da Bahia & Areia de praia & Inspeção visual & - & $\begin{array}{c}6751 \text { itens } \\
\text { (52-94\% plásticos) }\end{array}$ & 304 \\
\hline Praias de Salvador/BA & Areia de praia & Inspeção visual & - & $\begin{array}{c}7858 \text { itens } \\
(87,1 \% \text { plásticos })\end{array}$ & 305 \\
\hline Litoral sul da Bahia & Areia de praia & Inspeção visual & - & 1430 pellets & 306 \\
\hline Praias de Salvador/BA & $\begin{array}{c}\text { Areia de praia; separação com } \\
\text { água do mar }\end{array}$ & Inspeção visual & - & 1967 pellets & 307 \\
\hline Praias da Ilha de Itaparica/BA & Areia de praia & Inspeção visual & - & $\begin{array}{c}2220 \text { itens na estação } \\
\text { (49\% plásticos) e } \\
508 \text { itens na baixa estação } \\
\text { (59\% plásticos) }\end{array}$ & 308 \\
\hline Litoral de Sergipe & Areia de praia & Inspeção visual & - & $\begin{array}{c}1484 \text { itens } \\
(\sim 85 \% \text { plásticos })\end{array}$ & 309 \\
\hline
\end{tabular}

\begin{tabular}{|c|c|c|c|c|c|}
\hline Reservatório de água de chuva/SP & $\begin{array}{l}\text { Sedimento; separação com } \\
\text { solução de } \mathrm{ZnCl}_{2} \text {; filtração em } \\
\text { membrana de nitro celulose } \\
\text { e secagem a temperatura } \\
\text { ambiente }\end{array}$ & Microscopia óptica & ATR-FTIR e Raman & $57.542 \mathrm{MP} \mathrm{kg}^{-1}$ & 310 \\
\hline Praias de Santos/SP & $\begin{array}{l}\text { Areia de praia; pinça para } \\
\text { coleta de pellets }\end{array}$ & Inspeção visual & - & $\begin{array}{c}\text { Concentração de orgânicos } \\
\text { sorvidos em pellets }\end{array}$ & 311 \\
\hline Praias de Santos/SP & $\begin{array}{l}\text { Areia de praia; pinça para } \\
\text { coleta de pellets, separação } \\
\text { com solução de } \mathrm{H}_{2} \mathrm{O} \text { /etanol } \\
\end{array}$ & Inspeção visual & - & $\begin{array}{l}\text { Concentração de orgânicos } \\
\text { sorvidos em pellets }\end{array}$ & 312 \\
\hline Praias de Santos/SP & $\begin{array}{l}\text { Areia de praia; profundidade } \\
\text { de até } 1 \mathrm{~m} \text { com trado, } \\
\text { separação com água do mar e } \\
\text { peneiração em } 1 \mathrm{~mm}\end{array}$ & Inspeção visual & - & $\begin{array}{l}\text { Concentrações de } \\
\text { pellets em diferentes } \\
\text { profundidades }\end{array}$ & 171 \\
\hline Praias de Santos/SP & Areia de praia & Inspeção visual & - & Até $260-300$ pellets $\mathrm{m}^{-2}$ & 313 \\
\hline Praias de Santos/SP & Areia de praia & Inspeção visual & - & 456 itens ( $84 \%$ plásticos) & 314 \\
\hline Praias de Santos/SP & $\begin{array}{l}\text { Areia de praia; profundidade } \\
\text { de até } 25 \mathrm{~cm} \text { com corer } \\
\text { cilíndrico, separação com água } \\
\text { do mar e peneiração em } 1 \mathrm{~mm}\end{array}$ & Inspeção visual & - & 13.138 pellets & 174 \\
\hline Ponta da Praia em Santos/SP & $\begin{array}{l}\text { Areia de praia; profundidade } \\
\text { de até } 1 \mathrm{~m} \text { com pá de metal, } \\
\text { peneiração em malha fina }\end{array}$ & Inspeção visual & - & $\begin{array}{l}\text { Concentração de orgânicos } \\
\text { sorvidos em pellets }\end{array}$ & 315 \\
\hline
\end{tabular}


Tabela 1. Ocorrência de microplásticos (MP) e resíduos plásticos em matrizes ambientais de água e sedimento no Brasil (cont.)

\begin{tabular}{|c|c|c|c|c|c|}
\hline Local & $\begin{array}{l}\text { Amostragem e preparo de } \\
\text { amostra }\end{array}$ & Identificação & $\begin{array}{c}\text { Caracterização } \\
\text { química }\end{array}$ & Quantificação & Referência \\
\hline Estuário de São Vicente/SP & Areia de praia & Inspeção visual & - & $\begin{array}{c}2129 \text { itens } \\
(37,28 \% \text { plásticos })\end{array}$ & 316 \\
\hline Praias de Santos/SP & $\begin{array}{l}\text { Areia de praia; peneiração em } \\
\qquad 0,1 \mathrm{~mm}\end{array}$ & Inspeção visual & - & Até 2,5 pellets $\mathrm{m}^{-1}$ & 317 \\
\hline Litoral de São Paulo & $\begin{array}{l}\text { Areia de praia; profundidade } \\
\text { de até } 1 \mathrm{~m} \text { com trado, } \\
\text { peneiração em } 1 \mathrm{~mm}\end{array}$ & Inspeção visual & Raman & $\begin{array}{l}18 \% \text { PP, } 78,2 \% \text { PE e } 3,8 \% \\
\text { mistura de PP e PE }\end{array}$ & 318 \\
\hline Litoral de São Paulo & $\begin{array}{c}\text { Areia de praia; profundidade } \\
\text { de até } 1 \mathrm{~m} \text { com trado, } \\
\text { peneiração em } 1 \mathrm{~mm}\end{array}$ & Inspeção visual & - & $\begin{array}{c}\text { Média máxima de cerca de } \\
140 \text { pellets } \mathrm{m}^{-2}\end{array}$ & 319 \\
\hline Litoral de São Paulo & $\begin{array}{l}\text { Areia de praia; pinça para } \\
\text { coleta de pellets }\end{array}$ & Inspeção visual & - & $\begin{array}{l}\text { Concentração de orgânicos } \\
\text { sorvidos em pellets }\end{array}$ & 320 \\
\hline Litoral de São Paulo & Areia de praia & Inspeção visual & - & $\begin{array}{l}\text { Concentração de metais } \\
\text { sorvidos em pellets }\end{array}$ & 321 \\
\hline $\begin{array}{l}\text { Estuário de Santos e } \\
\text { São Vicente/SP }\end{array}$ & $\begin{array}{c}\text { Sedimento; draga Van Veen, } \\
\text { secagem a } 50{ }^{\circ} \mathrm{C} \\
\text { peneiração em } 4 \text { malhas }\end{array}$ & Microscopia óptica & py-GC-MS & $1000-30.000$ partículas $\mathrm{g}^{-1}$ & 322 \\
\hline Praias de Niterói/RJ & Areia de praia & Inspeção visual & - & $\begin{array}{c}27.372 \text { itens } \\
(52,7 \% \text { plásticos })\end{array}$ & 323 \\
\hline Praias de Niterói/RJ & Areia de praia & Inspeção visual & - & 2789 itens ( $71 \%$ plásticos) & 324 \\
\hline Litoral do Rio de Janeiro & Areia de praia & Inspeção visual & - & 391 itens (97\% plásticos) & 325 \\
\hline Praia de Camboinhas/RJ & Areia de praia & Inspeção visual & - & 41,5-58,34\% plásticos & 326 \\
\hline Baía de Guanabara/RJ & $\begin{array}{c}\text { Areia de praia; profundidade } \\
\text { de } 5 \mathrm{~cm} \text {, separação com } \\
\text { solução de } \mathrm{NaCl} \text {, filtração em } \\
\text { membrana de papel e secagem } \\
\text { a } 60^{\circ} \mathrm{C}\end{array}$ & Microscopia óptica & - & 8766 partículas de MP & 170 \\
\hline Baía de Guanabara/RJ & $\begin{array}{l}\text { Sedimento; draga Van Veen; } \\
\text { profundidade de } 5 \mathrm{~cm} \text {; } \\
\text { secagem a } 60{ }^{\circ} \mathrm{C} \text {; separação } \\
\text { com solução de } \mathrm{NaCl} \text {, } \\
\text { peneiração em } 15 \mu \mathrm{m}\end{array}$ & Microscopia óptica & ATR-FTIR & $\begin{array}{l}160-1000 \text { itens } \mathrm{kg}^{-1} \text { ou } \\
4367-25.794 \text { itens m}^{-2}\end{array}$ & 327 \\
\hline Baía de Guanabara/RJ & $\begin{array}{c}\text { Sedimento; draga Van Veen; } \\
\text { profundidade de } 20 \text { a } 55 \mathrm{~m} \text {, } \\
\text { separação com solução de } \\
\mathrm{NaCl} \text {, filtração em membrana } \\
\text { de nitro celulose e secagem } \\
\text { a } 21^{\circ} \mathrm{C}\end{array}$ & Microscopia óptica & - & $\begin{array}{l}1 \mathrm{MP} \text { por } 10 \mathrm{~g} \mathrm{de} \\
\text { sedimento }\end{array}$ & 173 \\
\hline Praia Grande e Praia Grussaí/RJ & Areia de praia & Inspeção visual & - & $\begin{array}{c}20.040 \text { itens } \\
\text { (> } 80 \% \text { plásticos) }\end{array}$ & 328 \\
\hline Praias de Arraial do Cabo/RJ & Areia de praia & Inspeção visual & - & $\begin{array}{l}1080 \text { itens no inverno } \\
\text { (61,4\% plásticos) e } \\
1533 \text { itens no verão } \\
\text { (54,5\% plásticos) }\end{array}$ & 329 \\
\hline Niterói/RJ & $\begin{array}{c}\text { Sedimento e areia de praia; } \\
\text { draga Van Veen, profundidade } \\
\text { de } 2 \text { a } 8 \text { m; secagem a } \\
60^{\circ} \mathrm{C} \text {; peneiração em } \\
3 \text { malhas; separação com } \\
\text { solução de } \mathrm{NaCl} \text {; filtração em } \\
\text { membrana de nitrocelulose e } \\
\text { secagem a } 60^{\circ} \mathrm{C}\end{array}$ & Microscopia óptica & ATR-FTIR & $\begin{array}{c}563 \text { itens no sedimento } \\
\left(20,74 \text { itens } \mathrm{kg}^{-1}\right) \mathrm{e} \\
6912 \text { itens na areia de praia } \\
\left(166,50 \text { itens } \mathrm{kg}^{-1}\right)\end{array}$ & 285 \\
\hline Praias de Armação dos Búzios/RJ & Areia de praia & Inspeção visual & - & $\begin{array}{l}15.832 \text { itens } \\
\text { (64\% plásticos) }\end{array}$ & 330 \\
\hline Ilha da Trindade/ES & Areia de praia & Inspeção visual & ATR-FTIR & 1057 itens (77\% plásticos) & 58 \\
\hline Baía de Vitória/ES & $\begin{array}{l}\text { Sedimento; draga Van Veen; } \\
\text { separação com solução de } \\
\mathrm{NaCl} \text {, filtração em membrana } \\
\text { de nitrocelulose e secagem a } \\
\text { temperatura ambiente }\end{array}$ & $\begin{array}{l}\text { Microscopia óptica e } \\
\text { SEM }\end{array}$ & - & $\begin{array}{c}0 \text { a } 38 \text { partículas por } \\
\text { amostra }\end{array}$ & 172 \\
\hline
\end{tabular}


Tabela 1. Ocorrência de microplásticos (MP) e resíduos plásticos em matrizes ambientais de água e sedimento no Brasil (cont.)

\begin{tabular}{|c|c|c|c|c|c|}
\hline Local & $\begin{array}{l}\text { Amostragem e preparo de } \\
\text { amostra }\end{array}$ & Identificação & $\begin{array}{l}\text { Caracterização } \\
\text { química }\end{array}$ & Quantificação & Referência \\
\hline $\begin{array}{l}\text { Praias de Vitória, Fundão e Regên- } \\
\text { cia/ES }\end{array}$ & Areia de praia & Inspeção visual & - & $\begin{array}{c}4752 \text { itens } \\
(73,2-85,9 \% \text { plásticos }) \\
\end{array}$ & 331 \\
\hline Praia de Pontal do Sul/PR & $\begin{array}{l}\text { Areia de praia; peneiração em } \\
\qquad 2 \text { malhas }\end{array}$ & Inspeção visual & - & $\begin{array}{l}\text { Máximo de cerca de } \\
100 \text { pellets }\end{array}$ & 332 \\
\hline Estuário de Paranaguá/PR & Areia de praia & Inspeção visual & - & 924 itens ( $81,3 \%$ plásticos) & 333 \\
\hline Litoral do Paraná & $\begin{array}{l}\text { Areia de praia; pinça para } \\
\text { coleta de pellets }\end{array}$ & Inspeção visual & - & $\begin{array}{l}\text { Concentração de orgânicos } \\
\text { sorvidos em pellets }\end{array}$ & 334 \\
\hline Litoral do Paraná & Areia de praia & Inspeção visual & - & $\begin{array}{c}12.048 \text { itens } \\
(74,8 \% \text { plásticos })\end{array}$ & 335 \\
\hline Litoral de Santa Catarina & Areia de praia & Inspeção visual & - & 6953 itens (69\% plásticos) & 336 \\
\hline Ilha de Florianópolis/SC & Areia de praia & Inspeção visual & - & 4291 itens (97\% plásticos) & 337 \\
\hline Praias de Florianópolis/SC & Areia de praia & Inspeção visual & - & $\begin{array}{c}10.226 \text { itens } \\
\left(\sim 90 \text { itens } 100 \mathrm{~m}^{-2}\right)\end{array}$ & 338 \\
\hline Praias de Laguna/SC & Areia de praia & Inspeção visual & - & 2142 itens (17 plásticos) & 339 \\
\hline Praia do Cassino/RS & Areia de praia & Inspeção visual & - & $0,6-6,6$ itens $\mathrm{m}^{-1} \mathrm{~d}^{-1}$ & 340 \\
\hline Praia do Cassino/RS & Areia de praia & Inspeção visual & - & $\begin{array}{l}0,3-60,7 \text { itens } \mathrm{m}^{-1} \\
(56,1 \% \text { plásticos })\end{array}$ & 341 \\
\hline
\end{tabular}

(-): Caracterização química não realizada; ATR: reflectância total atenuada; FTIR: espectroscopia no infravermelho com transformada de Fourier; SEM: microscopia eletrônica de varredura; py-GC-MS: pirolisador acoplado a um cromatógrafo a gás e espectrômetro de massas; PP: polipropileno; PE: polietileno.

( $\mathrm{n}=12)$ e na matriz sedimento $(\mathrm{n}=37)$ não utilizou nenhuma etapa de preparo da amostra. Nos estudos que realizaram a separação por densidade para isolar as partículas foram utilizadas soluções salinas distintas ( $\mathrm{NaCl}, \mathrm{NaI}, \mathrm{ZnCl}_{2}$ e água do mar), permitindo que $\mathrm{MP}$ de diferentes composições poliméricas tenham sido encontrados.

As quantidades de MP reportadas no Brasil foram bastante variadas entre as diferentes regiões do país, tanto em valores absolutos quanto pelas unidades expressas, dificultando uma comparação de cenário, conforme discutido anteriormente neste trabalho. Além disso, 48 trabalhos usaram a inspeção visual e 19 trabalhos utilizaram a microscopia como método de identificação (atribuição se a partícula era ou não MP), sem posterior confirmação por meio de caracterização química usando técnicas analíticas. Somente 4 trabalhos utilizaram alguma técnica instrumental para a caracterização química das partículas após realizar a inspeção visual, sendo que desses, 3 utilizaram FTIR e 1 utilizou Raman. Ao todo, 9 trabalhos utilizaram a microscopia seguida de uma técnica analítica para caracterização química dos MP, sendo que desses, 6 utilizaram FTIR, 1 utilizou py-GC-MS e 2 utilizaram duas técnicas (FTIR e Raman). Até 2018, somente dois trabalhos utilizaram técnicas para caracterizar quimicamente os MP e de 2018 a 2020 foi observado um crescimento na quantidade de estudos que realizaram essa caracterização $(\mathrm{n}=$ 7), indicando uma tendência crescente em confirmar a composição das partículas coletadas no ambiente. No entanto, os dados sobre a identidade dos polímeros mais encontrados no Brasil ainda são escassos.

\section{CONSIDERAÇÕES FINAIS E CONCLUSÃO}

Os MP são considerados contaminantes onipresentes no ambiente, tendo sido detectados mundialmente em todos os compartimentos ambientais. São oriundos de diversas fontes, sejam terrestres ou aquáticas. A elucidação da dimensão e dos impactos relacionados à poluição por MP torna essa uma pesquisa multidisciplinar e bastante complexa do ponto de vista ambiental. A amostragem e o preparo de amostras sempre foram etapas desafiadoras nos métodos analíticos e não são diferentes para a análise dos MP, dada a complexidade das matrizes ambientais, o tamanho das partículas, a identidade e as propriedades físico-químicas do polímero, que influenciam diretamente sua distribuição. Apesar dos avanços e das diversas possibilidades já descritas na literatura para os métodos analíticos panorama que foi explorado neste trabalho - ainda não há métodos oficiais.

A caracterização e/ou quantificação de MP pode requerer a determinação do seu tamanho, a composição química do polímero, a morfologia, a origem do MP (primária ou secundária) e o grau de degradação deles no ambiente, uma vez que essas informações ajudam a explicar a toxicidade, os mecanismos de transporte, a capacidade de lixiviação e de sorção dos MP e, consequentemente, o nível de contaminação a que os seres vivos estão expostos.

Os químicos ambientais têm um compromisso importante nessa área, pois os protocolos analíticos estão em crescente desenvolvimento e, em sua maioria, estão baseados na aplicação de técnicas comumente empregadas em análise de materiais, mas agora adaptadas ao contexto ambiental. De maneira geral, técnicas complementares são necessárias para responder a uma ou mais perguntas da área, tornando a escolha dos métodos analíticos estritamente relacionada com a hipótese da pesquisa, a logística de amostragem e a complexidade das amostras coletadas.

A inspeção visual tem sido a maneira mais usual de se caracterizar os MP em amostras ambientais, no entanto, há uma tendência e demanda importante pela caracterização química, o que tem impulsionado o desenvolvimento de diferentes métodos analíticos nessa área. Os maiores avanços relacionados à caracterização são consequentes da necessidade de diminuir cada vez mais a subjetividade da análise, possibilitados pelos avanços na instrumentação analítica. Assim, a caracterização vem se tornando mais precisa em evitar falsos positivos, bem como a produtividade aumentada pela possibilidade de análises de MP cada vez menores e com técnicas cada vez mais rápidas e modernas, como o $\mu$-FPA-FTIR e TED-GC-MS. A automatização pode ser vista como uma tendência a ser explorada.

Como perspectivas para estabelecer diretrizes e as bases para futuro monitoramento, as discussões estratégicas abordam a decisão do compartimento ambiental, localização e frequência de amostragem; a harmonização dos métodos (protocolos de amostragem, preparo de amostras, parâmetros como a faixa de tamanho, critérios e unidades de 
quantificação) para compilação e comparação de dados, respeitando o controle analítico e de qualidade, em especial com relação a evitar contaminações cruzadas e confirmação da identidade dos polímeros, e incluindo testes de proficiência.

Finalmente, ainda há um campo bastante vasto de pesquisas sobre MP para serem realizadas no Brasil, desde o monitoramento deles nos diferentes compartimentos ambientais até a avaliação do comportamento, remoção pelos sistemas convencionais de tratamentos de águas e efluentes e os riscos ou danos ambientais às espécies nativas expostas a esse tipo de contaminante. A revisão da literatura mostrou 80 trabalhos publicados, os quais exploraram apenas matrizes aquáticas e sedimento. Este artigo pode ser usado como um importante ponto de partida nesse sentido, inclusive de forma a subsidiar o trabalho dos químicos analíticos em uma linha de pesquisa tão interdisciplinar na qual as inovações estão constantemente sendo publicadas na literatura.

\section{AGRADECIMENTOS}

Os autores agradecem à Fundação de Amparo à Pesquisa do Estado de São Paulo (FAPESP Proc. 2018/21733-0), ao Conselho Nacional de Desenvolvimento Científico e Tecnológico (CNPq Proc. 428826/2018-0) e ao Instituto Nacional de Ciências e Tecnologias Analíticas Avançadas-INCTAA (FAPESP Proc. 2014/50951-4 e CNPq Proc. 465768/2014-8) pelo auxílio financeiro concedido aos projetos. CNPq Proc. 311422/2020-9 pela bolsa de produtividade em pesquisa de CCM. O presente trabalho foi realizado com apoio da Coordenação de Aperfeiçoamento de Pessoal de Nível Superior - Brasil (CAPES) - Código de Financiamento 001.

\section{REFERENCIAS}

1. Carpenter, E. J.; Anderson, S. J.; Harvey, G. R.; Miklas, H. P.; Peck, B. B.; Science 1972, 178, 749 .

2. Gomes, C. M. B.; Lançamento de partículas de polietileno à costa do Rio Grande do Sul, Separatas da Revista Veritas, 70/73, pp. 174-206.

3. Andrady, A. L.; Mar. Pollut. Bull. 2011, 62, 1596.

4. Cole, M.; Lindeque, P.; Halsband, C.; Galloway, T. S.; Mar. Pollut. Bull. 2011, 62, 2588.

5. Thompson, R. C.; Science 2004, 304, 838.

6. Olivatto, G. P.; Carreira, R.; Tornisielo, V. L.; Montagner, C. C.; Rev. Virtual Quim. 2018, 10, 1968.

7. Hanvey, J. S.; Lewis, P. J.; Lavers, J. L.; Crosbie, N. D.; Pozo, K.; Clarke, B. O.; Anal. Methods 2017, 9, 1369.

8. Arthur, C.; Baker, J. E.; Bamford, H. A. In Proceedings of the International Research Workshop on the Occurrence, Effects, and Fate of Microplastic Marine Debris; NOAA Marine Debris Program, 2009; p. 530.

9. ISO Plastics - Environmental aspects - State of knowledge and methodologies. ISO/TR 21960:2020.

10. Richardson, S. D.; Kimura, S. Y.; Anal. Chem. 2016, 88, 546.

11. Richardson, S. D.; Kimura, S. Y.; Anal. Chem. 2020, 92, 473.

12. Spinacé, M. A. da S.; De Paoli, M. A.; Quim. Nova 2005, 28, 65.

13. do Sul, J. A. I.; Costa, M. F.; Environ. Pollut. 2014, 185, 352.

14. Tourinho, P. S.; Kočí, V.; Loureiro, S.; van Gestel, C. A. M.; Environ. Pollut. 2019, 252, 1246.

15. Geyer, R.; Jambeck, J. R.; Law, K. L.; Sci. Adv. 2017, 3, e1700782.

16. Akdogan, Z.; Guven, B.; Environ. Pollut. 2019, 254, 113011.

17. ABIPLAST Perfil 2018; 2018.

18. WWF Brasil é o $4^{\circ}$ país do mundo que mais gera lixo plástico, $W W F$, 2019.

19. Kataoka, T.; Nihei, Y.; Kudou, K.; Hinata, H.; Environ. Pollut. 2019, 244 , 958.
20. Jambeck, J. R.; Geyer, R.; Wilcox, C.; Siegler, T. R.; Perryman, M.; Andrady, A.; Narayan, R.; Law, K. L.; Science 2015, 347, 768.

21. WHO Global Biodiversity Outlook 5; 2020.

22. Picó, Y.; Barceló, D.; ACS Omega 2019, 4, 6709.

23. Crawford, C. B.; Quinn, B.; Microplastic Pollutants; Elsevier: Amsterdam, 2017.

24. Boucher, J.; Friot, D.; Primary microplastics in the oceans: A global evaluation of sources; IUCN International Union for Conservation of Nature: Gland, Switzerland, 2017.

25. Fendall, L. S.; Sewell, M. A.; Mar. Pollut. Bull. 2009, 58, 1225.

26. Napper, I. E.; Bakir, A.; Rowland, S. J.; Thompson, R. C.; Mar. Pollut. Bull. 2015, 99, 178.

27. Browne, M. A.; Crump, P.; Niven, S. J.; Teuten, E.; Tonkin, A.; Galloway, T.; Thompson, R.; Environ. Sci. Technol. 2011, 45, 9175.

28. Barnes, D. K. A.; Galgani, F.; Thompson, R. C.; Barlaz, M.; Philos. Trans. R. Soc., B 2009, 364, 1985.

29. Rocha-Santos, T.; Duarte, A. C.; TrAC-Trends Anal. Chem. 2015, 65 , 47.

30. Ceccarini, A.; Corti, A.; Erba, F.; Modugno, F.; La Nasa, J.; Bianchi, S.; Castelvetro, V.; Environ. Sci. Technol. 2018, 52, 5634.

31. Wagner, M.; Lambert, S. In The Handbook of Environmental Chemistry; Barceló, D.; Kostianoy, A. G., ed.; Springer International Publishing: New York, 2018; Vol. 58.

32. De Paoli, M. A.; Degradação e Estabilização de Polímeros, $2^{\text {a }}$ ed., Chemkeys: Campinas, 2008.

33. Waldman, W. R.; Rillig, M. C.; Environ. Sci. Technol. 2020, 54, 7751.

34. Mai, L.; Bao, L.-J.; Shi, L.; Wong, C. S.; Zeng, E. Y.; Environ. Sci. Pollut. Res. 2018, 25, 11319.

35. Wu, P.; Huang, J.; Zheng, Y.; Yang, Y.; Zhang, Y.; He, F.; Chen, H.; Quan, G.; Yan, J.; Li, T.; Gao, B.; Ecotoxicol. Environ. Saf. 2019, 184, 109612.

36. Rabello, M.; De Paoli, M. A.; Aditivação de Termoplásticos, Editora Artliber: São Paulo, 2013

37. Avio, C. G.; Gorbi, S.; Regoli, F.; Mar. Environ. Res. 2017, 128, 2.

38. Takada, H.; Int. Pellet Watch 2006, 52, 1547.

39. Endo, S.; Takizawa, R.; Okuda, K.; Takada, H.; Chiba, K.; Kanehiro, H.; Ogi, H.; Yamashita, R.; Date, T.; Mar. Pollut. Bull. 2005, 50, 1103.

40. Rios, L. M.; Moore, C.; Jones, P. R.; Mar. Pollut. Bull. 2007, 54, 1230.

41. Duis, K.; Coors, A.; Environ. Sci. Eur. 2016, $28,2$.

42. Derraik, J. G. B.; Mar. Pollut. Bull. 2002, 44, 842.

43. Gregory, M. R.; Philos. Trans. R. Soc., B 2009, 364, 2013.

44. Long, M.; Moriceau, B.; Gallinari, M.; Lambert, C.; Huvet, A.; Raffray, J.; Soudant, P.; Mar. Chem. 2015, 175, 39.

45. Moore, C. J.; Environ. Res. 2008, 108, 131

46. Van Cauwenberghe, L.; Devriese, L.; Galgani, F.; Robbens, J.; Janssen, C. R.; Mar. Environ. Res. 2015, 111, 5.

47. Wright, S. L.; Thompson, R. C.; Galloway, T. S.; Environ. Pollut. 2013, $178,483$.

48. Wright, S. L.; Kelly, F. J.; Environ. Sci. Technol. 2017, 51, 6634

49. Naik, R. K.; Naik, M. M.; D'Costa, P. M.; Shaikh, F.; Mar. Pollut. Bull. 2019, 149, 110525

50. Rummel, C. D.; Jahnke, A.; Gorokhova, E.; Kühnel, D.; Schmitt-Jansen, M.; Environ. Sci. Technol. Lett. 2017, 4, 258.

51. Kirstein, I. V.; Kirmizi, S.; Wichels, A.; Garin-Fernandez, A.; Erler, R.; Löder, M.; Gerdts, G.; Mar. Environ. Res. 2016, 120, 1.

52. Jamieson, A. J.; Brooks, L. S. R.; Reid, W. D. K.; Piertney, S. B.; Narayanaswamy, B. E.; Linley, T. D.; R. Soc. Open Sci. 2019, 6, 180667.

53. Napper, I. E.; Davies, B. F. R.; Clifford, H.; Elvin, S.; Koldewey, H. J.; Mayewski, P. A.; Miner, K. R.; Potocki, M.; Elmore, A. C.; Gajurel, A. P.; Thompson, R. C.; One Earth 2020, 3, 621.

54. Liu, C.; Li, J.; Zhang, Y.; Wang, L.; Deng, J.; Gao, Y.; Yu, L.; Zhang, J.; Sun, H.; Environ. Int. 2019, 128, 116. 
55. do Sul, J. A. I.; Spengler, Â.; Costa, M. F.; Mar. Pollut. Bull. 2009, 58, 1236.

56. do Sul, J. A. I.; Costa, M. F.; Fillmann, G.; Water, Air, Soil Pollut. 2014, 225, 2004.

57. Lima, A. R. A.; Barletta, M.; Costa, M. F.; Front. Environ. Sci. 2016, 4, 56.

58. Andrades, R.; Santos, R. G.; Joyeux, J.; Chelazzi, D.; Cincinelli, A.; Giarrizzo, T.; Mar. Pollut. Bull. 2018, 137, 180.

59. He, P.; Chen, L.; Shao, L.; Zhang, H.; Lü, F.; Water Res. 2019, 159, 38.

60. UNEP Plastic in Cosmetics - Are we polluting the environment through our personal care?, 2015.

61. Kalčíková, G.; Alič, B.; Skalar, T.; Bundschuh, M.; Gotvajn, A. Ž.; Chemosphere 2017, 188, 25.

62. Salvador Cesa, F.; Turra, A.; Baruque-Ramos, J.; Sci. Total Environ. 2017, 598, 1116.

63. Napper, I. E.; Thompson, R. C.; Mar. Pollut. Bull. 2016, 112, 39.

64. De Falco, F.; Di Pace, E.; Cocca, M.; Avella, M.; Sci. Rep. 2019, 9, 1.

65. IBGE Pesquisa Nacional de Saneamento Básico 2020.

66. GESAMP Guidelines for the Monitoring and Assessment of Plastic Litter in the Ocean; 2019.

67. Dehghani, S.; Moore, F.; Akhbarizadeh, R.; Environ. Sci. Pollut. Res. 2017, 24, 20360.

68. Abbasi, S.; Keshavarzi, B.; Moore, F.; Turner, A.; Kelly, F. J.; Dominguez, A. O.; Jaafarzadeh, N.; Environ. Pollut. 2019, 244, 153.

69. Dris, R.; Gasperi, J.; Mirande, C.; Mandin, C.; Guerrouache, M.; Langlois, V.; Tassin, B.; Environ. Pollut. 2017, 221, 453.

70. Dris, R.; Gasperi, J.; Rocher, V.; Saad, M.; Renault, N.; Tassin, B.; Environ. Chem. 2015, 12, 592.

71. Brahney, J.; Hallerud, M.; Heim, E.; Hahnenberger, M.; Sukumaran, S.; Science 2020, 368, 1257.

72. Allen, S.; Allen, D.; Phoenix, V. R.; Le Roux, G.; Durántez Jiménez, P.; Simonneau, A.; Binet, S.; Galop, D.; Nat. Geosci. 2019, 12, 339.

73. Ambrosini, R.; Azzoni, R. S.; Pittino, F.; Diolaiuti, G.; Franzetti, A.; Parolini, M.; Environ. Pollut. 2019, 253, 297.

74. Zhang, Y.; Gao, T.; Kang, S.; Sillanpää, M.; Environ. Pollut. 2019, 254, 1.

75. Steinmetz, Z.; Wollmann, C.; Schaefer, M.; Buchmann, C.; David, J.; Tröger, J.; Muñoz, K.; Frör, O.; Schaumann, G. E.; Sci. Total Environ. 2016, 550, 690 .

76. Huang, Y.; Liu, Q.; Jia, W.; Yan, C.; Wang, J.; Environ. Pollut. 2020, 260, 114096.

77. Corradini, F.; Meza, P.; Eguiluz, R.; Casado, F.; Huerta-Lwanga, E.; Geissen, V.; Sci. Total Environ. 2019, 671, 411.

78. Westphalen, H.; Abdelrasoul, A. In Water Challenges of an Urbanizing World; InTech, 2018; p. 83

79. Simon, M.; van Alst, N.; Vollertsen, J.; Water Res. 2018, 142, 1.

80. CONAMA Resolução CONAMA N 375 de 29 de agosto de 2006 Ministério do Meio Ambiente 2006.

81. Stock, F.; Kochleus, C.; Bänsch-Baltruschat, B.; Brennholt, N.; Reifferscheid, G.; TrAC-Trends Anal. Chem. 2019, 113, 84.

82. Prata, J. C.; da Costa, J. P.; Duarte, A. C.; Rocha-Santos, T.; TrAC Trends Anal. Chem. 2019, 110, 150.

83. Van Melkebeke, M.; Janssen, C.; De Meester, S.; Environ. Sci. Technol. 2020, 54, 8668 .

84. Van Cauwenberghe, L.; Vanreusel, A.; Mees, J.; Janssen, C. R.; Environ. Pollut. 2013, 182, 495.

85. Zhao, S.; Danley, M.; Ward, J. E.; Li, D.; Mincer, T. J.; Anal. Methods 2017, 9, 1470

86. Watts, A. J. R.; Lewis, C.; Goodhead, R. M.; Beckett, S. J.; Moger, J.; Tyler, C. R.; Galloway, T. S.; Environ. Sci. Technol. 2014, 48, 8823.

87. Barboza, L. G. A.; Vethaak, A. D.; Lavorante, B. R. B. O.; Lundebye, A.-K.; Guilhermino, L.; Mar. Pollut. Bull. 2018, 133, 336.

88. Tourinho, P. S.; do Sul, J. A. I.; Fillmann, G.; Mar. Pollut. Bull. 2010, $60,396$.
89. do Sul, J. A. I.; Costa, M. F.; Barletta, M.; Cysneiros, F. J. A.; Mar. Pollut. Bull. 2013, 75, 305.

90. Possatto, F. E.; Barletta, M.; Costa, M. F.; do Sul, J. A. I.; Dantas, D. V.; Mar. Pollut. Bull. 2011, 62, 1098.

91. Vendel, A. L.; Bessa, F.; Alves, V. E. N.; Amorim, A. L. A.; Patrício, J.; Palma, A. R. T.; Mar. Pollut. Bull. 2017, 117, 448.

92. Ferreira, G. V. B.; Barletta, M.; Lima, A. R. A.; Dantas, D. V.; Justino, A. K. S.; Costa, M. F.; ICES J. Mar. Sci. 2016, 73, 2695.

93. Ferreira, G. V. B.; Barletta, M.; Lima, A. R. A.; Morley, S. A.; Justino, A. K. S.; Costa, M. F.; Environ. Pollut. 2018, 236, 706.

94. Pegado, T. de S. e S.; Schmid, K.; Winemiller, K. O.; Chelazzi, D.; Cincinelli, A.; Dei, L.; Giarrizzo, T.; Mar. Pollut. Bull. 2018, 133, 814.

95. Andrade, M. C.; Winemiller, K. O.; Barbosa, P. S.; Fortunati, A.; Chelazzi, D.; Cincinelli, A.; Giarrizzo, T.; Environ. Pollut. 2019, 244, 766.

96. Ferreira, G. V. B.; Barletta, M.; Lima, A. R. A.; Morley, S. A.; Costa, M. F.; Sci. Rep. 2019, 9, 13514.

97. Dantas, N. C. F. M.; Duarte, O. S.; Ferreira, W. C.; Ayala, A. P.; Rezende, C. F.; Feitosa, C. V.; Mar. Pollut. Bull. 2020, 153, 110959.

98. Silva, J. D. B.; Barletta, M.; Lima, A. R. A.; Ferreira, G. V. B.; Environ. Pollut. 2018, 242, 1010.

99. Lima, A. R. A.; Silva, M. D.; Possatto, F. E.; Ferreira, G. V. B.; Krelling, A. P. In The Handbook of Environmental Chemistry, 2020; pp. 1-34.

100. Silva-Cavalcanti, J. S.; Silva, J. D. B.; de França, E. J.; de Araújo, M. C. B.; Gusmão, F.; Environ. Pollut. 2017, 221, 218.

101. Urbanski, B. Q.; Denadai, A. C.; Azevedo-Santos, V. M.; Nogueira, M. G.; Biota Neotrop. 2020, 20, e20201005.

102. Rizzi, M.; Rodrigues, F. L.; Medeiros, L.; Ortega, I.; Rodrigues, L.; Monteiro, D. S.; Kessler, F.; Proietti, M. C.; Mar. Pollut. Bull. 2019, 140, 536.

103. Petry, M. V.; Benemann, V. R. F.; Mar. Pollut. Bull. 2017, 117, 131.

104. Rossi, L. C.; Scherer, A. L.; Petry, M. V.; Mar. Pollut. Bull. 2019, 138, 235.

105. Brentano, R.; de Brum, A. C.; Montone, R. C.; Petry, M. V.; Mar. Pollut. Bull. 2020, 151, 110815.

106. Santana, M. F. M.; Ascer, L. G.; Custódio, M. R.; Moreira, F. T.; Turra, A.; Mar. Pollut. Bull. 2016, 106, 183

107. Morais, L. M. S.; Sarti, F.; Chelazzi, D.; Cincinelli, A.; Giarrizzo, T.; Martinelli Filho, J. E.; Environ. Pollut. 2020, 265, 114817.

108. Attademo, F. L. N.; Balensiefer, D. C.; Freire, A. C. da B.; de Sousa, G. P.; da Cunha, F. A. G. C.; Luna, F. de O.; Mar. Pollut. Bull. 2015, 101, 284.

109. Di Beneditto, A. P. M.; Siciliano, S.; Mar. Pollut. Bull. 2017, 125, 330.

110. Sampaio, C. L. S.; Leite, L.; Reis-Filho, J. A.; Loiola, M.; Miranda, R. J.; de Anchieta, C. C.; Nunes, J.; Macena, B. C. L.; Environ. Biol. Fishes 2018, 101, 1285.

111. Brentano, R.; Petry, M. V.; Mar. Pollut. Bull. 2020, 150, 110595.

112. Costa, L. L.; Arueira, V. F.; da Costa, M. F.; Di Beneditto, A. P. M.; Zalmon, I. R.; Mar. Pollut. Bull. 2019, 145, 5.

113. Gusmão, F.; Domenico, M. Di; Amaral, A. C. Z.; Martínez, A.; Gonzalez, B. C.; Worsaae, K.; do Sul, J. A. I.; Lana, P. C.; Environ. Pollut. 2016, 216, 584

114. Bessa, F.; Ratcliffe, N.; Otero, V.; Sobral, P.; Marques, J. C.; Waluda, C. M.; Trathan, P. N.; Xavier, J. C.; Sci. Rep. 2019, 9, 14191.

115. Hwang, J.; Choi, D.; Han, S.; Choi, J.; Hong, J.; Sci. Total Environ. 2019, 684, 657

116. Rist, S.; Almroth, B. C.; Hartmann, N. B.; Karlsson, T. M.; Sci. Total Environ. 2018, 626, 720.

117. Karami, A.; Golieskardi, A.; Choo, C. K.; Larat, V.; Karbalaei, S.; Salamatinia, B.; Sci. Total Environ. 2018, 612, 1380.

118. Zuccarello, P.; Ferrante, M.; Cristaldi, A.; Copat, C.; Grasso, A.; Sangregorio, D.; Fiore, M.; Conti, G. O.; Water Res. 2019, 157, 365.

119. Mason, S. A.; Welch, V. G.; Neratko, J.; Front. Chem. 2018, 6, 407. 
120. Shruti, V. C.; Pérez-Guevara, F.; Elizalde-Martínez, I.; KutralamMuniasamy, G.; Environ. Pollut. 2021, 268, 115811.

121. Senathirajah, K.; Attwood, S.; Bhagwat, G.; Carbery, M.; Wilson, S.; Palanisami, T.; J. Hazard. Mater. 2021, 404, 124004.

122. Cox, K. D.; Covernton, G. A.; Davies, H. L.; Dower, J. F.; Juanes, F.; Dudas, S. E.; Environ. Sci. Technol. 2019, 53, 7068.

123. Amato-Lourenço, L. F.; Galvão, L. S.; de Weger, L. A.; Hiemstra, P. S.; Vijver, M. G.; Mauad, T.; Sci. Total Environ. 2020, 749, 141676.

124. Masura, J.; Baker, J. E.; Foster, G. D.; Arthur, C.; Herring, C.; Laboratory methods for the analysis of microplastics in the marine environment: recommendations for quantifying synthetic particles in waters and sediments. NOAA Mar. Debris Progr. 2015.

125. Dehaut, A.; Hermabessiere, L.; Duflos, G.; TrAC-Trends Anal. Chem. 2019, 116, 346.

126. Prata, J. C.; Reis, V.; da Costa, J. P.; Mouneyrac, C.; Duarte, A. C.; Rocha-Santos, T.; J. Hazard. Mater. 2021, 403, 123660.

127. Brander, S. M.; Renick, V. C.; Foley, M. M.; Steele, C.; Woo, M.; Lusher, A.; Carr, S.; Helm, P.; Box, C.; Cherniak, S.; Andrews, R. C.; Rochman, C. M.; Appl. Spectrosc. 2020, 74, 1099.

128. Hidalgo-Ruz, V.; Gutow, L.; Thompson, R. C.; Thiel, M.; Environ. Sci. Technol. 2012, 46, 3060

129. Bergmann, M.; Gutow, L.; Klages, M. In Marine Anthropogenic Litter; Bergmann, M.; Gutow, L.; Klages, M., eds.; Springer International Publishing, 2015.

130. Castro, R. O.; Silva, M. L.; Marques, M. R. C.; de Araújo, F. V.; Mar. Pollut. Bull. 2016, 110, 555.

131. Kapp, K. J.; Yeatman, E.; Environ. Pollut. 2018, 241, 1082.

132. Bruge, A.; Dhamelincourt, M.; Lanceleur, L.; Monperrus, M.; Gasperi, J.; Tassin, B.; Sci. Total Environ. 2020, 718, 137319.

133. Lima, A. R. A.; Costa, M. F.; Barletta, M.; Environ. Res. 2014, 132, 146.

134. Lima, A. R. A.; Barletta, M.; Costa, M. F.; Ramos, J. A. A.; Dantas, D. V.; Melo, P. A. M. C.; Justino, A. K. S.; Ferreira, G. V. B.; J. Fish Biol. 2016, 89, 619 .

135. Schönlau, C.; Karlsson, T. M.; Rotander, A.; Nilsson, H.; Engwall, M.; van Bavel, B.; Kärrman, A.; Mar. Pollut. Bull. 2020, 153, 111019.

136. Baini, M.; Fossi, M. C.; Galli, M.; Caliani, I.; Campani, T.; Finoia, M. G.; Panti, C.; Mar. Pollut. Bull. 2018, 133, 543.

137. Silva, A. B.; Bastos, A. S.; Justino, C. I. L.; da Costa, J. P.; Duarte, A. C.; Rocha-Santos, T. A. P.; Anal. Chim. Acta 2018, 1017, 1.

138. Setälä, O.; Magnusson, K.; Lehtiniemi, M.; Norén, F.; Mar. Pollut. Bull. 2016, 110, 177.

139. Lindeque, P. K.; Cole, M.; Coppock, R. L.; Lewis, C. N.; Miller, Z.; Watts, A. J. R. R.; Wilson-McNeal, A.; Wright, S. L.; Tamara, S.; Miller, R. Z.; Watts, A. J. R. R.; Wilson-McNeal, A.; Wright, S. L.; Galloway, T. S.; Environ. Pollut. 2020, 265,114721.

140. Tamminga, M.; Stoewer, S.-C.; Fischer, E. K.; Environ. Pollut. 2019, 254,112970

141. Karlsson, T. M.; Kärrman, A.; Rotander, A.; Hassellöv, M.; Environ. Sci. Pollut. Res. 2020, 27, 5559.

142. Ng, K. L.; Obbard, J. P.; Mar. Pollut. Bull. 2006, 52, 761.

143. Zhang, L.; Liu, J.; Xie, Y.; Zhong, S.; Yang, B.; Lu, D.; Zhong, Q.; Sci. Total Environ. 2020, 708, 135176.

144. Bannick, C. G.; Szewzyk, R.; Ricking, M.; Schniegler, S.; Obermaier, N.; Barthel, A. K.; Altmann, K.; Eisentraut, P.; Braun, U.; Water Res. 2019, 149, 650 .

145. Koelmans, A. A.; Mohamed Nor, N. H.; Hermsen, E.; Kooi, M.; Mintenig, S. M.; De France, J.; Water Res. 2019, 155, 410.

146. Ryan, P. G.; Suaria, G.; Perold, V.; Pierucci, A.; Bornman, T. G.; Aliani, S.; Environ. Pollut. 2020, 258, 113413.

147. Song, Y. K.; Hong, S. H.; Jang, M.; Kang, J.-H.; Kwon, O. Y.; Han, G. M.; Shim, W. J.; Environ. Sci. Technol. 2014, 48, 9014.

148. Barrows, A. P. W.; Neumann, C. A.; Berger, M. L.; Shaw, S. D.; Anal. Methods 2017, 9, 1446.
149. Green, D. S.; Kregting, L.; Boots, B.; Blockley, D. J.; Brickle, P.; da Costa, M.; Crowley, Q.; Mar. Pollut. Bull. 2018, 137, 695.

150. Barrows, A. P. W.; Christiansen, K. S.; Bode, E. T.; Hoellein, T. J.; Water Res. 2018, 147, 382.

151. McEachern, K.; Alegria, H.; Kalagher, A. L.; Hansen, C.; Morrison, S.; Hastings, D.; Mar. Pollut. Bull. 2019, 148, 97.

152. Schmidt, L. K.; Bochow, M.; Imhof, H. K.; Oswald, S. E.; Environ. Pollut. 2018, 239, 579.

153. Courtene-Jones, W.; Quinn, B.; Gary, S. F.; Mogg, A. O. M.; Narayanaswamy, B. E.; Environ. Pollut. 2017, 231, 271.

154. Möller, J. N.; Löder, M. G. J.; Laforsch, C.; Environ. Sci. Technol. 2020 , 54, 2078.

155. Pagter, E.; Frias, J.; Nash, R.; Mar. Pollut. Bull. 2018, 135, 932.

156. de Araújo, M. C. B.; Santos, P. J. P.; Costa, M. F.; Mar. Pollut. Bull. 2006, 52, 957.

157. Dris, R.; Gasperi, J.; Saad, M.; Mirande, C.; Tassin, B.; Mar. Pollut. Bull. 2016, 104, 290

158. Cai, L.; Wang, J.; Peng, J.; Tan, Z.; Zhan, Z.; Tan, X.; Chen, Q.; Environ. Sci. Pollut. Res. 2017, 24, 24928.

159. Klein, M.; Fischer, E. K.; Sci. Total Environ. 2019, 685, 96.

160. Stanton, T.; Johnson, M.; Nathanail, P.; MacNaughtan, W.; Gomes, R. L.; Sci. Total Environ. 2019, 666, 377.

161. Wright, S. L.; Ulke, J.; Font, A.; Chan, K. L. A.; Kelly, F. J.; Environ. Int. 2020, 136, 105411

162. Liu, K.; Wu, T.; Wang, X.; Song, Z.; Zong, C.; Wei, N.; Li, D.; Environ. Sci. Technol. 2019, 53, 10612

163. Liu, K.; Wang, X.; Fang, T.; Xu, P.; Zhu, L.; Li, D.; Sci. Total Environ. 2019, 675, 462

164. Liu, K.; Wang, X.; Wei, N.; Song, Z.; Li, D.; Environ. Int. 2019, 132, 105127.

165. Li, Y.; Shao, L.; Wang, W.; Zhang, M.; Feng, X.; Li, W.; Zhang, D.; Sci. Total Environ. 2020, 705, 135967

166. Wright, S. L.; Levermore, J. M.; Kelly, F. J.; Environ. Sci. Technol. 2019, $53,8947$.

167. Hurley, R. R.; Lusher, A. L.; Olsen, M.; Nizzetto, L.; Environ. Sci. Technol. 2018, 52, 7409.

168. Bläsing, M.; Amelung, W.; Sci. Total Environ. 2018, 612, 422.

169. Li, J.; Song, Y.; Cai, Y.; Environ. Pollut. 2020, 257, 113570.

170. Carvalho, D. G.; Baptista Neto, J. A.; Ocean \& Coastal Management 2016, 128,10

171. Fisner, M.; Majer, A. P.; Balthazar-Silva, D.; Gorman, D.; Turra, A.; Environ. Sci. Pollut. Res. 2017, 24, 13732.

172. Baptista Neto, J. A.; Gaylarde, C.; Beech, I.; Bastos, A. C.; Quaresma, V. S.; de Carvalho, D. G.; Ocean \& Coastal Management 2019, 169, 247.

173. Baptista Neto, J. A.; de Carvalho, D. G.; Medeiros, K.; Drabinski, T. L.; de Melo, G. V.; Silva, R. C. O.; Silva, D. C. P.; Batista, L. S.; Dias, G. T. M.; da Fonseca, E. M.; dos Santos Filho, J. R.; Mar. Pollut. Bull. 2019, $149,110558$.

174. Izar, G. M.; Morais, L. G.; Pereira, C. D. S.; Cesar, A.; Abessa, D. M. S.; Christofoletti, R. A.; Reg. Stud. Mar. Sci. 2019, 29, 100705.

175. Dioses-Salinas, D. C.; Pizarro-Ortega, C. I.; De-la-Torre, G. E.; Sci. Total Environ. 2020, 730, 139164.

176. Lusher, A. L.; Bråte, I. L. N.; Munno, K.; Hurley, R. R.; Welden, N. A.; Appl. Spectrosc. 2020, 74, 1139.

177. Klein, S.; Worch, E.; Knepper, T. P.; Environ. Sci. Technol. 2015, 49, 6070.

178. Jung, M. R.; Horgen, F. D.; Orski, S. V.; Rodriguez C., V.; Beers, K. L.; Balazs, G. H.; Jones, T. T.; Work, T. M.; Brignac, K. C.; Royer, S.-J.; Hyrenbach, K. D.; Jensen, B. A.; Lynch, J. M.; Mar. Pollut. Bull. 2018, 127, 704.

179. Amigo, J. M.; Babamoradi, H.; Elcoroaristizabal, S.; Anal. Chim. Acta 2015, 896,34 
180. Harrison, J. P.; Ojeda, J. J.; Romero-González, M. E.; Sci. Total Environ. 2012, 416, 455 .

181. Bergmann, M.; Mützel, S.; Primpke, S.; Tekman, M. B.; Trachsel, J.; Gerdts, G.; Sci. Adv. 2019, 5, 1.

182. Pabortsava, K.; Lampitt, R. S.; Nat. Commun. 2020, 11, 4073.

183. Liu, F.; Olesen, K. B.; Borregaard, A. R.; Vollertsen, J.; Sci. Total Environ. 2019, 671, 992.

184. Liu, F.; Nord, N. B.; Bester, K.; Vollertsen, J.; Water 2020, 12, 1085.

185. Löder, M. G. J.; Kuczera, M.; Mintenig, S.; Lorenz, C.; Gerdts, G.; Environ. Chem. 2015, 12, 563.

186. Käppler, A.; Windrich, F.; Löder, M. G. J.; Malanin, M.; Fischer, D.; Labrenz, M.; Eichhorn, K. J.; Voit, B.; Anal. Bioanal. Chem. 2015, 407, 6791.

187. Elert, A. M.; Becker, R.; Duemichen, E.; Eisentraut, P.; Falkenhagen, J.; Sturm, H.; Braun, U.; Environ. Pollut. 2017, 231, 1256.

188. Käppler, A.; Fischer, D.; Oberbeckmann, S.; Schernewski, G.; Labrenz, M.; Eichhorn, K. J.; Voit, B.; Anal. Bioanal. Chem. 2016, 408, 8377.

189. Primpke, S.; Dias, P. A.; Gerdts, G.; Anal. Methods 2019, 11, 2138.

190. Karlsson, T. M.; Grahn, H.; Van Bavel, B.; Geladi, P.; J. Near Infrared Spectrosc. 2016, 24, 141.

191. Pasquini, C.; J. Braz. Chem. Soc. 2003, 14, 198.

192. Pasquini, C.; Anal. Chim. Acta 2018, 1026, 8.

193. Corradini, F.; Bartholomeus, H.; Huerta Lwanga, E.; Gertsen, H.; Geissen, V.; Sci. Total Environ. 2019, 650, 922.

194. Pakhomova, S.; Zhdanov, I.; van Bavel, B.; Appl. Sci. 2020, 10, 1.

195. Amigo, J. M.; Anal. Bioanal. Chem. 2010, 398, 93.

196. Vidal, C.; Pasquini, C.; Environ. Pollut. 2021, $285,117251$.

197. Serranti, S.; Palmieri, R.; Bonifazi, G.; Cózar, A.; Waste Manage. 2018, $76,117$.

198. Zhang, Y.; Wang, X.; Shan, J.; Zhao, J.; Zhang, W.; Liu, L.; Wu, F.; Environ. Sci. Technol. 2019, 53, 5151.

199. Ballent, A.; Corcoran, P. L.; Madden, O.; Helm, P. A.; Longstaffe, F. J.; Mar. Pollut. Bull. 2016, 110, 383.

200. Absher, T. M.; Ferreira, S. L.; Kern, Y.; Ferreira, A. L.; Christo, S. W.; Ando, R. A.; Environ. Sci. Pollut. Res. 2019, 26, 292.

201. Di, M.; Wang, J.; Sci. Total Environ. 2018, 616-617, 1620.

202. Enders, K.; Lenz, R.; Stedmon, C. A.; Nielsen, T. G.; Mar. Pollut. Bull. 2015, 100, 70.

203. Frère, L.; Paul-Pont, I.; Rinnert, E.; Petton, S.; Jaffré, J.; Bihannic, I.; Soudant, P.; Lambert, C.; Huvet, A.; Environ. Pollut. 2017, 225, 211.

204. Horton, A. A.; Svendsen, C.; Williams, R. J.; Spurgeon, D. J.; Lahive, E.; Mar. Pollut. Bull. 2017, 114, 218.

205. Imhof, H. K.; Wiesheu, A. C.; Anger, P. M.; Niessner, R.; Ivleva, N. P.; Laforsch, C.; Sci. Total Environ. 2018, 613-614, 530.

206. Kazour, M.; Jemaa, S.; Issa, C.; Khalaf, G.; Amara, R.; Sci. Total Environ. 2019, 696, 133933.

207. Kniggendorf, A. K.; Wetzel, C.; Roth, B.; Sensors 2019, 19, 12.

208. Pan, Z.; Liu, Q.; Sun, Y.; Sun, X.; Lin, H.; Mar. Pollut. Bull. 2019, 146, 215.

209. Sobhani, Z.; Zhang, X.; Gibson, C.; Naidu, R.; Megharaj, M.; Fang, C.; Water Res. 2020, 174, 115658.

210. Sruthy, S.; Ramasamy, E. V.; Environ. Pollut. 2017, 222, 315.

211. Tong, H.; Jiang, Q.; Hu, X.; Zhong, X.; Chemosphere 2020, 252, 126493.

212. Xiong, X.; Zhang, K.; Chen, X.; Shi, H.; Luo, Z.; Wu, C.; Environ. Pollut. 2018, 235, 899.

213. Yin, L.; Wen, X.; Du, C.; Jiang, J.; Wu, L.; Zhang, Y.; Hu, Z.; Hu, S.; Feng, Z.; Zhou, Z.; Long, Y.; Gu, Q.; Chemosphere 2020, 244, 125486.

214. Zhao, S.; Zhu, L.; Li, D.; Environ. Pollut. 2015, 206, 597.

215. Cole, M.; Lindeque, P.; Fileman, E.; Halsband, C.; Goodhead, R.; Moger, J.; Galloway, T. S.; Environ. Sci. Technol. 2013, 47, 6646.

216. Ghosal, S.; Chen, M.; Wagner, J.; Wang, Z. M.; Wall, S.; Environ. Pollut. 2018, 233, 1113.
217. Horton, A. A.; Jürgens, M. D.; Lahive, E.; van Bodegom, P. M.; Vijver, M. G.; Environ. Pollut. 2018, 236, 188.

218. Karlsson, T. M.; Vethaak, A. D.; Almroth, B. C.; Ariese, F.; van Velzen, M.; Hassellöv, M.; Leslie, H. A.; Mar. Pollut. Bull. 2017, 122, 403.

219. Wagner, J.; Wang, Z. M.; Ghosal, S.; Rochman, C.; Gassel, M.; Wall, S.; Anal. Methods 2017, 9, 1479.

220. Watts, A. J. R.; Urbina, M. A.; Goodhead, R.; Moger, J.; Lewis, C.; Galloway, T. S.; Environ. Sci. Technol. 2016, 50, 5364

221. Araujo, C. F.; Nolasco, M. M.; Ribeiro, A. M. P.; Ribeiro-Claro, P. J. A.; Water Res. 2018, 142, 426.

222. Imhof, H. K.; Schmid, J.; Niessner, R.; Ivleva, N. P.; Laforsch, C.; Limnol. Oceanogr. Methods 2012, 10, 524.

223. Lenz, R.; Enders, K.; Stedmon, C. A.; MacKenzie, D. M. A.; Nielsen, T. G.; Mar. Pollut. Bull. 2015, 100, 82.

224. Thiele, C. J.; Hudson, M. D.; Russell, A. E.; Mar. Pollut. Bull. 2019 , $142,384$.

225. Sobhani, Z.; Al Amin, M.; Naidu, R.; Megharaj, M.; Fang, C.; Anal. Chim. Acta 2019, 1077, 191.

226. Zada, L.; Leslie, H. A.; Vethaak, A. D.; Tinnevelt, G. H.; Jansen, J. J.; de Boer, J. F.; Ariese, F.; J. Raman Spectrosc. 2018, 49, 1136.

227. Furstenberg, R.; Kendziora, C. A.; Papantonakis, M. R.; Nguyen, V.; McGill, R. A.; Next-Generation Spectrosc. Technol. V 2012, 8374, 837411.

228. Marcott, C.; Kansiz, M.; Dillon, E.; Cook, D.; Mang, M. N.; Noda, I.; J. Mol. Struct. 2020, 1210, 128045.

229. Hale, R. C.; Seeley, M. E.; La Guardia, M. J.; Mai, L.; Zeng, E. Y.; J. Geophys. Res. Ocean. 2020, 125, 1.

230. Primpke, S.; Wirth, M.; Lorenz, C.; Gerdts, G.; Anal. Bioanal. Chem. 2018, 410, 5131 .

231. KnowItAll U - Spectra Database. Wiley Sci. Solut. 2020

232. ASTM E2310-04 Standard Guide for Use of Spectral Searching by Curve Matching Algorithms with Data Recorded Using Mid-infrared Spectroscopy. ASTM 2004, $i$, 1-9.

233. Munno, K.; De Frond, H.; O'donnell, B.; Rochman, C. M.; Anal. Chem. 2020, $92,2443$.

234. Dong, M.; Zhang, Q.; Xing, X.; Chen, W.; She, Z.; Luo, Z.; Sci. Total Environ. 2020, 739, 139990.

235. Shan, J.; Zhao, J.; Liu, L.; Zhang, Y.; Wang, X.; Wu, F.; Environ. Pollut. 2018, 238, 121.

236. Wander, L.; Vianello, A.; Vollertsen, J.; Westad, F.; Braun, U.; Paul, A.; Anal. Methods 2020, 12, 781.

237. Da Silva, V. H.; Murphy, F.; Amigo, J. M.; Stedmon, C.; Strand, J.; Anal. Chem. 2020, 92, 13724.

238. Anger, P. M.; Prechtl, L.; Elsner, M.; Niessner, R.; Ivleva, N. P.; Anal. Methods 2019, 11, 3483.

239. Ellis, J. D.; Iqbal, R.; Yoshimatsu, K.; Anal. Chim. Acta 2020, 1103, 49.

240. Frère, L.; Paul-Pont, I.; Moreau, J.; Soudant, P.; Lambert, C.; Huvet, A.; Rinnert, E.; Mar. Pollut. Bull. 2016, 113, 461.

241. Hufnagl, B.; Lohninger, H.; Anal. Chim. Acta 2020, 1097, 37.

242. Renner, G.; Sauerbier, P.; Schmidt, T. C.; Schram, J.; Anal. Chem. 2019, 91, 9656.

243. Shim, W. J.; Hong, S. H.; Eo, S. E.; Anal. Methods 2017, 9, 1384

244. Yakovenko, N.; Carvalho, A.; ter Halle, A.; TrAC-Trends Anal. Chem. 2020, 131, 115979.

245. Fischer, M.; Scholz-Böttcher, B. M.; Anal. Methods 2019, 11, 2489.

246. Picó, Y.; Barceló, D.; TrAC - Trends Anal. Chem. 2020, 115964.

247. Zhang, Y.; Kang, S.; Allen, S.; Allen, D.; Gao, T.; Sillanpää, M.; EarthScience Rev. 2020, 203, 103118.

248. Peñalver, R.; Arroyo-Manzanares, N.; López-García, I.; HernándezCórdoba, M.; Chemosphere 2020, 242, 125170.

249. Steinmetz, Z.; Kintzi, A.; Muñoz, K.; Schaumann, G. E.; J. Anal. Appl. Pyrolysis 2020, 147, 104803. 
250. Sullivan, G. L.; Gallardo, J. D.; Jones, E. W.; Hollliman, P. J.; Watson, T. M.; Sarp, S.; Chemosphere 2020, 249, 126179.

251. Dierkes, G.; Lauschke, T.; Becher, S.; Schumacher, H.; Földi, C.; Ternes, T.; Anal. Bioanal. Chem. 2019, 411, 6959.

252. Okoffo, E. D.; Ribeiro, F.; O’Brien, J. W.; O’Brien, S.; Tscharke, B. J.; Gallen, M.; Samanipour, S.; Mueller, J. F.; Thomas, K. V.; Sci. Total Environ. 2020, 715, 136924.

253. Zhang, X.; Zhang, H.; Yu, K.; Li, N.; Liu, Y.; Liu, X.; Zhang, H.; Yang, B.; Wu, W.; Gao, J.; Jiang, J.; Anal. Chem. 2020, 92, 4656.

254. Bannach, G.; Perpétuo, G. L.; Cavalheiro, É. T. G.; Cavalheiro, C. C. S.; Rocha, R. R.; Quim. Nova 2011, 34, 1825.

255. Duemichen, E.; Braun, U.; Senz, R.; Fabian, G.; Sturm, H.; J. Chromatogr. A 2014, 1354, 117.

256. Duemichen, E.; Eisentraut, P.; Celina, M.; Braun, U.; J. Chromatogr. A 2019, 1592, 133.

257. Oßmann, B.; Schymanski, D.; Ivleva, N. P.; Fischer, D.; Fischer, F.; Dallmann, G.; Welle, F.; Water Res. 2019, 162, 516.

258. Zuccarello, P.; Ferrante, M.; Cristaldi, A.; Copat, C.; Grasso, A.; Sangregorio, D.; Fiore, M.; Oliveri Conti, G.; Water Res. 2019, 166, 115077.

259. K. V., A.; C. C., H.; N. K., A.; Algal Res. 2020, 48, 101924.

260. Yan, R.; Moon, S.; Kenny, S. J.; Xu, K.; Acc. Chem. Res. 2018, 51, 697.

261. Cole, M.; Sci. Rep. 2016, 6, 1.

262. Shim, W. J.; Song, Y. K.; Hong, S. H.; Jang, M.; Mar. Pollut. Bull. 2016, 113,469

263. Maes, T.; Jessop, R.; Wellner, N.; Haupt, K.; Mayes, A. G.; Sci. Rep. 2017, 7, 1

264. Prata, J. C.; Alves, J. R.; da Costa, J. P.; Duarte, A. C.; Rocha-Santos, T.; Sci. Total Environ. 2020, 719, 137498.

265. Gaston, E.; Woo, M.; Steele, C.; Sukumaran, S.; Anderson, S.; Appl. Spectrosc. 2020, 74, 1079

266. Iannilli, V.; Corami, F.; Grasso, P.; Lecce, F.; Buttinelli, M.; Setini, A.; Environ. Sci. Pollut. Res. 2020, 27, 14711.

267. Kankanige, D.; Babel, S.; Sci. Total Environ. 2020, 717, 137232.

268. Scircle, A.; Cizdziel, J. V.; J. Chem. Educ. 2020, 97, 234.

269. Vermeiren, P.; Muñoz, C.; Ikejima, K.; Environ. Pollut. 2020, 262, 114198.

270. Sierra, I.; Chialanza, M. R.; Faccio, R.; Carrizo, D.; Fornaro, L.; PérezParada, A.; Environ. Sci. Pollut. Res. 2020, 27, 7409.

271. Bertoldi, C.; Lara, L. Z.; Gomes, A. A.; Fernandes, A. N.; Microchem. J. 2021, 160, 105690.

272. Gauci, A.; Deidun, A.; Montebello, J.; Abela, J.; Galgani, F.; Ocean \& Coastal Management 2019, 182, 104950.

273. Chetwynd, A.; Nel, H. A.; Krause, S.; Lynch, I. In SETAC Europe 30th Annual Meeting Abstract Book; 2020; p. 34.

274. Schirinzi, G. F.; Llorca, M.; Seró, R.; Moyano, E.; Barceló, D.; Abad, E.; Farré, M.; Chemosphere 2019, 236, 124321.

275. Zarfl, C.; Anal. Bioanal. Chem. 2019, 411, 3743.

276. Lima, A. R. A.; Barletta, M.; Costa, M. F.; Estuar. Coast. Shelf Sci. 2015 165, 213.

277. Barletta, M.; Costa, M. F.; Dantas, D. V.; MethodsX 2020, 7, 100861

278. Ramos, J. A. A.; Pessoa, W. V. N.; Mar. Pollut. Bull. 2019, 142, 428.

279. Possatto, F. E.; Spach, H. L.; Cattani, A. P.; Lamour, M. R.; Santos, L. O.; Cordeiro, N. M. A.; Broadhurst, M. K.; Mar. Pollut. Bull. 2015, 91, 548.

280. Fernandino, G.; Elliff, C. I.; Frutuoso, G. A.; da Silva, E. V. N. M.; Gama, G. S.; Sousa, J. H. de O.; Silva, I. R.; Mar. Pollut. Bull. 2016, 110, 591.

281. Garcia, T. M.; Campos, C. C.; Mota, E. M. T.; Santos, N. M. O.; Campelo, R. P. de S.; Prado, L. C. G.; Melo Junior, M.; Soares, M. de O.; Mar. Pollut. Bull. 2020, 150, 110705.

282. Olivatto, G. P.; Martins, M. C. T.; Montagner, C. C.; Henry, T. B.; Carreira, R. S.; Mar. Pollut. Bull. 2019, 139, 157.
283. Silva, M. M.; Maldonado, G. C.; Castro, R. O.; Felizardo, J. S.; Cardoso, R. P.; dos Anjos, R. M.; de Araújo, F. V.; Mar. Pollut. Bull. 2019, 141, 561.

284. Figueiredo, G. M.; Vianna, T. M. P.; Mar. Pollut. Bull. 2018, 135, 256.

285. Castro, R. O.; da Silva, M. L.; Marques, M. R. C.; de Araújo, F. V.; Mar. Pollut. Bull. 2020, 160, 111537.

286. Bertoldi, C.; Lara, L. Z.; Mizushima, F. A. de L.; Martins, F. C. G.; Battisti, M. A.; Hinrichs, R.; Fernandes, A. N.; Sci. Total Environ. 2020, $759,143503$.

287. Ferraz, M.; Bauer, A. L.; Valiati, V. H.; Schulz, U. H.; Water 2020, 12, 3115.

288. Lorenzi, L.; Reginato, B. C.; Mayer, D. G.; Dantas, D. V.; Environ. Sci. Pollut. Res. 2020, 27, 8797.

289. Gerolin, C. R.; Pupim, F. N.; Sawakuchi, A. O.; Grohmann, C. H.; Labuto, G.; Semensatto, D.; Sci. Total Environ. 2020, 749, 141604.

290. Novaes, G. de O.; Monteiro, S. de M.; Rollnic, M.; J. Coast. Res. 2020, 95,780

291. Martinelli Filho, J. E.; Monteiro, R. C. P.; Mar. Pollut. Bull. 2019, 145, 219.

292. Palombini, F. L.; Demori, R.; Cidade, M. K.; Kindlein, W.; de Jacques, J. J.; Environ. Sci. Pollut. Res. 2018, 25, 26218.

293. Belarmino, P. H. P.; da Silva, S. M.; Rufener, M.-C.; de Araújo, M. C. B.; Rev. Gestão Costeira Integr. 2014, 14, 447.

294. Cavalcante, R. M.; Pinheiro, L. S.; Teixeira, C. E. P.; Paiva, B. P.; Fernandes, G. M.; Brandão, D. B.; Frota, F. F.; Filho, F. J. N. S.; Schettini, C. A. F.; Waste Manage. 2020, 108, 13.

295. Costa, M. F.; Silva-Cavalcanti, J. S.; Barbosa, C. C.; Portugal, J. L.; Barletta, M.; J. Coast. Res. 2011, 64, 339.

296. do Sul, J. A. I.; Costa, M. F.; J. Coast. Res. 2013, 65, 48.

297. Silva-Cavalcanti, J. S.; de Araújo, M. C. B.; da Costa, M. F.; Waste Manage. Res. 2009, 27, 93.

298. Pinheiro, L. M.; Monteiro, R. C. P.; do Sul, J. A. I.; Costa, M. F.; Mar. Pollut. Bull. 2019, 141, 569.

299. Costa, M. F.; do Sul, J. A. I.; Silva-Cavalcanti, J. S.; Araújo, M. C. B.; Spengler, Â.; Tourinho, P. S.; Environ. Monit. Assess. 2010, 168, 299.

300. Araújo, M. C. B.; Silva-Cavalcanti, J. S.; Costa, M. F.; Front. Mar. Sci. 2018, 5,1

301. Monteiro, R. C. P.; do Sul, J. A. I.; Costa, M. F.; Ocean Coast. Res. 2020, 68, e20235.

302. Santos, I. R.; Friedrich, A. C.; Barretto, F. P.; Mar. Pollut. Bull. 2005, 50, 778.

303. Santos, I. R.; Friedrich, A. C.; do Sul, J. A. I.; Environ. Monit. Assess. 2009, $148,455$.

304. do Sul, J. A. I.; Santos, I. R.; Friedrich, A. C.; Matthiensen, A.; Fillmann, G.; Estuaries and Coasts 2011, 34, 814.

305. Leite, A. S.; Santos, L. L.; Costa, Y.; Hatje, V.; Mar. Pollut. Bull. 2014, 81, 242.

306. Majer, A. P.; Vedolin, M. C.; Turra, A.; Mar. Pollut. Bull. 2012, 64, 1143.

307. Fernandino, G.; Elliff, C. I.; Silva, I. R.; Bittencourt, A. C. S. P.; Journal of Integrated Coastal Zone Management 2015, 15, 325.

308. de Souza, J. L.; Silva, I. R.; Soc. Nat. 2015, 27, 469.

309. Santos, A. A.; Nobre, F. S. de M.; Ribeiro, F.; Nilin, J.; Mar. Pollut. Bull. 2020, 153, 111015 .

310. Moruzzi, R. B.; Speranza, L. G.; Conceição, F. T.; Martins, S. T. de S.; Busquets, R.; Campos, L. C.; Water 2020, 12, 1994.

311. Fisner, M.; Taniguchi, S.; Majer, A. P.; Bícego, M. C.; Turra, A.; Mar. Pollut. Bull. 2013, 76, 349.

312. Fisner, M.; Majer, A.; Taniguchi, S.; Bícego, M.; Turra, A.; Gorman, D.; Mar. Pollut. Bull. 2017, 122, 323.

313. Gorman, D.; Gutiérrez, A. R.; Turra, A.; Manzano, A. B.; Balthazar-Silva, D.; Oliveira, N. R.; Harari, J.; Front. Environ. Sci. 2020, 8, 559405.

314. Cordeiro, T. C.; Barrella, W.; Butturi-Gomes, D.; Petrere Júnior, M.; Mar. Pollut. Bull. 2018, 128, 333. 
315. Fisner, M.; Taniguchi, S.; Moreira, F.; Bícego, M. C.; Turra, A.; Mar. Pollut. Bull. 2013, 70, 219.

316. Cordeiro, C. A. M. M.; Costa, T. M.; Mar. Pollut. Bull. 2010, 60, 1762.

317. Balthazar-Silva, D.; Turra, A.; Moreira, F. T.; Camargo, R. M.; Oliveira, A. L.; Barbosa, L.; Gorman, D.; Front. Environ. Sci. 2020, 8, 123.

318. Turra, A.; Manzano, A. B.; Dias, R. J. S.; Mahiques, M. M.; Barbosa, L.; Balthazar-Silva, D.; Moreira, F. T.; Sci. Rep. 2014, 4, 4435.

319. Moreira, F. T.; Balthazar-Silva, D.; Barbosa, L.; Turra, A.; Environ. Pollut. 2016, 218, 313.

320. Taniguchi, S.; Colabuono, F. I.; Dias, P. S.; Oliveira, R.; Fisner, M.; Turra, A.; Izar, G. M.; Abessa, D. M. S.; Saha, M.; Hosoda, J.; Yamashita, R.; Takada, H.; Lourenço, R. A.; Magalhães, C. A.; Bícego, M. C.; Montone, R. C.; Mar. Pollut. Bull. 2016, 106, 87.

321. Vedolin, M. C.; Teophilo, C. Y. S.; Turra, A.; Figueira, R. C. L.; Mar. Pollut. Bull. 2018, 129, 487.

322. Gimiliani, G. T.; Fornari, M.; Redígolo, M. M.; Bustillos, J. O. W. V.; Abessa, D. M. de S.; Pires, M. A. F.; Case Studies in Chemical and Environmental Engineering 2020, 2, 100020.

323. da Silva, M. L.; de Araújo, F. V.; Castro, R. O.; Sales, A. S.; Mar. Pollut. Bull. 2015, 92, 233.

324. da Silva, M. L.; Sales, A. S.; Martins, S.; Castro, R. de O.; de Araújo, F. V.; Mar. Pollut. Bull. 2016, 113, 36.

325. Costa, L. L.; Rangel, D. F.; Zalmon, I. R.; Mar. Pollut. Bull. 2018, 128, 438.

326. Perez, L.; Soares-Gomes, A.; Bernardes, M. C.; J. Coast. Conserv. 2018, 22,1085 .

327. Alves, V. E. N.; Figueiredo, G. M.; Mar. Pollut. Bull. 2019, 146, 326.
328. Suciu, M. C.; Tavares, D. C.; Costa, L. L.; Silva, M. C. L.; Zalmon, I. R.; Mar. Pollut. Bull. 2017, 119, 133.

329. da Silva, M. L.; Castro, R. O.; Sales, A. S.; de Araújo, F. V.; Mar. Pollut. Bull. 2018, 130, 153 .

330. Oigman-Pszczol, S. S.; Creed, J. C.; J. Coast. Res. 2007, 23, 421.

331. Andrades, R.; Martins, A. S.; Fardim, L. M.; Ferreira, J. S.; Santos, R. G.; Mar. Pollut. Bull. 2016, 109, 192.

332. Moreira, F. T.; Prantoni, A. L.; Martini, B.; de Abreu, M. A.; Stoiev, S. B.; Turra, A.; Mar. Pollut. Bull. 2016, 102, 114.

333. Krelling, A. P.; Souza, M. M.; Williams, A. T.; Turra, A.; Mar. Pollut. Bull. 2017, 119, 48.

334. Gorman, D.; Moreira, F. T.; Turra, A.; Fontenelle, F. R.; Combi, T.; Bícego, M. C.; de Castro Martins, C.; Chemosphere 2019, 223, 608.

335. Krelling, A. P.; Turra, A.; Mar. Pollut. Bull. 2019, 139, 282.

336. Marin, C. B.; Niero, H.; Zinnke, I.; Pellizzetti, M. A.; Santos, P. H.; Rudolf, A. C.; Beltrão, M.; Waltrick, D. de S.; Polette, M.; Reg. Stud. Mar. Sci. 2019, 31, 100771.

337. Corraini, N. R.; de Lima, A. S.; Bonetti, J.; Rangel-Buitrago, N.; Mar. Pollut. Bull. 2018, 131, 572.

338. Widmer, W. M.; Hennemann, M. C.; J. Coast. Res. 2010, $26,993$.

339. Farias, E. G. G.; Preichardt, P. R.; Dantas, D. V.; Environ. Sci. Pollut. Res. 2018, 25, 16246.

340. Santos, I. R.; Friedrich, A. C.; Wallner-Kersanach, M.; Fillmann, G.; Ocean \& Coastal Management 2005, 48, 742.

341. Wetzel, L.; Fillmann, G.; Niencheski, L. F. H.; Int. J. Environ. Pollut. 2004, 21, 153. 